\title{
Vimentin protects differentiating stem cells from stress
}

\author{
Dissertation \\ For the award of the degree \\ "Doctor of Philosophy" Ph.D. Division of Natural Sciences \\ Of the Georg-August-Universitat Gottingen \\ Within the Doctoral Program of Biology \\ Of the Georg-August University School of Science (GAUSS)
}

\section{Submitted by}

Sundararaghavan Pattabiraman

India

Gottingen, 2019 


\section{Thesis committee}

(1) Prof. Daniel Kaganovich, Department of Experimental Neurodegeneration, UMG

(2) Prof. Tiago Outeiro, Department of Experimental Neurodegeneration, UMG

(3) Prof. Martin Goepfert, Department of Cellular Neurobiology, UMG

\section{Members of Examination Board}

First Reviewer : Prof. Thomas Meyer, Klinik für Psychosomatische Medizin, UMG

Second Reviewer : Prof. Silvio Rizzoli, Department of Neuro and sensory physiology

Third Reviewer : Prof. Markus Zweckstetter, Department of Molecular Neurobiology

Date of Oral Examination : 12th December, 2019 


\section{CONTENTS}

\section{Title}

Page

Chapter 1

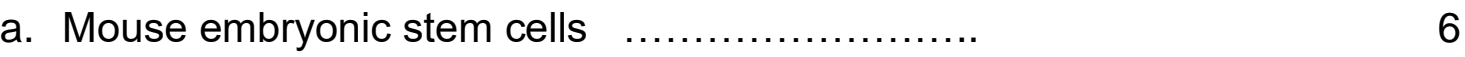

b. Differentiation of mESCs $\quad$........................

c. Differentiation to specific lineages .................. 8

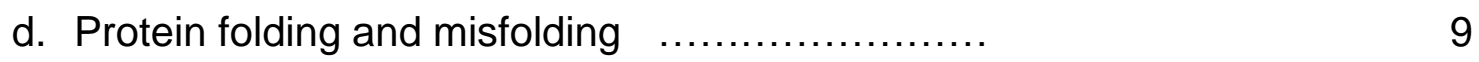

e. Cytoskeleton 12

f. Microtubules $\quad \ldots \ldots \ldots \ldots \ldots \ldots \ldots \ldots$

g. Actin 13

h. Cytoskeleton and differentiation .....................

i. Vimentin intermediate filament ..................... 16

j. Structure of vimentin $\quad \ldots \ldots \ldots \ldots \ldots \ldots \ldots \ldots \ldots \ldots$

k. Vimentin and stress $\quad \ldots \ldots \ldots \ldots \ldots \ldots \ldots \ldots \ldots$

References - chapter $1 \quad \ldots \ldots \ldots \ldots \ldots \ldots \ldots \ldots \ldots \ldots \ldots \ldots \ldots$

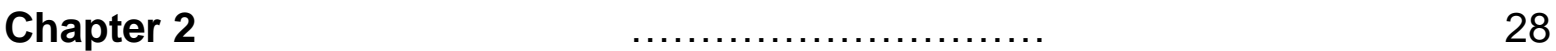

(Imperfect asymmetry)

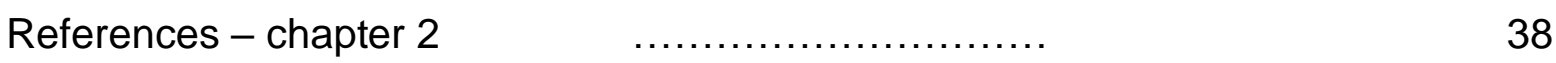

Chapter $3 \quad \ldots \ldots \ldots \ldots \ldots \ldots \ldots \ldots . \ldots \ldots \ldots$

(Vimentin protects differentiating stem cells from stress)

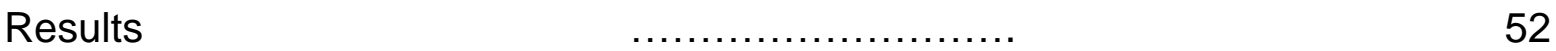

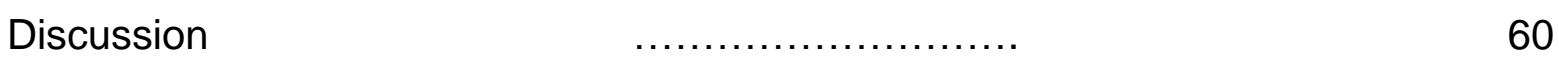

Future directions $\quad \ldots \ldots \ldots \ldots \ldots \ldots \ldots \ldots \ldots \ldots \ldots$

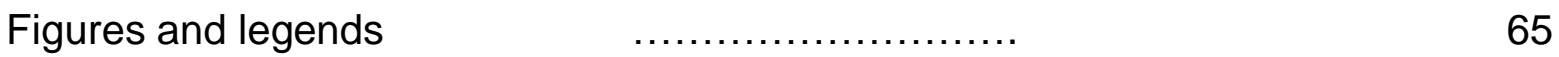

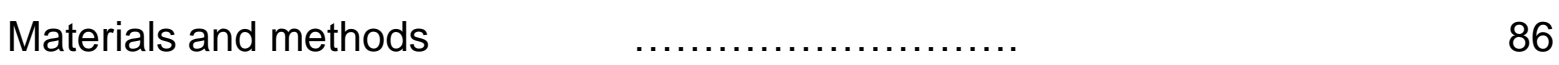

References - chapter $3 \quad \ldots \ldots \ldots \ldots \ldots \ldots \ldots \ldots \ldots \ldots \ldots \ldots$ 


\section{Acknowledgements}

I would like to thank Prof. Daniel Kaganovich for giving me the opportunity to complete my doctoral studies in his lab. He has always been supporting me for my ideas and gave me full freedom to pursue my research interests. Dan was very patient during the initial phase of my PhD when I was getting hold of things and optimizing various experiments. The whole project was concocted by Dan and I just built upon his idea which gave way to this interesting hypothesis. He has always been encouraging for collaborations which also helped in my PhD career. In short, I was very happy during all these years and was able to complete this PhD smoothly because of Dan's method to approach and teach students and at the same time knowing the knack of extracting the work from them.

I would like to next thank Prof. Tiago Outeiro for his support after coming to Germany, and being available all the time for the successful completion of my PhD. His lab people have been very friendly and sweet paving way for an amazing environment to work. They have helped and accommodated for finishing various experiments during this course of time. I would like to specifically thank Mary, Evi, Innes for continuing to help whenever possible and also making me comfortable in the new surroundings. I would also take this opportunity to thank my other thesis committee people Prof. Martin Goepfert and Prof. Schwappah Blanche for their time and valuable comments during the thesis meetings. These comments gave insights to that needs to be done in the project.

The next person I want to thank whole heartedly will be Dr. Triana Amen, my senior in the lab. She has always been very kind to me, and I can easily say that without her, adjusting to the new lab and performing the experiments would have been a hard process. She has always been there for me starting from helping me with molecular biology techniques to being, a well-wisher and advising me whenever possible. I would also want to thank Rivkah Brown, Shlomi and Swetha for helping me with experiments of the project and with other bioinformatic tools. Apart from the experiments, swetha is more of a family than a friend who gives me un-hindering support. I want to thank Prof. Eran Meshorer and Dr. Gajendra Kumar Azad for their collaborations in the project and helping for the completion of the same.

Last but definitely not the least, I would like to thank my parents, my elder brother and close family, who taught me the will to freely decide, what I want to pursue in my life and without whom I would not be here. I am and I will always be grateful to them for the confidence they have in me. 


\section{CHAPTER 1}

1. Mouse embryonic stem cells and differentiation

2. Protein misfolding

3. Cytoskeletal proteins

4. Vimentin intermediate filaments 


\section{Mouse embryonic stem cells}

The embryonic stem cells are extracted from the mouse embryos that proceed to the pre-implantation stage [1,2]. The first steps of differentiation take place at this point. Three distinct location now start to appear and get organized in the blastomeres - (1) tropho-ectoderm, the outside epithelial cells, (2) primitive endoderm, cells at the blastocoel surface of the inner cell mass (ICM), and (3) primitive ectoderm, the inside cells of the ICM. The primitive ectoderm layer of cells give rise to the ES cells, the transiently existing group of cells in the embryo [3]. However, within a day of differentiation of the embryo the ectodermal cells diminish. The main characteristic of the ES cells is the ability to self-renew although they retain the purpose of their origin in the aspect of developmental potential [4]. Therefore it has to be noted that, ES cells are not there in-vivo and are considered only for cell culture purposes. However, the main use and function that can be studied using these cells is that, they can differentiate and develop into all the cell types of the proper embryo and postnatal animal $[4,5]$. Furthermore, their inability to contribute to the tropho-ectoderm lineage (the trophoblast of the placenta) and the primitive endoderm, the visceral and parietalendoderm remain as their one of the limitations [6]. These unique features enable the mouse ES cells as tools of in vitro culture, and they cannot be compared with adult organism somatic stem cells. The mouse ES cells offer us ways to study genetic, developmental and disease studies.

The development of the mouse begins with fertilized oocyte, subsequently giving rise to the embryo, and all extra-embryonic tissues that are necessary for supporting its development $[7,11]$. Till it reaches the blastocyst stage, the cells maintain the totipotent state. Cells then undergo functional specialization, by gradually losing their developmental potency. A compact sphere is formed by the cells, containing two different cell layers, when the morula stage is reached [8]. The fetal portion of the placenta is formed by the tropho-ectoderm (the outermost layer), following implantation, and the cells inside the embryo still remain pluripotent. The yolk sac, allantois and amnion originate from these fractions of embryonic cell when they differentiate to primitive endoderm. By embryonic days 3-4 (E3-E4) in the mouse, the embryo comprises tropho-ectoderm cells, primitive endoderm and the pluripotent stem cells of the inner cell mass (ICM). The ESCs are normally isolated from the ICM (inner cellular mass) which is after the morula stage $[8,9]$.

The potential of mESCs to self-renew is marked by two main characteristics - (1) rapid proliferation, and (2) high telomerase activity. The maintenance of these two characteristics allow the ESCs to maintain the pluripotent status and grow continuously without leading to genetic anomalies, which are observed in transformed cells. These mechanisms depend on the transcription factors that are involved in regulating pluripotency. 


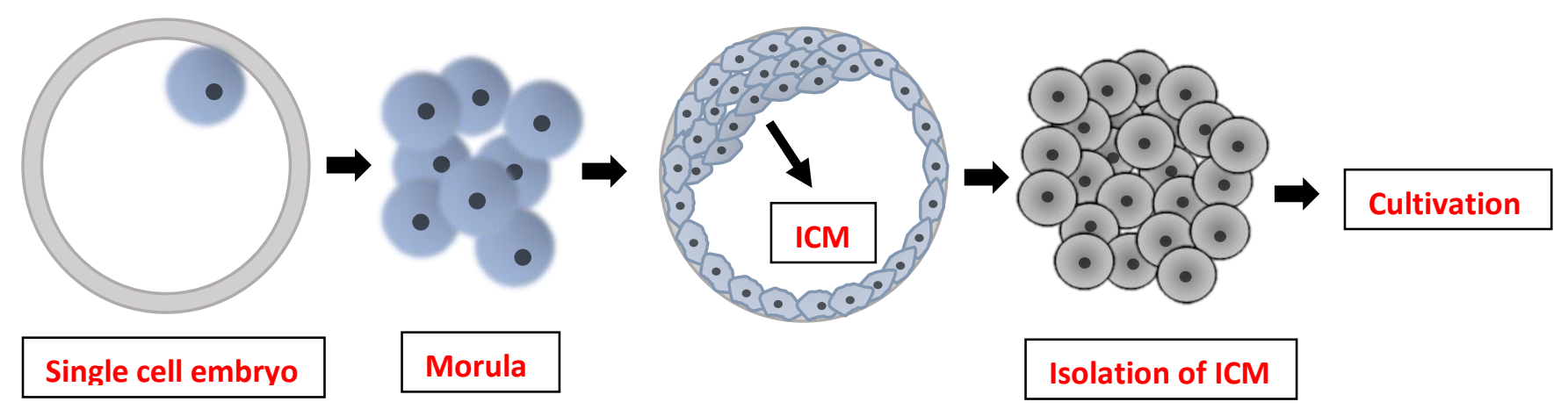

Figure 1: Schematic showing the extraction and the cultivation of mESCs.

\section{Differentiation of mESCs}

Scientists have always been pondering on the extent, to which the observations from mouse embryonic stem cells (mESCs) are transferrable to humans. The basic common characteristic of both the cells is, they are pluripotent, meaning they are capable of forming all the 200 different cell types of the body $[9,11]$. For example, they have an active OCT4 transcription factor which is responsible and essential for making egg cells, maintaining pluripotency and potentially immortal early embryos. These are the basic observations explaining the common factors in both mouse and human pluripotent stem cells $[10,12]$.

Taking the above in consideration, however various groups have discovered that human and mouse ES cells differ enormously in certain aspects. Substances that direct the differentiation of mouse cells to nerve, liver or muscle cells have totally different or no effect on the differentiation of human ES cells [13]. The reasons behind the difference is uncertain as most of the gene expression are conserved between mouse and humans. A new type of pluripotent cells were isolated in 2007 by two research teams known as the epi-blast stem cells (EpiSC). These cells arise during later stage of embryonic development $[13,14]$. The normal ES cells are harvested from a few days old embryo in the blastocyst stage. When the embryo lodges itself on to the uterus, the embryo is called as the epiblast and the cells harvested from them are epiblast stem cells [15].

The epi-blast stem cells are more similar, to the human cells than the normal mouse stem cells, even-though they are extracted from a place later in the development. By the addition of FGF2 growth factor, and maintaining the cells in this factor, both human ES cells and epi-blast cells can be differentiated into any tissue at all $[14,16]$. The important property, distinguishing the ESCs from other adult stem cells is pluripotency, wherein the cells are capable of both self-renewal and differentiation to various cell types $[8,11]$, whereas the adult stem cells are capable only to self-renew. Hence the capability of establishing, that the mESCs can be differentiated remains as the significant step to characterize them which can in-turn be assessed by various 
experimental settings and stringencies. For example, the formation of embryoid bodies by these cells, shows the ability to form broad range of tissues since they contain cells from all the three germ layers - endoderm, ectoderm and mesoderm [19]. Terratomas, containing tissues from three germ layers discussed above can be obtained by injecting the mESCs, in-vivo into an immuno-compromised mouse [20]. Generation of chimeras, through germ line transmission and cell injection into blastocysts, [21] has shown potential to form the germ cells of an adult organism by forming the tissues. For the past three decades, this has been the method to generate transgenic mice for genomic studies to study the function of cell of different origin [22]. The tetraploidcomplementation remains to be the most stringent step for pluripotency till date. When tetraploid host morulae are formed using the mESCs, only extraembryonic lineages arise from them and not the embryonic lineage [23]. Donor cells are able to give rise to all the cell types in the body to form a functional organism without any support of host cells by the method of tetraploid-complementation $[24,25,26]$.

The most important pathway for the maintenance of pluripotent cells, is the LIFsignaling pathway. mESCs require LIF, in combination with two small-molecule inhibitors (referred to as 2i) that block the glycogen synthase kinase 3 (GSK3) [27], MAP2Ks or when grown in the presence of bone morphogenetic proteins (BMPs) [28]. $\mathrm{mESCs}$ can also be grown without serum and just $2 \mathrm{i}$ in the media. The $2 \mathrm{i}$ in the media makes the cell colonies more homogenous, and the cell also exhibit a more uniform gene expression profile. Without 2i, the cells are more susceptible to aneuploidy, and have altered differentiation potential, resulting from fluctuations in the expression of lineage specific and expression of pluripotency factors [29].

The mESCs arise from the progenitor cells, that reside inside the epiblast of the late blastocyst. They express pluripotency associated factors, such as OCT3/4, SOX2 and NANOG [30]. Disruption of these factors leads to immediate differentiation to trophoectoderm or embryonic endoderm. The pluripotency factors are bound to the promoters of their own gene and form an autoregulatory loops. The in-vitro and in-vivo differentiation of ESCs, to three germ layers also require OCT4 expression [31, 32], since low expressing cells fail to differentiate and gets locked into the self-renewing state. The PE and EPI lineage segregation is promoted, when OCT4 acts through the FGF pathway. The OCT4 null embryos resulted in the cells, no longer resolving their lineage identity [33].

\section{Specific lineage differentiation of embryonic stem cells}

Vertebrates require retinoic acid (RA), a hormonal signal derived from vitamin $A$, to control processes involving patterning of embryos and organogenesis, differentiation, cell proliferation, homeostasis and apoptosis [34]. The combined action of retinaldehyde dehydrogenases, and RA - metabolizing cytochrome P450 (CYP26) controls the local levels of RA. There are two types of nuclear receptors, to which the retinoic acid binds - the RARs ( $\alpha, \beta$ and $y$ isotypes, that bind both all-trans and 9-cis- 
RA) and the RXRs. In these, the RARs act as transcriptional regulatory proteins mainly in the form of heterodimers [35, 36].

Embryoid bodies (EBs) are formed from the ES cells, after the growth factors are withdrawn and are placed in high density suspension culture. The precursors of the derivatives of each germ layer are present in the embryoid bodies, and when they are transferred to the conditions that promote adhesion to the substrate, the cells start migrating, and differentiate randomly into specific cell types [19]. Human and mouse embryoid bodies, have been differentiated specifically to various cell types and lineages using protocols developed through time. These protocols have been developed by producing growth factors specific for each lineage by studying their growth and differentiation patterns.

For in-vitro differentiation, the strategy adopted is to induce cell aggregation, into socalled embryoid bodies in non-adhesive dishes or hanging drops. The inducing conditions of EBs determine the proportions of the three germ layer cells, that differentiate inside the EBs [35, 37]. Exposing the cells to high concentration of RA leads to neural lineage differentiation, and the low concentration to cardiomyocyte lineage cells [35]. Two major strategies employed to make neuronal cells are: EB formation and serum-free differentiation [38]. The EB formation method involve RA induction, into the media leading to the promotion of neural gene expression and downregulate mesodermal gene expression. Serum free culturing of the cells lead to selection of the neuronal cells. The homophilic binding of the E-cadherin, which is expressed in undifferentiated pluripotent stem cells leads to the formation of EBs [39]. Once the cells form EBs, morphogenic and molecular signals begin to fire, and the events within the EBs summarize various aspects of embryo development, leading to the differentiation of cells to the three germ layers (ectoderm, endoderm and mesoderm). The numerous aspects of the embryo development are recapitulated within the EBs due to the molecular and cellular morphogenic signals, resulting in the three germ-layer differentiation, similar to the epiblast stage gastrulation in-vivo [40]. The spatial coordination of cell-cell interactions happening inside the EB, is thought to determine the course of cell differentiation, and in turn control the cell number, size of EBs and the quality of the morphology of embryoid body [41, 42].

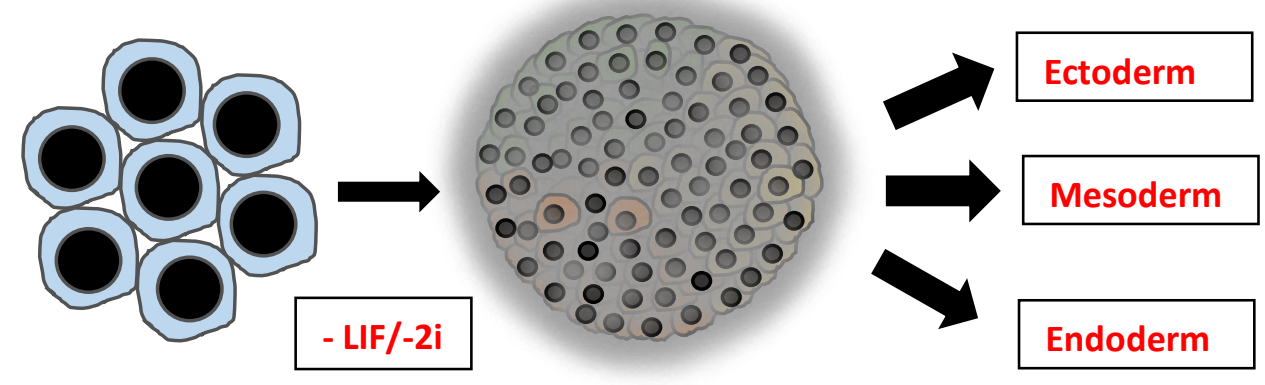

Pluoripotent stem cells
Embryoid body consisting all the three germ layers 
Figure 2: Schematic showing the differentiation to EBs from plouripotent stem cells

\section{Protein folding and misfolding}

Protein structure is inherently hierarchical. Due to the chemistry of their amino acids, there normally occurs steric constraints on the proteins. By the hydrogen-bonding properties of the peptide backbone [43], the chiral nature of amino acids and the interaction of the side chain atoms the secondary structure in proteins are formed. Identifying the backbone torsion angles $(\Phi$ and $\Psi$ ), and the hydrogen-bonding between the carbonyl and amide groups the secondary structure can be identified and marked [44]. By building small repeating patterns in protein structure using the secondary structure (generally $\alpha$-helices and $\beta$-sheets), these are called as 'supersecondary- structure' or 'motifs' [45]. A 3-dimensional biologically functional conformation, a protein acquires through a physical process is commonly known as protein folding. This type of folding occurs in the endoplasmic reticulum of the cell [46]. This is a vital process in the cell for the proteins to function properly. The fine-tuned balance of cellular protein levels, through an enormous network of biochemical pathways is termed as proteostasis. Proteostasis requires regulated protein folding, degradation of proteins and post-translational modifications [47]. Polypeptide chain has to acquire proper structure and function, and for this protein folding is highly essential. HSPs also called as chaperones assist the process and are essential for protein folding. Chaperonins, the multimeric complexes forming hollow structures also participate in protein folding [48]. The elimination of the $\mathrm{N}$-terminal formyl methionine residue, formation of disulfide bonds between cysteines, covalent modifications, hydroxylation, carboxylation, acetylation, methylation, amidation, deamidation, phosphorylation, ADP-ribosylation, addition of oligosaccharides, addition of prostheticgroups, sumoylation, and nucleotidylation are other posttranslational modifications, critical to protein function [45]. In neurons, the protein folding mediated by the chaperones plays a critical role in normal brain function and neurodegenerative diseases. Although the chaperone activity, the mechanism by which they facilitate neuroprotection are being studied extensively by many big laboratories, deep insights of the same are still lacking [49]. However, HSPs or the molecular chaperones remain as an attractive target for therapeutic intervention in neurodegenerative diseases [50]. Each individual protein directs the protein folding by using the specific amino acid sequences. By shielding the hydrophobic residues from the aqueous environment, the cytosolic proteins gain their driving force. Before the protein synthesis reaches completion, folding of independent domains begin [51]. To be specific, they start once the nascent polypeptide gets excited from the ribosomal tunnel but are still attached to the peptidyl transferase center of the ribosome [51,52]. The folding process is always prone to error inside the cytosol, at high protein concentrations (300-400 $\mathrm{mg} / \mathrm{ml}$ ), however the molecular chaperones help in the refolding in an ATP-dependent way, preventing the formation of toxic aggregates [48]. 


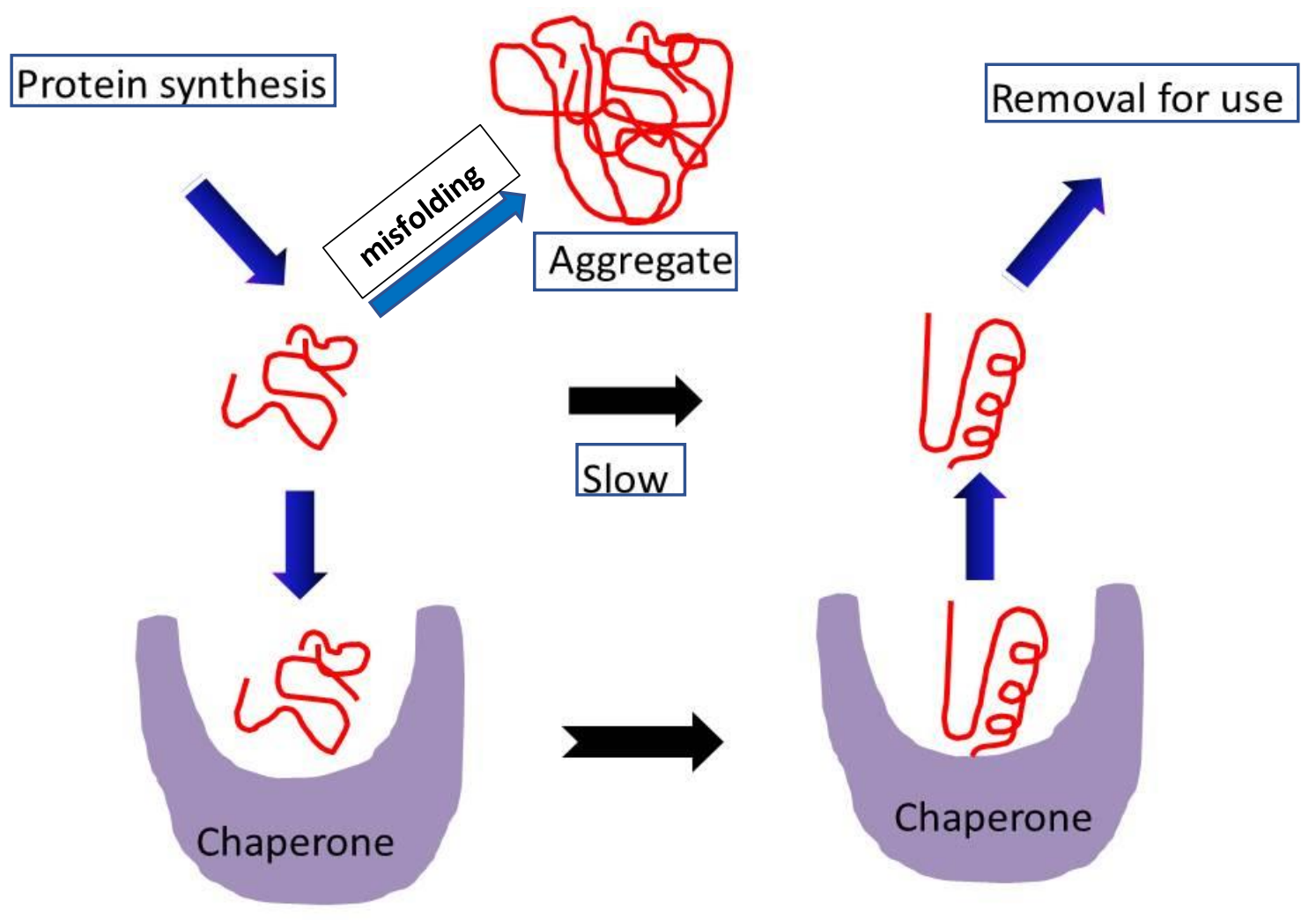

Figure 3: A schematic diagram showing that, the potential to form large and difficult to degrade aggregates, makes the unfolded proteins toxic to the cell. Hence for the cell to function properly catalysing the protein folding becomes essential, and chaperones are a class of proteins which help in this process of successful protein folding useful for the cellular processes.

The presence of specific and distinct protein inclusions, in and around the affected neurons, in the hallmark regions of the brain is the main characteristic of many neurodegenerative diseases [49]. The misfolded, aggregated and other toxic forms of proteins make the basic composition of the inclusions. The deposition of the protein alpha-synuclein is the characteristic of PD, for AD, it is the amyloid- $\beta$ plaques and tangles of phosphorylated tau [53], huntingtin aggregates are associated with HD, contain repeats of glutamine in the nucleus and cytoplasm [54]. There are different types of inclusions forming in the brain. These inclusions lead to neuro-degenerative diseases in the brain. The bunina bodies, ubiquitinated inclusions characterizes the ALS pathology [55]. 


\section{Cytoskeleton}

The shape, structure and internal organization of the cells are maintained by the cytoskeleton comprising of different types of proteins. The mechanical support is also provided by these proteins helping in the processes, like division and movement. Several cytoskeletal component work together to help the cell carry out the functions $[56,57]$.

In eukaryotic cells, the cytoskeleton is comprised mostly of filamentous proteins providing structure and mechanical support to the constituents of the cytoplasm [57]. The proteins have common elements differing in protein composition and size. Microtubules cover as the largest protein in the filament family with 25 nanometer diameter and composed of the protein called as tubulin [58]. Actin are smaller proteins with a diameter of 6 nanometers. The mid-sized and with a diameter around 10 nanometers, are called as intermediate filaments. Different types of protein subunits build the intermediate filaments [59].

\section{Microtubules}

There are two polypeptide units in tubulin filament and in these subunits, the dimers are strung together, to make long strands called protofilaments. The microtubules are then formed by thirteen protofilaments, coming together forming hollow straw shaped filaments [60]. Tubulin dimers are constantly added and subtracted thus making the microtubules constantly subjected to change [61]. The rates of these changes are not balanced. The end that grows rapidly is termed as the plus end and the other end is the minus end. MTOC (microtubule organizing centers), are anchored by the minus end of the microtubules [61,62]. The centrosome adjacent to the nucleus, serves as the primary MTOC of the various cell types. The tubulin grows from the anchoring place, the MTOC. They grow out to the plasma membrane from the centrosome. In the cells not dividing, basic organization of the cytoplasm, and positioning of the organelles is done by the microtubule network radiating out from the centrosome [62, 63].

The cylindrical structure of the microtubules is obtained by the association of the $\alpha$ and $\beta$-tubulin heterodimers [62]. Each type of tubulin protein has a specific function, in the development of specific tissue in development. These tubulin family is composed of eight $\alpha$-tubulin isotypes and seven $\beta$-tubulin isotypes. Although the members of the tubulin family vary highly in proportion, at their carboxy-terminal (Cterminal) tail, they do share a lot of common homology structurally and morphologically [64]. Interaction with other proteins are carried out by the C-terminal end of the tubulin family. These sites also act as sites for post-translational modifications, conferring uniqueness in functionality [65]. Motor proteins translocate cell components on microtubule tracks, and protein-protein interactions, with other adaptor proteins coordinate this process [66]. Tubulin heterodimers also exist in soluble form in cells, and protein interactions with this tubulin population regulate microtubule behavior [62]. 
During mitosis, microtubules form the spindle to enable correct chromosomal segregation [63]. Chemotherapeutic drugs suppress spindle dynamics, during the cell cycle, majorly during the G1-M phase leading to mitotic arrest and cell death in dividing cells. Tubulin binding agents serve as these chemotherapeutic drugs [67].

\section{Actin}

Actin filaments are semi-flexible filaments, forming cross linked structures and dendrites which are in contrast to intermediate filaments and microtubules. The length of the single filament is in the order of the filament length, explaining the name semiflexible [68]. Actin filaments are semi flexible polymer which get bent by thermal fluctuations thus producing additional inhibiting forces, that tend to stretch the filament. Out of the three cytoskeletal filaments, actin is the most dynamic filament leading to significant changes in the structure, within the order of minutes leading to the change in the shape of the cell $[68,69]$. There are actin monomers, called as globular actin (G-actin) and there is another type of actin called as the F-Actin. Stress fibers are another type of structures, related to actin which are neither associated to the lamellapodium or the filopodia [70]. Anti-parallel actin bundles, containing parallel filaments or the myosin filaments give rise to the stress fibers. Bundles of 10-30 actin filaments assembled and cross-linked, in a bipolar fashion by $\alpha$-actinin forms the stress fibers [71]. The binding sites that connects the cell to the substrate, is the focal adhesion points. Cell contractility in many animal cells is contributed by the other actin family filament known as the contractile stress fibers [72]. Since myosin is responsible and regulates the contractility of these stress fibers, the contractility is in many ways similar to the activity and regulation of myosin filaments [69]. Stress fibers are thick in nonmotile cells and they are very stable. However, in the motile cells, they are quite the opposite where they are highly dynamic, less stable and not thicker. The contractile stress fibers are comprised of actin and myosin and the non-contractile ones don't have myosin in them [73].

\section{Interaction of actin and tubulin with aggregating proteins and transport of cargoes}

Misfolded proteins accumulate as a result of ER stress and other stresses. As a protective mechanism, cells form aggresomes for storing the accumulated misfolded proteins for the future [74]. Evidences point out that, KATs/HDACs are main players in the ER stress, and more observations tell that for alleviating ER stress, agents are targeted towards these proteins. The transport of these misfolded proteins is microtubule and actin dependent [74, 75].

Cargoes are anchored, delivered and transported along the tracks made up by the actin and microtubule filaments. The cytoplasm in the cell is organized by these cytoskeletal filaments. Each type of transport is different, and the arrangement of the filament changes accordingly to suit those [76]. To sustain the directed transport and 
the organelle tethering both the networks of actin, tubulin and myosin complement each other. Along the radially arranged microtubules, kinesin and dynein help in the transport of cargo over long distances in a steady state eukaryotic cell [77]. The cell periphery is condensed with the actin filaments, and the myosin motors take care of the short-range transport [78]. The two motors kinesin and dynein have separate ends, towards which they move- dynein towards the negatively charged end, and the kinesin towards the positive charged end [79]. When compared to the microtubules, the actin filaments are polarized and shorter. This facilitates them to form a meshwork or a net structure near the cell cortex [57]. The localized, short-ranged movement of cargoes is done by the myosin filaments and motors which move along the actin filaments [69]. The viruses replicate and spread by seizing and taking control of the cytoskeleton transport system. For example, kinesin dependent transport is used by the vaccina virus, which assembles the viral particles, and genome replication is done in the cell cytoplasm, after which it takes the kinesin motors to transport the viral particles to release from the cell. The interaction of kinesin and the viral particles is regulated ensuring only mature viral replication particles are transported to the cell periphery [80].

Three distinct processes are required for the cargo transport, by the cytoskeletal motors or the intermediate associated proteins - 1 . interaction between the motor and the cargo to be shuttled [76] 2. each cargo transport has a distinct track, hence binding of the motor to the specific track and 3. subsequently the motor moving along the specific track. However, all these processes have their own regulatory mechanisms depending on various factors [76, 81].

\section{Cytoskeletal proteins in stem cells and differentiation}

In mES cells, much is still unknown about the cytoskeletal network, which governs the mechanoresponse. Many studies have been performed to find out the change in the expression of cytoskeleton expression and consequently their remodeling during differentiation. When the cytoskeleton protein expression was checked in ES cells, reprogrammed and non-reprogrammed MEFs, it was observed by various groups that pluoripotent cells have an under-developed cytoskeleton organization compared to the differentiated fibroblasts [82].

Both extracellular and intracellular factors, which encompasses environmental and the chemicals added in the media regulates the stem cell differentiation in a spatial and temporal fashion [4]. Cytoskeleton of the cells, comprising the microtubules, intermediate filaments and the actin family which are complex, and structural filaments functions, as the main regulator of differentiation of multipotent and pluripotent adult stem cells [82]. In mesenchymal stem cells (MSCs), the adipogenic differentiation rate is upregulated, by the use of small molecule antagonists which in turn disrupt the actin filaments and a decrease in osteogenic differentiation [83]. The timing of the addition of factors or cues, also determines and has specific effects on the differentiation. For example, the WNT signaling pathway needs to be activated, in order for the cells to 
differentiate to cardiac progenitors from pluripotent stem cells. Cyclic compression of the cells, resulted in chondrogenic differentiation of the cells, however the mechanical stress resulted in the expression of cytoskeleton protein, but inhibited the process of chondrogenic differentiation [84]. These types of the multipotent cell differentiation have been observed to be done by the actin and tubulin polymerization, [83] and the interaction between actin and myosin. But the exact mechanism of action of these cytoskeleton elements, in the differentiation has to be studied completely.

Gene and protein expression of smooth muscle cell actin, vimentin, lamin A, and nestin were markedly lower for ESCs than MEFs [82]. iPSC samples on the other hand, had cytoskeleton protein expression similar to both ES cells and the MEFs. However, most portion of the cells had an expression profile similar to ES cells [85]. Hence during reprogramming, the cytoskeleton is remodeled, according to the expression pattern of a less developed state. Cytoskeleton intermediate filament expression in undifferentiated cells increased significantly due to shear stress mediated differentiation. However, this observation was not the same in iPSC cells [86]. When spontaneous differentiation was done and compared between ES and iPSC cells, both had similar type of expression patterns. With further differentiation, however, gene levels were significantly higher for iPSCs compared to ESCs. Results from various labs, tell that iPSC cells acquire cytoskeleton proteins readily during differentiation, and the ES cells need to form these proteins by de novo synthesis. The strategic selection of the parental phenotype is thus critical not only in the context of reprogramming, but also the ultimate functionality of the iPSC-differentiated cell population [82, 87]. Differentiated fibroblasts consisted of actin stress fibers, and also lamin expression, but pluripotent cells did not have their expression [83]. The small and rounded ES cell morphology is consistent with less to no expression of cytoskeleton proteins, which is the opposite in differentiated cells, where the cells are spread out the cytoskeleton to nucleus size ratio is higher [88]. The iPSC had the expression of cytoskeleton proteins, in an intermediate level and not exactly mimicking the ES cells. A couple of other phenotypes observed from protein patterns tell us that the iPSC are a heterogenous group of cells.

The type of differentiation, whether it is stress driven differentiation, or spontaneous differentiation decides the expression pattern of cytoskeleton proteins in both ES and iPS cells [89]. Shear stress applied to ESCs, previously shown to promote mesodermal differentiation, resulted in an increase in expression of intermediate filaments. In iPSC cultures, a similar differentiation response seems to occur, but there was no similar increase in intermediate filament expression [86]. 


\section{Vimentin intermediate filament}

Vimentin is a type III intermediate filament (IF) and is the first cytoplasmic filament to be expressed upon differentiation [90]. This IFP is considered to be the primordial member of the intermediate filament family, because it is present in most, if not all, fetal cells early in development. Vimentin, from the latin name vimentum [97] explaining that it contains an array of flexible rods, was initially isolated from mouse fibroblast culture. The size of vimentin protein is 57-KD [98]. Vimentin has evolved as one of the important markers of differentiation as it is not cell type specific [90]. Vimentin shows more resemblance to desmin when considering the mesenchymal tumor pathology. Vimentin is very near in structure to GFAP, NFPs than to the keratin intermediate filaments. Embryonic Stem Cells (ESCs) have low levels of Vimentin, which is turned on early in differentiation, and is later replaced by tissue specific intermediate filaments in most cell types [91]. It is composed of flexible head and tail regions, which vary between different type III IFs such as GFAP, Neurofilaments, Desmin, and Peripherin; and two coiled-coil rod domains which are conserved between type III IFs [92]. Vimentin associates with the actin and tubulin cytoskeleton, with organelles, including mitochondria and Lipid Droplets, and with chaperones like $\alpha \beta$-crystallin [93, 94]. The cellular function of Vimentin is not completely established, although it was shown to contribute to cell stiffness, cell motility, actin positioning, and organelle trafficking $[95,96]$.

Vimentin filaments are significantly resistant to mechanical stress, by forming highly resilient filaments. They promote optimal tissue function by integrating actin filaments and microtubules to establish a functional cytoskeleton [99]. These filaments are mediated by prominent plakin family and motor cyto-linker proteins. Although they are thought to be involved only in the mechanical structure and cell flexibility [100], they are observed to be involved in cell division and the motility to the topological organization of transmembrane channels [101]. Due to the versatile functions of the vimentin filament, mutations in the same can cause a range of genetic diseases [102]. 


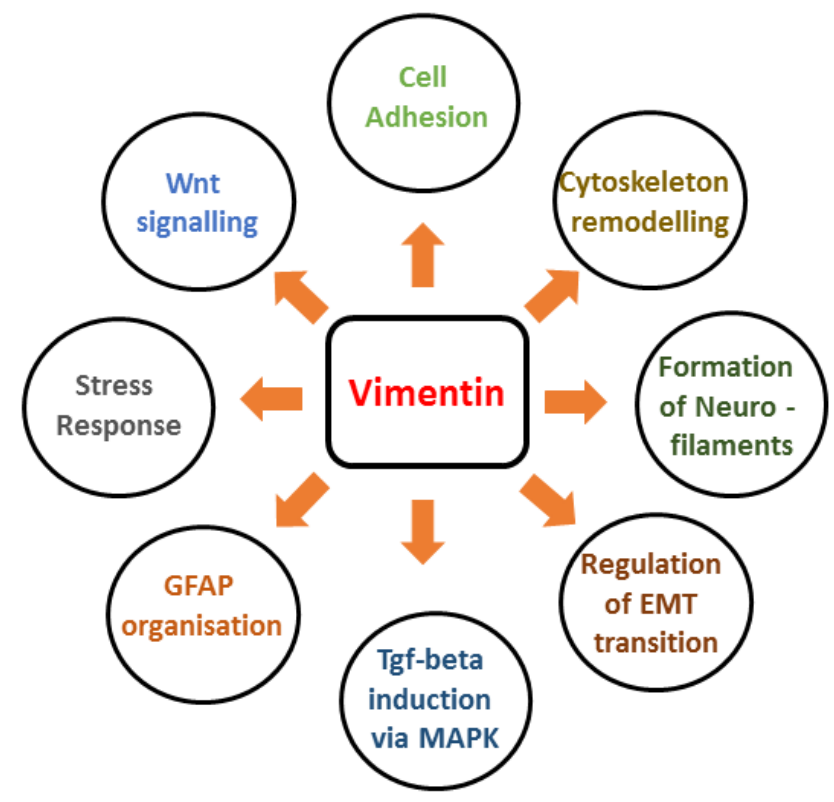

Figure 4: Schematic showing the pathways vimentin is observed to be involved.

\section{Structure}

IFs display a tripartite structure, made up of an $\alpha$-helical central "rod" and flanking nona-helical "head" and "tail" domains, and assemble to give rise to nuclear [103] lamins, or various cytoplasmic IF networks consisting of proteins such as keratins (K), vimentin, neurofilaments (NFs), peripherin, desmin and glial fibrillary acidic protein (GFAP) depending on tissue and cell type. Building blocks of the vimentin filament, the single dimers, consists of 466 amino acids. The structural segments are formed, by linking in the sequence $1 \mathrm{~A}, 1 \mathrm{~B}, 2 \mathrm{~A}$ and $2 \mathrm{~B}$ suggested by the experimental studies by different groups. These are connected buy the linkers L1, L12 and L2 [104]. The heterogeneous distribution is revealed by this analysis showing the bending stiffness along the axis. The non-alpha helical linkers define the flexible hinge like regions, connecting the protein's stiffer regions [105].

The assembly of vimentin starts from the formation of in-parallel and in-register coiledcoil dimers. The dimers associate with the half-staggered tetramer in an antiparallel fashion [106]. When the renaturation of vimentin from $8 \mathrm{M}$ urea, the tetrameric complex forms and constitutes the smallest soluble complex, that can be handled in nondenaturing conditions. The filament assemble is initiated, by the addition of the salt and the release of the strong basic charged head domain leading from the interaction with acidic rod [107]. An average of eight tetramers associate resulted from the increase in the ionic strength, leads to the formation of one unit-length filament, referred to as the ULF [108]. The longitudinal annealing of the ULF results in the formation of filaments. An $\sim 3-\mathrm{nm}$ overlap is formed during the filament elongation. This overlap happens between dimers of two filaments, through the interaction determined by the chemical cross-linking and electron microscopy. They can grow to about $20 \mu \mathrm{M}$ in length in this fashion [109]. Since they exchange subunits at a very 
fast rate, the filaments are very stable in-vitro. Unlike the microtubules and microfilaments, the polymerization of the vimentin filament is non-polar [103]. The polymerization occurs at both ends of the filament, and there is exchange of individual subunits anywhere along the filament length. During stress conditions, glutathionylation, nitrosylation or carbonylation are involved in the, predominantly oxidative in nature, non-enzymatic modification of the vimentin filament [110].

\section{Vimentin and stress}

The 73 genes products, which comprises the cytoskeletal intermediate filament family are expressed in development dependent manner in tissue, cell and differentiation. Intermediate filaments associated proteins regulate the filaments by interacting with signaling molecules consisting of proteins, apoptosis related proteins, phosphatases and kinases [99]. They are also regulated by the posttranslational modifications (PTMs). The most significant is the phosphorylation among the intermediate filament PTMs. These regulate the IF solubility, and the associated protein binding and some cytoprotective functions are also provided [111]. During apoptosis, the IFs are degraded by the caspases, leading to the situation where ubiquitination and proteosomal degradation, targets them as part of normal protein turnover during apoptosis [112].

Multiple stress inducible genes encoding various prominent HSPs, are upregulated during heat shock response (HSR) in the cell. This upregulation of the HSPs is both conserved and ubiquitous, implicating in protection against different forms of stress $[113,114]$. Both tissue and the genes involved during these stresses, governs the changes in the IF level, which is not the case observed in the classic HSP induction. Vimentin is very much heat sensitive, and becomes elevated in non-neuronal cells, human promonocytic cells and the hippocampus unlike the K8, K18, K19 and the astrocyte IF GFAP, whose levels remain unaltered even after heat and other stress exposure. However, the vimentin level is diminished in heat shocked rat embryos [115].

It has observed by research groups that, after neurotrauma, attenuated reactive gliosis gets developed in double-null vimentin/GFAP mice [116]. There is hyperphosphorylation of the vimentin, and K18 filaments during heat stress and also reorganization of GFAP, vimentin and keratin [117]. The physical association between the HSPs and vimentin, remains as the likely functional link between them. Mrj and HSP70 preferentially associates with $\mathrm{K} 18$ and K8. However, with the case vimentin and GFAP, there is interaction with both HSP27 and aB-crystallin [118]. There is upregulation of HSP levels, during several IF mutation including the cells expressing GFAP filaments that is not able assemble GFAP due to the mutation in vimentin [119]. The importance of vimentin like with keratins in shear stress becomes evident when vimentin null cells become smaller, and less able to adhere to the substratum [120]. When repair of damaged muscle take place, during early differentiation or myogenesis 
- vimentin and nestin are significantly upregulated which are only present during the early phase [121]. The mouse fibroblast cells knocked out for vimentin, are stiffer and slower wound healing is observed in vimentin null embryos [122]. The astrocytes activated by a wound reverts back to the situation that includes de-novo expression of vimentin and nestin along with resident GFAP. The upregulation of vimentin is also resulted by the response of HSPs, due to the stress caused by the age increase or high caloric intake [123]. Increase in age corresponds to increase in the GFAP and nestin expression in the astrocytes and rat pituitary [124]. Whereas chronic food restriction leads to the decrease in GFAP. The vimentin protein and RNA increase 45 -fold in mice with bone fracture, or soft tissue trauma followed by upregulation of the K19 mRNA. In concordance with this, there is reorganization of the filament in senescent fibroblasts [125].

In vimentin depleted cells, there is abnormal mitochondrial morphology, and organization [126]. The crosstalk between endosomes and lysosomes, the position, sorting and movement of the lysosomes [127] are also affected by vimentin, NF and desmin. The transport of melanosomes are actively done by vimentin and keratins as observed by some research studies [128]. 


\section{REFERENCES - Chapter 1}

1. 1. Bryja, V., Bonilla, S. \& Arenas, E. Derivation of mouse embryonic stem cells. Nat Protoc 1, 2082-2087 (2006) doi:10.1038/nprot.2006.355

2. Evans, M.J. \& Kaufman, M.H. Establishment in culture of pluripotential cells from mouse embryos. Nature 292, 154-156

3. Richard L. Gardner, Pluripotential Stem Cells from Vertebrate

Embryos, Handbook of Stem Cells, 10.1016/B978-0-12-385942-6.00003-2, (1326), (2013).

4. Shenghui He, Daisuke Nakada, Sean J. Morrison. Mechanisms of Stem Cell SelfRenewal. Annual Review of Cell and Developmental Biology 2009 25:1, 377-406.

5. Huang, G., Ye, S., Zhou, X. et al. Cell. Mol. Life Sci. (2015) 72: 1741.

6. RGEdwards. Personal pathways to embryonic stem cells. Reproductive

BioMedicine Online, Volume 4, Issue 3, 2002, Pages 263-278

7. González S, Ibáñez E, Santaló J. Establishment of mouse embryonic stem cells from isolated blastomeres and whole embryos using three derivation methods. $J$ Assist Reprod Genet. 2010;27(12):671-682. doi:10.1007/s10815-010-9473-9

8. Yu, S., Yan, X., Chen, D. et al. Isolation and characterization of mouse embryonic stem cell line by parthenogenesis. Cell Res 18, S120 (2008)

doi:10.1038/cr.2008.210

9. Mahmoud Hashemi-Tabar., Fatemeh Javadnia., Mahmoud Orazizadeh., Maryam

Baazm. Isolation and differentiation of mouse embryonic stem cells. Iranian Journal of Reproductive Medicine Vol.3. No.1 pp: 42-46, 2005.

10. Rossant J. Stem cells and early lineage development. Cell. 2008;132:527-31.

doi: 10.1016/j.cell.2008.01.039

11. Chung Y, Klimanskaya I, Becker S, Marh J, Lu SJ, Johnson J, et al. Embryonic and extraembryonic stem cell lines derived from single mouse

blastomeres. Nature. 2006;439:216-9.

12. Fujimori T, Kurotaki Y, Miyazaki J, Nabeshima Y. Analysis of cell lineage in twoand four-cell mouse embryos. Development. 2003;130:5113-22. doi:

10.1242/dev.00725.

13. Yoji Kojima. The Transcriptional and Functional Properties of Mouse Epiblast Stem Cells Resemble the Anterior Primitive Streak. Cell Stem Cell. Volume 14, 2014, Pages 107-120

14. D.W. Han, N. Tapia, J.Y. Epiblast stem cell subpopulations represent mouse embryos of distinct pregastrulation stages. Cell, 143 (2010), pp. 617-627.

15. K. Hayashi, M.A. Surani. Self-renewing epiblast stem cells exhibit continual delineation of germ cells with epigenetic reprogramming in vitro. Development, 136 (2009), pp. 3549-3556.

16. L. Vallier., et al. Activin/Nodal signalling maintains pluripotency by controlling Nanog expression. Development, 136 (2009), pp. 1339-1349

17. K. Kim et al. Donor cell type can influence the epigenome and differentiation potential of human induced pluripotent stem cells. Nat. Biotechnol., 29 (2011), pp. 
1117-1119

18. R. Osorno, A. Tsakiridis. The developmental dismantling of pluripotency is reversed by ectopic Oct4 expression. Development, 139 (2012), pp. 2288-2298.

19. TomohiroKonno., KunihikoAkita. Formation of embryoid bodies by mouse embryonic stem cells on plastic surfaces. Journal of bioscience. Volume 100, Issue 1, July 2005, Pages 88-93.

20. Aldahmash A. et al. Teratoma formation in immunocompetent mice after syngeneic and allogeneic implantation of germline capable mouse embryonic stem cells. Asian Pac J Cancer Prev. 2013;14(10):5705-11.

21. Jitong Guo, Baojiang Wu, Shuyu Li, et al. Contribution of Mouse Embryonic Stem Cells and Induced Pluripotent Stem Cells to Chimeras through Injection and Coculture of Embryos," Stem Cells International, vol. 2014.

22. Gertsenstein M, Nutter LMJ, Reid T, Pereira M, Stanford WL, Rossant J, et al. (2010) Efficient Generation of Germ Line Transmitting Chimeras from C57BL/6N ES Cells by Aggregation with Outbred Host Embryos. PLoS ONE 5(6): e11260. 23. Kang L, Gao S. Pluripotency of induced pluripotent stem cells. J Anim Sci Biotechnol. 2012;3(1):5. Published 2012 Feb 28. doi:10.1186/2049-1891-3-5 24. Denker HW. Time to reconsider stem cell induction strategies. Cells. 2012;1(4):1293-1312. Published 2012 Dec 17.

25. Polejaeva I, Mitalipov S. Stem cell potency and the ability to contribute to chimeric organisms. Reproduction. 2013;145(3):R81-R88. Published 2013 Mar 7. 26. Wen D, Saiz N, Rosenwaks Z, Hadjantonakis AK, Rafii S. Completely ES cellderived mice produced by tetraploid complementation using inner cell mass (ICM) deficient blastocysts. PLoS One. 2014;9(4):e94730. Published 2014 Apr 14. 27. Patterson PH (August 1994). "Leukemia inhibitory factor, a cytokine at the interface between neurobiology and immunology". Proceedings of the National Academy of Sciences of the United States of America. 91 (17): 7833-5.

28. Kento Onishi, Peter W. Zandstra. LIF signaling in stem cells and development. Development 2015 142: 2230-2236;

29. Sim YJ, Kim MS, Nayfeh A, et al. 2i Maintains a Naive Ground State in ESCs through Two Distinct Epigenetic Mechanisms. Stem Cell Reports. 2017;8(5):13121328.

30. R. Osorno, A. Tsakiridis. The developmental dismantling of pluripotency is reversed by ectopic Oct4 expression. Development, 139 (2012), pp. 2288-2298. 31. X. Chen, S. Ye, Q.L. Ying. Stem cell maintenance by manipulating signaling pathways: past, current and future. BMB Rep., 48 (2015), pp. 668-676.

32. Niwa H., Miyazaki J., Smith A.G. Quantitative expression of Oct-3/4 defines differentiation, dedifferentiation or self-renewal of ES cells. Nat. Genet. 2000;24:372376.

33. Li S, Xiao F, Zhang J, et al. Disruption of OCT4 Ubiquitination Increases OCT4 Protein Stability and ASH2L-B-Mediated H3K4 Methylation Promoting Pluripotency Acquisition. Stem Cell Reports. 2018;11(4):973-987. 
34. Zhang J, Gao Y, Yu M, et al. Retinoic Acid Induces Embryonic Stem Cell Differentiation by Altering Both Encoding RNA and microRNA Expression. PLoS One. 2015;10(7):e0132566.

35. Janesick, A., Wu, SC, \& Blumberg, B. (2015). Retinoic acid signaling and neuronal differentiation. Cellular and Molecular Life Sciences, 72(8), 1559-1576. 36. Huang P, Chandra V, Rastinejad F. Retinoic acid actions through mammalian nuclear receptors. Chem Rev. 2014;114(1):233-254. doi:10.1021/cr400161b 37. Spelke D.P., Ortmann D., Khademhosseini A., Ferreira L., Karp J.M. (2011) Methods for Embryoid Body Formation: The Microwell Approach. Methods in Molecular Biology (Methods and Protocols), vol 690. Humana Press.

38. Pacherník J. Neural differentiation of pluripotent mouse embryonal carcinoma cells by retinoic acid: inhibitory effect of serum. Physiol Res. 2005;54(1):115-22. 39. Chen D, Wu Z, Luo LJ, et al. E-cadherin maintains the activity of neural stem cells and inhibits the migration. Int J Clin Exp Pathol. 2015;8(11):14247-14251. 40. Bratt-Leal AM, Carpenedo RL, McDevitt TC. Engineering the embryoid body microenvironment to direct embryonic stem cell differentiation. Biotechnol Prog. 2009;25(1):43-51.

41. Douglas E. White. Spatial Pattern Dynamics of 3D Stem Cell Loss of Pluripotency via Rules-Based Computational Modeling. PLOS. March 14, 2013. 42. Goh S-K, Olsen P, Banerjee I (2013) Extracellular Matrix Aggregates from Differentiating Embryoid Bodies as a Scaffold to Support ESC Proliferation and Differentiation. PLoS ONE 8(4): e61856.

43. Englander SW, Mayne L, Krishna MM. Protein folding and misfolding: mechanism and principles. Q Rev Biophys. 2007;40(4):287-326.

44. Chiang YS, Gelfand TI, Kister AE, Gelfand IM (2007). "New classification of supersecondary structures of sandwich-like proteins uncovers strict patterns of strand assemblage". Proteins. 68 (4): 915-921.

45. Dobson, C. Protein folding and misfolding. Nature 426, 884-890 (2003).

46. Skår J., Protein folding and misfolding: a paradigm of self-assembly and regulation in complex biological systems. Philosophical Transactions of the Royal Society of London. Series A: Mathematical, Physical and Engineering Sciences. 47. Cieplak AS (2017) Protein folding, misfolding and aggregation: The importance of two-electron stabilizing interactions. PLoS ONE 12(9): e0180905.

48. Hartl, F. U. \& Hayer-Hartl, M. Molecular chaperones in the cytosol: from nascent chain to folded protein. Science 295, 1852-1858 (2002).

49. Sweeney $P$, Park $H$, Baumann $M$, et al. Protein misfolding in neurodegenerative diseases: implications and strategies. Transl Neurodegener. 2017;6:6.

50. M. U. Sajjad, B. Samson and A. Wyttenbach, " Heat Shock Proteins:

Therapeutic Drug Targets for Chronic Neurodegeneration?”, Current Pharmaceutical Biotechnology (2010) 11: 198.

51. Emily J. Guinn, Pengfei Tian, Mia Shin, Robert B. Best, Susan Marqusee. A small single-domain protein folds through the same pathway on- and off- the ribosome. bioRxiv 347864 
52. Netzer, W., Hartl, F. Recombination of protein domains facilitated by cotranslational folding in eukaryotes. Nature 388, 343-349 (1997)

53. Ho CY, Troncoso JC, Knox D, Stark W, Eberhart CG. Beta-amyloid, phospho-tau and alpha-synuclein deposits similar to those in the brain are not identified in the eyes of Alzheimer's and Parkinson's disease patients. Brain Pathol. 2014;24(1):2532.

54. Young AB. Huntingtin in health and disease. J Clin Invest. 2003;111(3):299-302.

55. Okamoto, K., Mizuno, Y. and Fujita, Y. (2008), Bunina bodies in amyotrophic lateral sclerosis. Neuropathology, 28: 109-115.

56. Wickstead B, Gull K (August 2011). The evolution of the cytoskeleton. The Journal of Cell Biology. 194 (4): 513-25.

57. Frixione $E$ (June 2000). Recurring views on the structure and function of the cytoskeleton: a 300-year epic. Cell Motility and the Cytoskeleton. 46 (2): 73-94.

58. Lodish, Harvey. Cilia and Flagella: Structure and Movement. Archived from the original on 2 May 2018.

59. Gunning PW, Ghoshdastider U, Whitaker S, Popp D, Robinson RC (June 2015). The evolution of compositionally and functionally distinct actin filaments. Journal of Cell Science. 128 (11): 2009-19.

60. Ledbetter MC, Porter KR (1963). A "microtubule" in plant cell fine structure. Journal of Cell Biology. 19 (1): 239-50

61. Chaaban S, Brouhard GJ (2017). A microtubule bestiary: structural diversity in tubulin polymers. Molecular Biology of the Cell. 28 (22): 2924-31.

62. Desai A \& Mitchison TJ (1997). Microtubule polymerization dynamics. Annual Review of Cell and Developmental Biology. 13: 83-117.

63. Vinogradova T, Miller PM, Kaverina I (July 2009). Microtubule network asymmetry in motile cells: role of Golgi-derived array. Cell Cycle. 8 (14): 2168-74

64. Walker RA, O'Brien ET, Pryer NK, Soboeiro MF, Voter WA, Erickson HP, Salmon ED (October 1988). Dynamic instability of individual microtubules analyzed by video light microscopy: rate constants and transition frequencies. The Journal of Cell Biology. 107 (4): 1437-48.

65. Julien Lefèvre. The $C$ Terminus of Tubulin, a Versatile Partner for Cationic Molecules binding of tau, polyamines, and calcium. (2010). The Journal of Biological Chemistry. 286, 3065-3078.

66. Vale RD (February 2003). "The molecular motor toolbox for intracellular transport". Cell. 112 (4): 467-80.

67. Parker AL, Kavallaris M, McCarroll JA. Microtubules and their role in cellular stress in cancer. Front Oncol. 2014;4:153. Published 2014 Jun 18.

68. Roberts K, Raff M, Alberts B, Walter P, Lewis J, Johnson A (March 2002). Molecular Biology of the Cell (4th ed.)

69. Berg JM, Tymoczko JL, Stryer L (2002). "Myosins Move Along Actin Filaments". Biochemistry. 5th Edition. Archived from the original on 2018-05-02.

70. Dickinson RB, Southwick FS, Purich DL (October 2002). "A direct-transfer polymerization model explains how the multiple profilin-binding sites in the 
actoclampin motor promote rapid actin-based motility". Archives of Biochemistry and Biophysics. 406 (2): 296-301.

71. Cooper, Geoffrey M. (2000). "Actin, Myosin, and Cell Movement". The Cell: A Molecular Approach. 2nd Edition. Archived from the original on 2018-04-28.

72. Wu C. Focal adhesion: a focal point in current cell biology and molecular medicine. Cell Adh Migr. 2007;1(1):13-18.

73. Stéphanie Pellegrin. Actin stress fibres. Journal of Cell Science 2007 120: 3491 3499.

74. Haeri M, Knox BE. Endoplasmic Reticulum Stress and Unfolded Protein Response Pathways: Potential for Treating Age-related Retinal Degeneration. J Ophthalmic Vis Res. 2012;7(1):45-59.

75. Kahali S, Sarcar B, Prabhu A, Seto E, Chinnaiyan P. Class I histone deacetylases localize to the endoplasmic reticulum and modulate the unfolded protein response. FASEB J. 2012;26(6):2437-2445.

76. Barlan K, Gelfand VI. Microtubule-Based Transport and the Distribution, Tethering, and Organization of Organelles. Cold Spring Harb Perspect Biol. 2017;9(5):a025817. Published 2017 May 1.

77. Liu JJ. Regulation of dynein-dynactin-driven vesicular transport. Traffic. 2017 Jun; 18(6):336-347. Epub 2017 Mar 28.

78. Akhmanova A, Hammer JA III. 2010. Linking molecular motors to membrane cargo. Curr Opin Cell Biol 22: 479-487.

79. Roostalu J, Hentrich C, Bieling P, Telley IA, Schiebel E, Surrey T (2011).

Directional switching of the kinesin Cin8 through motor coupling. Science. 332 (6025): 94-9

80. Dodding MP, Way M. Coupling viruses to dynein and kinesin-1. EMBO J. 2011;30(17):3527-3539. Published 2011 Aug 31.

81. A K Boal et al 2006 Nanotechnology 17349

82. Boraas LC, Guidry JB, Pineda ET, Ahsan T (2016) Cytoskeletal Expression and Remodeling in Pluripotent Stem Cells. PLoS ONE 11(1)

83. Boraas LC, Pineda ET, Ahsan T. Actin and myosin II modulate differentiation of pluripotent stem cells. PLoS One. 2018;13(4):e0195588.

84. Yan Y, Bejoy J, Xia J, Griffin K, Guan J, Li Y. Cell population balance of cardiovascular spheroids derived from human induced pluripotent stem cells. Sci Rep. 2019;9(1):1295.

85. Boulting, G. L., Kiskinis, E., Croft, G. F., Amoroso, M. W., Oakley, D. H., Wainger, B. J., et al. (2011). A functionally characterized test set of human induced pluripotent stem cells. Nat. Biotechnol. 29, 279-286

86. Wolfe RP, Leleux J, Nerem RM, Ahsan T (2012) Effects of shear stress on germ lineage specification of embryonic stem cells. Integrative biology: quantitative biosciences from nano to macro 4: 1263-1273.

87. Ambriz X, de Lanerolle P, Ambrosio JR. The Mechanobiology of the Actin Cytoskeleton in Stem Cells during Differentiation and Interaction with Biomaterials. Stem Cells Int. 2018; 
88. Khatau SB, Kusuma S, Hanjaya-Putra D, et al. The differential formation of the LINC-mediated perinuclear actin cap in pluripotent and somatic cells. PLoS One. 2012;7(5):e36689.

89. Pineda ET, Nerem RM, Ahsan T. Differentiation patterns of embryonic stem cells in two- versus three-dimensional culture. Cells Tissues Organs. 2013; 197(5):399410.

90. Danielsson, F., Peterson, M.K., Caldeira Araujo, H., Lautenschlager, F., and Gad, A.K.B. (2018) Vimentin Diversity in Health and Disease. Cells 7.

91. Castro-Munozledo F, Meza-Aguilar DG, Dominguez-Castillo R, HernandezZequinely V, \& Sanchez-Guzman E (2017) Vimentin as a Marker of Early Differentiating, Highly Motile Corneal Epithelial Cells. J Cell Physiol 232(4):818-830. 92. Strelkov SV, Herrmann H, \& Aebi U (2003) Molecular architecture of intermediate filaments. Bioessays 25(3):243-251.

93. Katsumoto T.; Mitsushima A.; Kurimura T. (1990) "The role of the vimentin intermediate filaments in rat 3Y1 cells elucidated by immunoelectron microscopy and computer-graphic reconstruction". Biol Cell. 68, 139-46.

94. Nicholl ID \& Quinlan RA (1994) Chaperone activity of alpha-crystallins modulates intermediate filament assembly. EMBO J 13(4):945-953.

95. Matveeva EA, Venkova LS, Chernoivanenko IS, \& Minin AA (2015) Vimentin is involved in regulation of mitochondrial motility and membrane potential by Rac1. Biol Open 4(10):1290-1297.

96. Eckes B, et al. (1998) Impaired mechanical stability, migration and contractile capacity in vimentin-deficient fibroblasts. J Cell Sci 111 ( Pt 13):1897-1907.

97. Franke WW, Schmid E, Osborn M, Weber K (October 1978). Different intermediate-sized filaments distinguished by immunofluorescence microscopy.

Proceedings of the National Academy of Sciences of the United States of America.

75 (10): 5034-8.

98. Fuchs E, Weber K (1994). "Intermediate filaments: structure, dynamics, function, and disease". Annual Review of Biochemistry. 63: 345-82.

99. Sanghvi-Shah R, Weber GF. Intermediate Filaments at the Junction of Mechanotransduction, Migration, and Development. Front Cell Dev Biol. 2017. 100. Castañón MJ, Walko G, Winter L, Wiche G. Plectin-intermediate filament partnership in skin, skeletal muscle, and peripheral nerve. Histochem Cell Biol. 2013;140(1):33-53.

101. Yolanda de Pablo., et al. 2019. Vimentin Phosphorylation Is Required for Normal Cell Division of Immature Astrocytes. Cells, 8(9), 1016.

102. Hess JF, Budamagunta MS, FitzGerald PG, Voss JC. Characterization of structural changes in vimentin bearing an epidermolysis bullosa simplex-like mutation using site-directed spin labeling and electron paramagnetic resonance. $\mathrm{J}$ Biol Chem. 2005;280(3):2141-2146.

103. Herrmann H, Aebi U. Intermediate Filaments: Structure and Assembly. Cold Spring Harb Perspect Biol. 2016;8(11).

104. Qin Z, Kreplak L, Buehler MJ. Hierarchical structure controls nanomechanical 
properties of vimentin intermediate filaments. PLoS One. 2009;4(10).

105. Bragulla HH, Homberger DG. Structure and functions of keratin proteins in simple, stratified, keratinized and cornified epithelia. J Anat. 2009;214(4):516-559. 106. Hess JF, Budamagunta MS, Voss JC, FitzGerald PG. Structural characterization of human vimentin rod 1 and the sequencing of assembly steps in intermediate filament formation in vitro using site-directed spin labeling and electron paramagnetic resonance. J Biol Chem. 2004;279(43):44841-44846. 107. Köster S, Weitz DA, Goldman RD, Aebi U, Herrmann H. Intermediate filament mechanics in vitro and in the cell: from coiled coils to filaments, fibers and networks. Curr Opin Cell Biol. 2015;32:82-91.

108. Amélie Robert., et al. Vimentin filament precursors exchange subunits in an ATP-dependent manner. PNAS July 7, 2015112 (27) E3505-E3514. 109. Mücke N, Winheim S, Merlitz H, Buchholz J, Langowski J, Herrmann H (2016) In Vitro Assembly Kinetics of Cytoplasmic Intermediate Filaments: A Correlative Monte Carlo Simulation Study. PLoS ONE 11(6): e0157451.

110. Townsend DM. S-glutathionylation: indicator of cell stress and regulator of the unfolded protein response. Mol Interv. 2007;7(6):313-324.

111. Snider NT, Omary MB. Post-translational modifications of intermediate filament proteins: mechanisms and functions. Nat Rev Mol Cell Biol. 2014;15(3):163-177. 112. Vakifahmetoglu-Norberg $\mathrm{H}$, Norberg E, Perdomo AB, et al. Caspase-2 promotes cytoskeleton protein degradation during apoptotic cell death. Cell Death Dis. 2013;4(12):e940.

113. Tiwari S, Thakur R, Shankar J. Role of Heat-Shock Proteins in Cellular Function and in the Biology of Fungi. Biotechnol Res Int. 2015;2015:132635.

114. Morimoto RI. Proteotoxic stress and inducible chaperone networks in neurodegenerative disease and aging. Genes Dev. 2008 Jun 1; 22(11):1427-38. 115. Bechtold DA, Brown IR. Induction of Hsp27 and Hsp32 stress proteins and vimentin in glial cells of the rat hippocampus following hyperthermia. Neurochem Res. 2003;28(8):1163-73.

116. Widestrand A, et al. Increased neurogenesis and astrogenesis from neural progenitor cells grafted in the hippocampus of GFAP-/- Vim-/- mice. Stem Cells. 2007;25(10):2619-27.

117. Liao J, Lowthert LA, Omary MB. Heat stress or rotavirus infection of human epithelial cells generates a distinct hyperphosphorylated form of keratin 8 .

Experimental Cell Research. 1995;219(2):348-57

118. Perng MD, et al. Intermediate filament interactions can be altered by HSP27 and alphaB-crystallin. J Cell Sci. 1999;112(Pt 13):2099-112.

119. Perng MD, et al. Glial fibrillary acidic protein filaments can tolerate the incorporation of assembly-compromised GFAP-delta, but with consequences for filament organization and alphaB-crystallin association. Mol Biol Cell. 2008;19(10):4521-33.

120. Tsuruta $D$, Jones JC. The vimentin cytoskeleton regulates focal contact size and adhesion of endothelial cells subjected to shear stress. J Cell Sci. 2003;116(Pt 
24):4977-84.

121. Samuli Vaittinen, Riitta Lukka. The Expression of Intermediate Filament protein Nestin as Related to Vimentin and Desmin in Regenerating Skeletal Muscle, Journal of Neuropathology \& Experimental Neurology, Volume 60, Issue 6, June 2001, Pages 588-597.

122. Yaming Jiu. Vimentin intermediate filaments control actin stress fiber assembly through GEF-H1 and RhoA. J Cell Sci. 2017 Mar 1;130(5):892-902.

123. Westerheide SD, et al. Stress-inducible regulation of heat shock factor 1 by the deacetylase SIRT1. Science. 2009;323(5917):1063-6.

124. Gautron L, De-Smedt V, Laye S. Age-related changes in nestin immunoreactivity in the rat pituitary gland. Neuroendocrinology. 2009;90(1):19-30.

125. Matsutani T, et al. Young and middle-age associated differences in cytokeratin expression after bone fracture, tissue trauma, and hemorrhage. Am J Surg. 2007;193(1):61-8.

126. Tang $\mathrm{HL}$, et al. Vimentin supports mitochondrial morphology and organization. Biochem J. 2008;410(1):141-6.

127. Styers ML, Kowalczyk AP, Faundez V. Intermediate Filaments and Vesicular Membrane Traffic: The Odd Couple's First Dance? Traffic. 2005;6(5):359-65. 128. Chang $L$, et al. The dynamic properties of intermediate filaments during organelle transport. J Cell Sci. 2009. 


\section{CHAPTER 2}

Imperfect asymmetry: The mechanism governing asymmetric partitioning of damaged cellular components during mitosis.

Sundararaghavan Pattabiraman and Daniel Kaganovich Journal - Bioarchitecture, 2015 


\begin{abstract}
Aging is universally associated with organism-wide dysfunction and a decline in cellular fitness. From early development onwards, the efficiency of self-repair, energy production, and homeostasis all decrease. Due to the multiplicity of systems that undergo agingrelated decline, the mechanistic basis of organismal aging has been difficult to pinpoint. At the cellular level, however, recent work has provided important insight. Cellular aging is associated with the accumulation of several types of damage, in particular damage to the proteome and organelles. Groundbreaking studies have shown that replicative aging is the result of a rejuvenation mechanism that prevents the inheritance of damaged components during division, thereby confining the effects of aging to specific cells, while removing damage from others. Asymmetric inheritance of misfolded and aggregated proteins, as well as reduced mitochondria, has been shown in yeast. Until recently, however, it was not clear whether a similar mechanism operates in mammalian cells, which were thought to mostly divide symmetrically. Our group has recently shown that vimentin establishes mitotic polarity in immortalized mammalian cells, and mediates asymmetric partitioning of multiple factors through direct interaction. These findings prompt a provocative hypothesis: that intermediate filaments serve as asymmetric partitioning modules or "sponges" that, when expressed prior to mitosis, can "clean" emerging cells of the damage they have accumulated.
\end{abstract}




\section{Replicative Rejuvenation}

Two important discoveries point to essential clues in the search for the mechanistic basis of aging: replicative rejuvenation and induced pluripotency, or reprogramming of induced pluripotent stem cells. $[1,2,3]$ Studies of replicative aging have shown that a robust mechanism for aging avoidance promotes the "replicative rejuvenation" of individual cells, from prokaryotes, to budding yeast, mammalian cell lines, and even differentiating stem cells.[4-7] These cells are thought to mitigate the causes and consequences of cellular aging by asymmetrically partitioning aging determinants during mitosis. Although several of these factors have been identified (oxidatively damaged proteins, old or reduced mitochondria, circular DNA, and misfolded proteins, among others) [6, 9-12], most factors, as well as the mechanism governing asymmetric inheritance, remain a mystery. Understanding the mechanism of replicative rejuvenation will offer definitive insight into the determinants of aging and the interplay between these determinants and disease.

iPSC reprogramming technology offers another conceptual window into the mechanism of aging, since reprogramming can effectively "undo" the aging process: it has been suggested that old or even senescent cells can be reprogrammed into "youthful" pluripotent cells.[1,2] This phenomenon demonstrates that aging and associated damage accumulation can be reversed through a reprogramming process that is not yet understood at the molecular level.

Despite these important advances, 2 key questions remain unanswered: How do cells recognize some materials as being old or unfit versus new and youthful? And how are unfit components retained in specific cells?

\section{Asymmetric inheritance of damaged factors in eukaryotes}

Asymmetric mitosis, yielding 2 daughter cells that are different in their components or their fates, is an essential feature of organismal development, stem cell renewal and differentiation, the creation of a germ line, and the establishment of fitness asymmetry through rejuvenation.[13-16] Replicative rejuvenation is the process of partitioning damaged cellular factors during mitosis away from a cell that has been dedicated to staying young (the renewing daughter), and into a daughter cell that ages (Fig. 1). $[17,19]$ It was only relatively recently that ground-breaking work in budding yeast Saccaromyces cerevisiae led to the discovery of this process.[8,20-22] Budding yeast is a single cell organism in which every division is polar in 2 respects: 1 . the mother and daughter cells are physically distinguishable from one another; and 2. with each division the mother cell becomes older while the daughter cell is rejuvenated. After a finite number of daughters, the mother cell shows signs of "aging decline," stops dividing and eventually dies.[23] Replicative rejuvenation ensures that each of the daughters turns into a new mother that enjoys a full replicative potential.[24] Because of this polarity, yeast presents an exquisitely tractable system for probing the mechanism of asymmetry-based rejuvenation, which we have exploited 
in previous work to elucidate one of the mechanisms for asymmetric inheritance of aggregate inclusions. $[25,26]$ Other work by the Nystrom group and colleagues has demonstrated that genes which participate in the regulation of asymmetric partitioning of aggregates (including Sir2, Actin, Hsp104) directly influence the yeast replicative lifespan, indicating that misfolded proteins and aggregates are bona fide determinants of aging.[9,11,27-29] These studies have shown that replicative rejuvenation relies on the coordinated function of overlapping mechanisms that identify aging factors and carefully partition them away from the daughter cell and into the mother cell during mitosis. The aging markers identified so far in yeast include aged organelles such as mitochondria, oxidatively damaged proteins, and extra-chromosomal DNA circles. [11,19,30-34] 

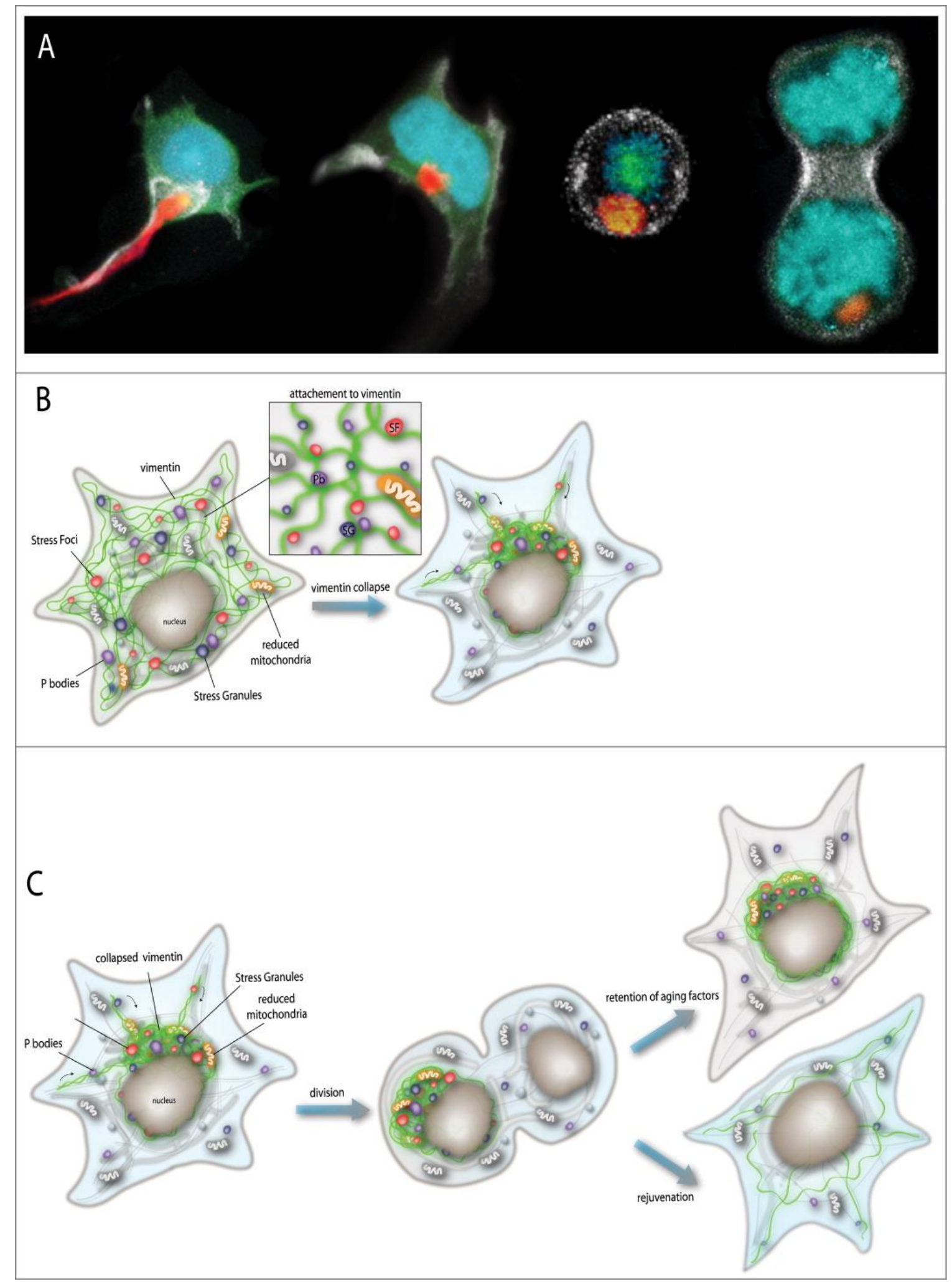

Figure 1. (A) 3D time-lapse (4D imaging) of a live neuronal-derived cell line entering asymmetric mitosis. Vimentin IF is red, Histone-2b is blue, alpha-Tubulin is green and F-Actin is white. Misfolded proteins in the collapsed VIF JUNQ are inherited by the aging cell. (B) Model of VIF attachment to aging determinants, including stress foci (misfolded proteins), p-bodies (RNA), stress granules (RNA), and old mitochondria. 
(C) Model of asymmetric inheritance of collapsed VIF during mitosis. However, yeast is merely the simplest and most tractable example of a cell that uses mitosis for rejuvenation.

Studies published within the last year have established that replicative rejuvenation is utilized in multiple examples of cell divisions in multicellular organisms and human cells. $[6,35,36]$ This is true for divisions of cells that are known to be polar (e. g. old centrosome partitioning to renewing stem cell), as well as divisions where polarity is not immediately apparent (e. g. dividing immortal cancer cells, stem cells differentiating to different tissues, pluripotent stem cells, etc.). $[37,38]$ Thus, just as yeast, multicellular organisms rejuvenate replicatively and the chronological lifespan, as opposed to cell type, determines the level of damaged proteins and other components present in the cell.[39] A list of asymmetrically partitioning factors is beginning to emerge in yeast, though it is far from comprehensive.[3] We know even less about what determines the organelles, proteins, and membrane compartments that partition asymmetrically in dividing mammalian somatic cells and stem cells, nor has it been explored how this happens.

\section{Mechanisms of replicative rejuvenation}

Four general mechanisms are thought to maintain asymmetric partitioning during mitosis (and thereby facilitate rejuvenation). These include 1. motor-driven transport (via actin/myosin and microtubules); 2 . direct or indirect association with one of the 2 centrosomes; 3 . confinement by diffusion barriers; and 4 . spatial sequestration into earmarked deposits that are attached to membranes[12,21,30,35,41-42] or are large enough in volume that their movement is significantly constrained. All of these have been clearly shown in budding yeast, but almost nothing is known about which of these mechanisms operate in mammalian cells. Since the yeast division is a priori polar (in every division there is a pre-defined mother cell and daughter cell) directed transport can pull new oxidized mitochondria [43] and high proton gradient vacuoles [44] into the bud as it emerges from the mother cell. The nuclear membrane remains intact during the yeast mitosis, and hence can be used as a platform for retention of misfolded proteins (in the JUNQ quality control compartment).[25] Insoluble aggregates (in the IPOD insoluble aggregate compartment) are also retained by virtue of spatial sequestration and adhesion to vacuoles earmarked for the mother cell.[25] During closed mitosis the nuclear membrane also contains diffusion barriers that have been shown by the Barral group to ensure the retention of extrachromosomal rDNA circles (ERCs) in the mother cell.[45] For these retention mechanisms, the specific adaptors that designate "old" vs. "new" are not yet known. It is unclear how reduced mitochondria and unfit vacuoles are recognized and transported. ERCs have been proposed to attach to old nuclear pores and thus retained during division, however this is far from clear.[46] 


\section{Asymmetry in multicellular organisms}

Asymmetry in mammalian cells is more difficult to track than in a budding organism like yeast because every division is a priori symmetrical in multicellular organisms and cultured cells. Asymmetry has been studied by following the fate of each cell (proliferation versus death; self-renewal vs. differentiation; etc.) $[38,39,47,48]$ or by tracking specific components (e. g. protein aggregates; ubiquitinated proteins; reduced mitochondria).[8, 49-51] These studies point to many instances of asymmetry (only one cell inheriting an aggregate) without necessarily observing polarity that designates one cell as "old" and the other as "young." However, organism-level studies in Drosophila have also observed asymmetric partitioning of damaged proteins and aggregates to specific cell lineages. [52] Intestinal cells, for example, partition damage to differentiating progeny and away from self-renewing cells.[12] One notable example of a characterized asymmetry mechanism in multi-cellular organisms is the inheritance of $\mathrm{P}$ granules during $C$. elegans development. $\mathrm{P}$ granules are membraneless organelle-like dynamic droplets packed with RNA and proteins that segregate to germ cell precursors during development.[53,54] Although not anchored to other organelles, $\mathrm{P}$ granules are retained asymmetrically by the dividing one-cell embryo by virtue of its assembly and disassembly dynamics and their large volume. In the posterior side of the embryo, destined to become the $\mathrm{P}$ granule inheriting cell, assembly kinetics are rapid, driven by high concentrations of $\mathrm{P}$ granule components. Conversely, at the anterior of the cell, disassembly is rapid, leading to rapidly diffusing components which are free to assemble at the posterior.

\section{Cytoskeleton: Vehicle for Replicative Rejuvenation}

The cytoskeleton mediates cell division, and also plays a key role in maintenance of division asymmetry.[55] In both yeast and mammalian cells the spindle pole body or the centrosome establish the polarity of division.[37,56,57] The old spindle pole body is always inherited by the bug in yeast, and the old mother centrosome is also inherited in a conserved manner in divisions where an axis of polarity exists (such as in development).[58]

The precise role of specific cytoskeletal components in yeast asymmetric aging and rejuvenation is a matter of some controversy, with actin, tubulin, and constrains on the movement of misfolded proteins all implicated to various degrees. The actin cytoskeleton is one of the major regulators of asymmetry and replicative rejuvenation in yeast.[41,59,60] The Nystrom group has demonstrated that deletion of the Sir2 aging regulator, which decreases replicative lifespan, acts via the actin cytoskeleton by decreasing actin production and thus the rate of retrograde transport of aggregates and other aging determinants.[41,60,61] In fact, a key experiment showed that even temporary pharmacological disruption of actin leads to daughter cell contamination by aging determinants, and that this daughter cell has a shorter replicative lifespan than subsequent daughter cells which were budded once F-actin was restored.[41] F-actin 
cables and associated myosin motors have also been implicated in the transport of fit mitochondria and vacuoles to the bud.[34]

The requirement of actin for rejuvenation and fitness appears to be highly conserved, though it remains to be seen whether the mechanism of its involvement is as well. In $C$. elegans, a recent study discovered that increasing the stability of the actin cytoskeleton by over-expressing the pat- 10 protein was sufficient to extend the lifespan of the nematode and to improve tolerance of heat stress.[62] Conversely, disrupting F-actin lead to decreased lifespan and heat tolerance in yeast,[41] C. elegans, and mammalian cell lines.[63-65] Not all of these effects can be attributed to the role of actin in replicative rejuvenation - clearly actin is also essential for maintaining cellular homeostasis, proper protein movement, and cytoplasmic organization.[66] However, the above-mentioned experiments clearly demonstrate an essential role for actin-based rejuvenation in maintaining cellular fitness. Hence, in looking for the mechanism of mammalian cell asymmetry, the cytoskeleton is an obvious target.

\section{Replicative rejuvenation in mammalian cells}

What is the role of the cytoskeleton in replicative rejuvenation and maintenance of asymmetry in mammalian cells? Besides the polarity of the division of the centrosome, not much is known about a possible role of the cytoskeleton in ensuring the asymmetric segregation of damage. It is possible that, as in yeast, mammalian cells use retrograde actin-based movement of aging determinants from one cell to the other during division. Another recent candidate for regulating replicative rejuvenation in mammalian cells is the intermediate filament vimentin (VIF). VIF is a versatile intermediate filament, which has been implicated in regulating differentiation, senescence, and immortalization. $[67,68]$ Fibroblasts lacking VIF exhibited an inability to become immortal, and VIF has been shown to protect cells from oxidative damage.[68,69]

Recent work from our group has demonstrated that a specific (collapsed) form of VIF consistently undergoes asymmetric partitioning in dividing immortal mammalian cell lines.[6] We hypothesize that VIF binds to certain aggregates, ribonuclear protein (RNP) granules, reduced mitochondria, and to misfolded proteins, including ones that are mobile and relatively soluble, and promotes their asymmetric inheritance by trapping them in collapsed VIF structure. We call these structures JUNQs (for juxtanuclear quality control compartments) because they contain mobile misfolded proteins (as opposed to aggregates) and because these misfolded proteins undergo proteasomal degradation within the inclusions.[6,70] These structures are distinct from insoluble aggregates (IPODs) or aggresomes, which we observe to form later in the aggregation process upon exposure to stress or higher levels of misfolded proteins.[70,71] JUNQ inclusions form very rapidly in response to high levels of misfolded proteins. This can be triggered by pharmacological proteasome inhibition, or (in our hands) simply by over-expression of model misfolded proteins including von- 
Hippel Lindau protein (VHL), the CL1 hydrophobic peptide, or a thermosensitive version of Ubc9 or Luciferase.[70,72,73] JUNQ structures are extremely dynamic and have high turnover rates. When we observe cells for longer periods of time, we see the appearance of small cytoplasmic foci, which we call stress foci because their appearance can be triggered by acute stress including heat shock, arsenite, chaperone inhibition, and disruption of the cytoskeleton.[25,70] Over time, stress foci are transported toward the JUNQ and accumulate around it. This corresponds to VIF collapse, and a transition from a dynamic JUNQ inclusion, to an immobile aggresome in place of the JUNQ. The collapsed VIF remains intact during mitosis, and is attached to the microtubule organizing center (MTOC) which mediates polar inheritance (example division shown in Fig. 1A). Hence, this study implicates the MTOC, tubulin, and VIF in the asymmetric aging of mammalian cells.

\section{Implications for cellular fitness and development}

We observed that cells which avoid inheriting the collapsed VIF are more "fit" than cells which do inherit it. Using our low phototoxicity 4D imaging approach we were able to follow multiple divisions of HEK and N2a cells, tracking the localization of the collapsed VIF inclusions. Interestingly, we observed that cells which fail to inherit the inclusion always divide before cells which do inherit it (6).

Although the reasons for the increased fitness of the cells which do not inherit the VIF are still unclear, our preliminary results indicate that VIF binds multiple aging determinants in addition to misfolded proteins. Similar to misfolded proteins (e. g. CL1 peptide and $\mathrm{VHL}$ ) we also observe reduced mitochondria, $\mathrm{p}$-body markers, and stress granule markers associating with VIF and trapped in collapsed VIF (model - Fig. 1B and $\mathbf{C})$.

\section{VIF - a potential master-regulator of replicative rejuvenation in mammalian cells}

VIF is upregulated early in differentiation, is usually expressed together with tissuespecific IFs, and is then downregulated.[74,75] Hence, its expression may be an early cleaning mechanism that mediates cell specification and the generation of pristine lineages. Conversely, VIF is an important player in immortalization and carcinogenesis, and may act to prevent senescence in rapidly dividing, metabolically active, and damage-prone cancer cells.[68, 76-78]. Contrary to past models of mitosis, we posit that many if not most mammalian mitotic divisions are asymmetric.[13] This asymmetry has sweeping implications for immortalization, carcinogenesis, stem cell maintenance and differentiation, aging, and induced pluripotency (or rejuvenation).[3, $38,79]$

Our model is that the expression of VIF in immortalized cells and differentiating stem cells regulates the asymmetric inheritance of aging determinants, including damaged, misfolded, and aggregated proteins and reduced mitochondria. VIF collapse (regulated by Rho kinase and p21-activated kinase) [80-82] traps aging determinants, as well as specific RNP granules, and mediates their asymmetric partitioning between 
2 daughter cells during mitosis. We posit that this asymmetry may function to rejuvenate specific lineages that are meant to be pristine (such as germ-line precursors and immortalized cells) and may also function to give specific cells a fitness advantage in the face of metabolic, oxidative, or protein folding stress.

\section{Future Directions}

The study of aging asymmetry or replicative rejuvenation is rapidly expanding in search of parallel mechanisms in mammalian cells to those that have been characterized in yeast, the specific elements that designate certain cellular components as "old," as well as the machinery that affects their selective retention. VIF provides a supple and elegant solution to the asymmetry problem, interacting with the actin/tubulin cytoskeleton as well as most organelles and with misfolded proteins. The asymmetric partitioning of collapsed VIF raises 2 key questions that should be the topic of future investigations. How does VIF interact with organelles and "old" dynamic droplets? An attractive model is that VIF acts as a "sponge" for dynamics droplets and misfolded proteins via its disordered regions. Another question is: what is the cost and benefit to cellular fitness of inheriting collapsed VIF with all of its associated aging factors? One possibility which should be investigated is that inheriting aging components is beneficial in the short term (since many of them can be re-used and there is a cost to removing them from the cell); whereas it may be costly in the long term, since they are ultimately less fit. As in previous studies, comparing and contrasting the mechanisms utilized by different organisms toward similar goals will likely prove useful in future investigations. 


\section{References - Chapter 2}

1. Lapasset L, Milhavet O, Prieur A, Besnard E, Babled A, Aït-Hamou N, Leschik J, Pellestor F, Ramirez JM, De Vos J, et al. Rejuvenating senescent and centenarian human cells by reprogramming through the pluripotent state. Genes Dev 2011; 25:2248-53; PMID:22056670; http://dx.doi.org/10.1101/gad.173922.111 [Crossref], [PubMed], [Web of Science $\AA$ ], [Google Scholar]

2. Takahashi K, Yamanaka S. Induction of pluripotent stem cells from mouse embryonic and adult fibroblast cultures by defined factors. Cell 2006; 126:663-76; http://dx.doi.org/10.1016/j.cell.2006.07.024 [Crossref], [PubMed], [Web of Science ®], [Google Scholar]

3. Nystrom T, Liu B. The mystery of aging and rejuvenation-a budding topic. Curr Opin Microbiol 2014; 18:61-7; http://dx.doi.org/10.1016/j.mib.2014.02.003 [Crossref], [PubMed], [Web of Science ${ }^{\circledR}$ ], [Google Scholar]

4. Lynch MD. Replicative aging in E. coli. Rejuvenation Res 2005; 8:79-81; PMID:15929714; http://dx.doi.org/10.1089/rej.2005.8.79 [Crossref], [PubMed], [Web of Science ${ }^{\circledR}$ ], [Google Scholar]

5. Nystrom T. A bacterial kind of aging. PLoS Genet 2007; 3:e224; PMID:18085827; http://dx.doi.org/10.1371/journal.pgen.0030224 [Crossref], [PubMed], [Web of Science ${ }^{\circledR}$ ], [Google Scholar]

6. Ogrodnik M, Salmonowicz H, Brown R, Turkowska J, Średniawa W, Pattabiraman $\mathrm{S}$, Amen T, Abraham AC, Eichler N, Lyakhovetsky R, et al. Dynamic JUNQ inclusion bodies are asymmetrically inherited in mammalian cell lines through the asymmetric partitioning of vimentin. Proc Natl Acad Sci U S A 2014; 111:8049-54;

PMID:24843142; http://dx.doi.org/10.1073/pnas.1324035111 [Crossref], [PubMed], [Web of Science $®$ ], [Google Scholar]

7. Liu L, Rando TA. Manifestations and mechanisms of stem cell aging. J Cell Biol 2011; 193:257-66; PMID:21502357; http://dx.doi.org/10.1083/jcb.201010131 [Crossref], [PubMed], [Web of Science $®$ ], [Google Scholar]

8. Katajisto P, Döhla J, Chaffer CL, Pentinmikko N, Marjanovic N, lqbal S, Zoncu R, Chen W, Weinberg RA, Sabatini DM. Stem cells. Asymmetric apportioning of aged mitochondria between daughter cells is required for stemness. Science. $2015 \mathrm{Apr}$ 17;348(6232):340-3. doi: 10.1126/science.1260384. Epub 2015 Apr 2.

PMID:25837514. [Crossref], [Google Scholar]

9. Erjavec N, Nystrom T. Sir2p-dependent protein segregation gives rise to a superior reactive oxygen species management in the progeny of Saccharomyces cerevisiae. Proc Natl Acad Sci U S A 2007; 104:10877-81; PMID:17581878; 
http://dx.doi.org/10.1073/pnas.0701634104 [Crossref], [PubMed], [Web of Science ®], [Google Scholar]

10. Coelho M, Lade SJ, Alberti S, Gross T, Tolic IM. Fusion of protein aggregates facilitates asymmetric damage segregation. PLoS Biol 2014; 12:e1001886; PMID:24936793; http://dx.doi.org/10.1371/journal.pbio.1001886PBIOLOGY-D-1304860 [Crossref], [PubMed], [Web of Science $®$ ], [Google Scholar]

11. Nystrom T. Aging: filtering out bad mitochondria. Curr Biol 2013; 23:R1037-9; PMID:24309277; http://dx.doi.org/10.1016/j.cub.2013.10.049 [Crossref], [PubMed], [Web of Science $®$ ], [Google Scholar]

12. Rujano MA, Bosveld F, Salomons FA, Dijk F, van Waarde MA, van der Want JJ, de Vos RA, Brunt ER, Sibon OC, Kampinga HH. Polarised asymmetric inheritance of accumulated protein damage in higher eukaryotes. Plos Biol 2006; 4:2325-35; PMID:17147470; http://dx.doi.org/10.1371/journal.pbio.0040417 [Crossref], [PubMed], [Web of Science ${ }^{\circledR}$ ], [Google Scholar]

13. Knoblich JA. Asymmetric cell division during animal development. Nat Rev Mol Cell Biol 2001; 2:11-20; http://dx.doi.org/10.1038/3504808535048085 [Crossref], [PubMed], [Web of Science $\AA$ ], [Google Scholar]

14. Gonczy P. Mechanisms of asymmetric cell division: flies and worms pave the way. Nat Rev Mol Cell Biol 2008; 9:355-66; PMID:18431399; http://dx.doi.org/10.1038/nrm2388 [Crossref], [PubMed], [Web of Science $®$ ], [Google Scholar]

15. Salzmann V, Chen C, Chiang CY, Tiyaboonchai A, Mayer M, Yamashita YM. Centrosome-dependent asymmetric inheritance of the midbody ring in Drosophila germline stem cell division. Mol Biol Cell 2014; 25:267-275; PMID:24227883; http://dx.doi.org/10.1091/mbc.E13-09-0541 [Crossref], [PubMed], [Web of Science (B], [Google Scholar]

16. England JL. Statistical physics of self-replication. J Chem Phys 2013; 139:121923; PMID:24089735; http://dx.doi.org/10.1063/1.4818538 [Crossref], [PubMed], [Web of Science ®], [Google Scholar]

17. Wright WE, Shay JW. Historical claims and current interpretations of replicative aging. Nat Biotechnol 2002; 20:682-8; PMID:12089552;

http://dx.doi.org/10.1038/nbt0702-682 [Crossref], [PubMed], [Web of Science ${ }^{\circledR}$ ], [Google Scholar]

18. Lindner AB, Madden R, Dernarez A, Stewart EJ, Taddei F. Asymmetric segregation of protein aggregates is associated with cellular aging and rejuvenation. P Natl Acad Sci U S A 2008; 105:3076-81; http://dx.doi.org/10.1073/pnas.0708931105 [Crossref], [PubMed], [Web of Science ®], [Google Scholar] 
19. Amen T, Kaganovich D. Dynamic droplets: the role of cytoplasmic inclusions in stress, function, and disease. Cell Mol Life Sci 2015; 72:401-15; PMID:25283146; http://dx.doi.org/10.1007/s00018-014-1740-y [Crossref], [PubMed], [Web of Science (B], [Google Scholar]

20. Liu B, Larsson L, Caballero A, Hao X, Oling D, Grantham J, Nyström T, et al. The polarisome is required for segregation and retrograde transport of protein aggregates. Cell 2010; 140:257-67; PMID:20141839;

http://dx.doi.org/10.1016/j.cell.2009.12.031 [Crossref], [PubMed], [Web of Science ®], [Google Scholar]

21. Shcheprova Z, Baldi S, Frei SB, Gonnet G, Barral Y. A mechanism for asymmetric segregation of age during yeast budding. Nature 2008; 454:728-U764; PMID:18660802; http://dx.doi.org/10.1038/Nature07212; [Crossref], [PubMed], [Web of Science ${ }^{B}$ ], [Google Scholar]

22. Erjavec N, Larsson L, Grantham J, Nystrom T. Accelerated aging and failure to segregate damaged proteins in Sir2 mutants can be suppressed by overproducing the protein aggregation-remodeling factor Hsp104p. Genes Dev 2007; 21:2410-21; PMID:17908928; http://dx.doi.org/10.1101/gad.439307 [Crossref], [PubMed], [Web of Science ${ }^{\circledR}$ ], [Google Scholar]

23. Fehrmann S, Paoletti C, Goulev Y, Ungureanu A, Aguilaniu H, Charvin G. Aging yeast cells undergo a sharp entry into senescence unrelated to the loss of mitochondrial membrane potential. Cell Rep 2013; 5:1589-99; PMID:24332850; http://dx.doi.org/10.1016/j.celrep.2013.11.013 [Crossref], [PubMed], [Web of Science ®], [Google Scholar]

24. Longo VD, Shadel GS., Kaeberlein M, Kennedy B. Replicative and chronological aging in Saccharomyces cerevisiae. Cell Metab 2012; 16:18-31; PMID:22768836; http://dx.doi.org/10.1016/j.cmet.2012.06.002 [Crossref], [PubMed], [Web of Science ®], [Google Scholar]

25. Spokoini R, Moldavski O, Nahmias Y, England JL, Schuldiner M, Kaganovich D. Confinement to organelle-associated inclusion structures mediates asymmetric inheritance of aggregated protein in budding yeast. Cell Rep 2012; 2:738-47; PMID:23022486; http://dx.doi.org/10.1016/j.celrep.2012.08.024 [Crossref], [PubMed], [Web of Science ${ }^{8}$ ], [Google Scholar]

26. Lippuner AD, Julou T, Barral Y. Budding yeast as a model organism to study the effects of age. Fems Microbiol Rev 2014; 38:300-25; PMID:24484434; http://dx.doi.org/10.1111/1574-6976.12060 [Crossref], [PubMed], [Web of Science ®], [Google Scholar]

27. Malinovska L, Kroschwald S, Munder MC, Richter D, Alberti S. Molecular chaperones and stress-inducible protein-sorting factors coordinate the spatiotemporal distribution of protein aggregates. Mol Biol Cell 2012; 23:3041-56; 
PMID:22718905; http://dx.doi.org/10.1091/mbc.E12-03-0194 [Crossref], [PubMed], [Web of Science $\circledast$ ], [Google Scholar]

28. Hill SM, Hao XX, Liu BD, Nystrom T. Life-span extension by a metacaspase in the yeast Saccharomyces cerevisiae. Science 2014; 344:1389-92; PMID:24855027; http://dx.doi.org/10.1126/science.1252634 [Crossref], [PubMed], [Web of Science ®], [Google Scholar]

29. Alberti S. Molecular mechanisms of spatial protein quality control. Prion 2012; 6:437-42; PMID:23051707; http://dx.doi.org/10.4161/pri.2247022470 [Taylor \& Francis Online], [Web of Science $®$ ], [Google Scholar]

30. Kaeberlein M. Lessons on longevity from budding yeast (vol 464, pg 513, 2010). Nature 2010; 464:513-9; PMID:20336133; http://dx.doi.org/10.1038/Nature09046; [Crossref], [PubMed], [Web of Science $®$ ], [Google Scholar]

31. Sinclair DA, Guarente L. Extrachromosomal rDNA circles - A cause of aging in yeast. Cell 1997; 91: 1033-42; PMID:9428525; http://dx.doi.org/10.1016/S00928674(00)80493-6 [Crossref], [PubMed], [Web of Science ®], [Google Scholar]

32. Spokoini R, Shamir M, Keness A, Kaganovich D. 4D imaging of protein aggregation in live cells. J Vis Exp 2013; PMID:23608881; http://dx.doi.org/10.3791/50083 [Crossref], [PubMed], [Web of Science $®$ ], [Google Scholar]

33. Nystrom T, Liu B. Protein quality control in time and space - links to cellular aging. FEMS Yeast Res 2013; http://dx.doi.org/10.1111/1567-1364.12095 1:40-8; [Crossref], [PubMed], [Web of Science ${ }^{\circledR}$ ], [Google Scholar]

34. Vevea JD, Swayne TC, Boldogh IR, Pon LA. Inheritance of the fittest mitochondria in yeast. Trends Cell Biol 2014; 24: 53-60; PMID:23932848; http://dx.doi.org/10.1016/j.tcb.2013.07.003 [Crossref], [PubMed], [Web of Science ®], [Google Scholar]

35. Strandkvist C, Juul J, Bendtsen KM. Asymmetric segregation of damaged cellular components in spatially structured multicellular organisms. PLoS One 2014; 9: e87917; http://dx.doi.org/10.1371/journal.pone.0087917 PONE-D-13-36280 [pii] [Crossref], [PubMed], [Web of Science $®$ ], [Google Scholar]

36. Volovik Y, Marques FC, Cohen E. The nematode Caenorhabditis elegans: a versatile model for the study of proteotoxicity and aging. Methods 2014; 68:458-64; PMID:24794346; http://dx.doi.org/10.1016/j.ymeth.2014.04.014 [Crossref], [PubMed], [Web of Science ${ }^{\circledR}$ ], [Google Scholar]

37. Yamashita YM. The centrosome and asymmetric cell division. Prion 2009; 3:8488. [Taylor \& Francis Online], [Web of Science ${ }^{\circledR}$ ], [Google Scholar] 
38. Huttner WB, Kosodo Y. Symmetric versus asymmetric cell division during neurogenesis in the developing vertebrate central nervous system. Curr Opin Cell Biol 2005; 17:648-57; PMID:16243506; http://dx.doi.org/10.1016/j.ceb.2005.10.005 [Crossref], [PubMed], [Web of Science $\AA^{8}$ ], [Google Scholar]

39. Bufalino MR, DeVeale B, van der Kooy D. The asymmetric segregation of damaged proteins is stem cell-type dependent. J Cell Biol 2013; 201:523-30; PMID:23649805; http://dx.doi.org/10.1083/jcb.201207052 [Crossref], [PubMed], [Web of Science $\circledast$ ], [Google Scholar]

40. Mishra $P$, Chan DC. Mitochondrial dynamics and inheritance during cell division, development and disease. Nat Rev Mol Cell Biol 2014; 15:634-46; PMID:25237825; http://dx.doi.org/10.1038/nrm3877 [Crossref], [PubMed], [Web of Science $®$ ], [Google Scholar]

41. Liu BD, Larsson L, Franssens V, Hao X, Hill SM, Andersson V, Höglund D, Song $\mathrm{J}$, Yang $\mathrm{X}$, Öling D, et al. Segregation of Protein Aggregates Involves Actin and the Polarity Machinery. Cell 2011; 147:959-61; PMID:22118450; http://dx.doi.org/10.1016/j.cell.2011.11.018 [Crossref], [PubMed], [Web of Science ®], [Google Scholar]

42. Clay L, Caudron F, Denoth-Lippuner A, Boettcher B, Buvelot Frei S, Snapp EL, Barral Y. A sphingolipid-dependent diffusion barrier confines ER stress to the yeast mother cell. Elife 2014; 3:e01883; PMID:24843009;

http://dx.doi.org/10.7554/eLife.01883 [Crossref], [PubMed], [Web of Science ${ }^{\circledR}$ ], [Google Scholar]

43. Higuchi-Sanabria R, Pernice WM, Vevea JD, Alessi Wolken DM, Boldogh IR, Pon LA. Role of asymmetric cell division in lifespan control in Saccharomyces cerevisiae. FEMS Yeast Res 2014; 14:1133-46; PMID:25263578;

http://dx.doi.org/10.1111/1567-1364.12216 [Crossref], [PubMed], [Web of Science ®], [Google Scholar]

44. Henderson KA, Hughes AL, Gottschling DE. Mother-daughter asymmetry of $\mathrm{pH}$ underlies aging and rejuvenation in yeast. Elife 2014; 3:e03504; PMID:25190112; http://dx.doi.org/10.7554/eLife.03504. [Crossref], [PubMed], [Web of Science ®], [Google Scholar]

45. Denoth-Lippuner A, Krzyzanowski MK, Stober C, Barral Y. Role of SAGA in the asymmetric segregation of DNA circles during yeast ageing. Elife 2014; 3:E1; PMID:20651645; http://dx.doi.org/10.7554/eLife.03790; [Crossref], [PubMed], [Web of Science ${ }^{\circledR}$ ], [Google Scholar]

46. Khmelinskii A, Keller PJ, Lorenz H, Schiebel E, Knop M. Segregation of yeast nuclear pores. Nature 2010; 466:E1; http://dx.doi.org/10.1038/nature09255 [Crossref], [PubMed], [Web of Science ${ }^{\circledR}$ ], [Google Scholar] 
47. Habib SJ, Chen BC, Tsai FC, Anastassiadis K, Meyer T, Betzig E, Nusse R. A localized wnt signal orients asymmetric stem cell division in vitro. Science 2013; 339:1445-8; PMID:23520113; http://dx.doi.org/10.1126/science.1231077 [Crossref], [PubMed], [Web of Science $\AA$ ], [Google Scholar]

48. Williams SE, Beronja S, Pasolli HA, Fuchs E. Asymmetric cell divisions promote Notch-dependent epidermal differentiation. Nature 2011; 470:353-8;

PMID:21331036; http://dx.doi.org/10.1038/nature09793 [Crossref], [PubMed], [Web of Science ${ }^{\circledR}$ ], [Google Scholar]

49. Fuentealba LC, Eivers E, Geissert D, Taelman V, De Robertis EM. Asymmetric mitosis: unequal segregation of proteins destined for degradation. P Natl Acad Sci USA 2008; 105: 7732-7; http://dx.doi.org/10.1073/pnas.0803027105 [Crossref], [PubMed], [Web of Science ®], [Google Scholar]

50. McFaline-Figueroa JR, Vevea J, Swayne TC, Zhou C, Liu C, Leung G, Boldogh IR, Pon LA. Mitochondrial quality control during inheritance is associated with lifespan and mother-daughter age asymmetry in budding yeast. Aging Cell 2011; 10:885-95; PMID:21726403; http://dx.doi.org/10.1111/j.1474-9726.2011.00731.x [Crossref], [PubMed], [Web of Science $\AA$ ], [Google Scholar]

51. Bufalino MR, van der Kooy D. The aggregation and inheritance of damaged proteins determines cell fate during mitosis. Cell Cycle 2014; 13:1201-7;

PMID:24553116; http://dx.doi.org/10.4161/cc.28106 [Taylor \& Francis Online], [Web of Science ${ }^{\circledR}$ ], [Google Scholar]

52. Neumuller RA, Knoblich JA. Dividing cellular asymmetry: asymmetric cell division and its implications for stem cells and cancer. Genes Dev 2009; 23:2675-99;

PMID:19952104; http://dx.doi.org/10.1101/gad.1850809 [Crossref], [PubMed], [Web of Science ${ }^{\circledR}$ ], [Google Scholar]

53. Brangwynne CP, Eckmann CR, Courson DS, Rybarska A, Hoege C, Gharakhani J, Jülicher F, Hyman AA. Germline P granules are liquid droplets that localize by controlled dissolution/condensation. Science 2009; 324:1729-32; PMID:19460965; http://dx.doi.org/10.1126/science.1172046 [Crossref], [PubMed], [Web of Science ${ }^{\circledR}$ ], [Google Scholar]

54. Hyman AA, Weber CA, Julicher F. Liquid-liquid phase separation in biology. Annu Rev Cell Dev Biol 2014; 30:39-58; PMID:25288112; http://dx.doi.org/10.1146/annurev-cellbio-100913-013325 [Crossref], [PubMed], [Web of Science ${ }^{\circledR}$ ], [Google Scholar]

55. Cooley J, Whitaker S, Sweeney S, Fraser S, Davidson B. Cytoskeletal polarity mediates localized induction of the heart progenitor lineage. Nat Cell Biol 2011; 13:952-U176; PMID:21785423; http://dx.doi.org/10.1038/ncb2291 [Crossref], [PubMed], [Web of Science ${ }^{\circledR}$ ], [Google Scholar] 
56. Bornens M. Organelle positioning and cell polarity. Nat Rev Mol Cell Bio 2008; 9:874-886; http://dx.doi.org/10.1038/Nrm2524 [Crossref], [PubMed], [Web of Science ®], [Google Scholar]

57. Yamashita YM. Regulation of asymmetric stem cell division: spindle orientation and the centrosome. Front Biosci 2009; 14:3003-11; http://dx.doi.org/10.2741/4030 [Crossref], [Web of Science $®$ ], [Google Scholar]

58. Winey M, O'Toole ET. The spindle cycle in budding yeast. Nat Cell Biol 2001; 3:E23-7; PMID:11146646; http://dx.doi.org/10.1038/35050663 [Crossref], [PubMed], [Web of Science $\AA$ ], [Google Scholar]

59. Aguilaniu H, Gustafsson L, Rigoulet M, Nystrom T. Asymmetric inheritance of oxidatively damaged proteins during cytokinesis. Science 2003; 299:1751-3; PMID:12610228; http://dx.doi.org/10.1126/science.1080418 [Crossref], [PubMed], [Web of Science $\circledast$ ], [Google Scholar]

60. Erjavec N, Nystrom T. Sir2p-dependent protein segregation gives rise to a superior reactive oxygen species management in the progeny of Saccharomyces cerevisiae. P Natl Acad Sci USA 2007; 104:10877-81;

http://dx.doi.org/10.1073/pnas.0701634104 [Crossref], [PubMed], [Web of Science ®], [Google Scholar]

61. Song J, Yang Q, Yang J, Larsson L, Hao X, Zhu X, Malmgren-Hill S, Cvijovic M, Fernandez-Rodriguez J, Grantham J, et al. Essential genetic interactors of SIR2 required for spatial sequestration and asymmetrical inheritance of protein aggregates. Plos Genet 2014; 10:e1004539;

http://dx.doi.org/10.1371/journal.pgen.1004539 [Crossref], [PubMed], [Web of Science $\AA$ ], [Google Scholar]

62. Baird NA, Douglas PM, Simic MS, Grant AR, Moresco JJ, Wolff SC, Yates JR 3rd, Manning G, Dillin A. HSF-1-mediated cytoskeletal integrity determines thermotolerance and life span. Science 2014; 346:360-3; PMID:25324391; http://dx.doi.org/10.1126/science.1253168 [Crossref], [PubMed], [Web of Science $®$ ], [Google Scholar]

63. Cohen E. Aging, protein aggregation, chaperones, and neurodegenerative disorders: mechanisms of coupling and therapeutic opportunities. Rambam Maimonides Med J 2012; 3:e0021; http://dx.doi.org/10.5041/RMMJ.10088rmmj-3-4e0021 [Crossref], [PubMed], [Google Scholar]

64. Ben-Zvi A, Miller EA, Morimoto RI. Collapse of proteostasis represents an early molecular event in Caenorhabditis elegans aging. Proc Natl Acad Sci U S A 2009; 106:14914-9; PMID:19706382; http://dx.doi.org/10.1073/pnas.0902882106 [Crossref], [PubMed], [Web of Science ${ }^{\circledR}$ ], [Google Scholar] 
65. Kirstein-Miles J, Morimoto RI. Caenorhabditis elegans as a model system to study intercompartmental proteostasis: interrelation of mitochondrial function, longevity, and neurodegenerative diseases. Dev Dynam 2010; 239:1529-38; PMID:20419784; http://dx.doi.org/10.1002/dvdy.22292 [Crossref], [PubMed], [Web of Science ${ }^{\circledR}$ ], [Google Scholar]

66. Kasza KE, Broedersz CP, Koenderink GH, Lin YC, Messner W, Millman EA, Nakamura F, Stossel TP, Mackintosh FC, Weitz DA. Actin Filament Length Tunes Elasticity of Flexibly Cross-Linked Actin Networks. Biophys J 2010; 99:1091-100; PMID:20712992; http://dx.doi.org/10.1016/j.bpj.2010.06.025 [Crossref], [PubMed], [Web of Science $\circledast$ ], [Google Scholar]

67. Nishio K, Inoue A, Qiao SL, Kondo H, Mimura A. Senescence and cytoskeleton: overproduction of vimentin induces senescent-like morphology in human fibroblasts. Histochem Cell Biol 2001; 116:321-7; PMID:11702190; http://dx.doi.org/10.1007/s004180100325 [Crossref], [PubMed], [Web of Science ®], [Google Scholar]

68. Tolstonog GV, Shoeman RL, Traub U, Traub P. Role of the intermediate filament protein vimentin in delaying senescence and in the spontaneous immortalization of mouse embryo fibroblasts. DNA Cell Biol 2001; 20:509-29; PMID:11747604; http://dx.doi.org/10.1089/104454901317094945 [Crossref], [PubMed], [Web of Science ${ }^{\circledR}$ ], [Google Scholar]

69. Matveeva EA, Chernoivanenko IS, Minin AA. Vimentin intermediate filaments protect mitochondria from oxidative stress. Biol Membrany 2010; 27:471-81. [Web of Science $\AA^{8}$ ], [Google Scholar]

70. Kaganovich D, Kopito R, Frydman J. Misfolded proteins partition between two distinct quality control compartments. Nature 2008; 454:1088-95; PMID:18756251; http://dx.doi.org/10.1038/nature07195 [Crossref], [PubMed], [Web of Science ${ }^{\circledR}$ ], [Google Scholar]

71. England JL, Kaganovich D. Polyglutamine shows a urea-like affinity for unfolded cytosolic protein. Febs Lett 2011; 585:381-4; PMID:21176779; http://dx.doi.org/10.1016/j.febslet.2010.12.023 [Crossref], [PubMed], [Web of Science ${ }^{\circledR}$ ], [Google Scholar]

72. Betting J, Seufert W. A yeast Ubc9 mutant protein with temperature-sensitive in vivo function is subject to conditional proteolysis by a ubiquitin- and proteasomedependent pathway. J Biol Chem 1996; 271:25790-6; PMID:8824207; http://dx.doi.org/10.1074/jbc.271.42.25790 [Crossref], [PubMed], [Web of Science ${ }^{\circledR}$ ], [Google Scholar]

73. Gupta R, Kasturi P, Bracher A, Loew C, Zheng M, Villella A, Garza D, Hartl FU, Raychaudhuri S. Firefly luciferase mutants as sensors of proteome stress. Nature 
Methods 2011; 8:879-U155; PMID:21892152; http://dx.doi.org/10.1038/nmeth.1697 [Crossref], [PubMed], [Web of Science $\AA$ ], [Google Scholar]

74. Tsuru A, Nakamura N, Takayama E, Suzuki Y, Hirayoshi K, Nagata K. Regulation of the expression of vimentin gene during the differentiation of mouse myeloid-leukemia cells. J Cell Biol 1990; 110:1655-64; PMID:1970825; http://dx.doi.org/10.1083/jcb.110.5.1655 [Crossref], [PubMed], [Web of Science ${ }^{\circledR}$ ], [Google Scholar]

75. Honke K, Wada Y. Regulation of vimentin expression and protease-mediated vimentin degradation during differentiation of human monocytic leukemia cells. Jap $\mathrm{J}$ Cancer Res 1997; 88:484-91; PMID:9247605; http://dx.doi.org/10.1111/j.13497006.1997.tb00407.x [Crossref], [PubMed], [Google Scholar]

76. Toivola DM, Tao GZ, Habtezion A, Liao J, Omary MB. Cellular integrity plus: organelle-related and protein-targeting functions of intermediate filaments. Trends Cell Biol 2005; 15:608-17; PMID:16202602;

http://dx.doi.org/10.1016/j.tcb.2005.09.004 [Crossref], [PubMed], [Web of Science ®], [Google Scholar]

77. Styers ML, Salazar G, Love R, Peden AA, Kowalczyk AP, Faundez V. The endolysosomal sorting machinery interacts with the intermediate filament cytoskeleton. Mol Biol Cell 2004; 15:5369-82; PMID:15456899; http://dx.doi.org/10.1091/mbc.E0403-0272 [Crossref], [PubMed], [Web of Science ${ }^{\circledR}$ ], [Google Scholar]

78. Ivaska J, Pallari HM, Nevo J, Eriksson JE. Novel functions of vimentin in cell adhesion, migration, and signaling. Exp Cell Res 2007; 313:2050-62;

PMID:17512929; http://dx.doi.org/10.1016/j.yexcr.2007.03.040 [Crossref], [PubMed], [Web of Science $\circledast$ ], [Google Scholar]

79. Strandkvist C, Juul J, Bendtsen KM. Asymmetric segregation of damaged cellular components in spatially structured multicellular organisms. PLoS One 2014; 9:e87917; PMID:24551071; http://dx.doi.org/10.1371/journal.pone.0087917 [Crossref], [PubMed], [Web of Science $®$ ], [Google Scholar]

80. Goto H, Tanabe K, Manser E, Lim L, Yasui Y, Inagaki M. Phosphorylation and reorganization of vimentin by p21-activated kinase (PAK). Genes Cells 2002; 7:91-7; PMID:11895474; http://dx.doi.org/10.1046/j.1356-9597.2001.00504.x [Crossref], [PubMed], [Web of Science $\AA$ ], [Google Scholar]

81. Sin WC, Chen XQ, Leung T, Lim L. RhoA-binding kinase alpha translocation is facilitated by the collapse of the vimentin intermediate filament network. Mol Cell Biol 1998; 18:6325-39; PMID:9774649 [Crossref], [PubMed], [Web of Science ®], [Google Scholar]

82. Robert A, Herrmann H, Davidson MW, Gelfand VI. Microtubule-dependent transport of vimentin filament precursors is regulated by actin and by the concerted 
action of Rho- and p21-activated kinases. Faseb J 2014; 28:2879-90;

PMID:24652946; http://dx.doi.org/10.1096/fj.14-250019 [Crossref], [PubMed], [Web of Science ${ }^{\circledR}$ ], [Google Scholar] 


\section{CHAPTER 3}

Vimentin protects differentiating stem cells from stress

Sundararaghavan Pattabiraman, Gajendra K.Azad, Triana Amen, Eran Meshorer and Daniel Kaganovich 


\section{Vimentin protects differentiating stem cells from stress}

Sundararaghavan Pattabiraman"1, Gajendra Kumar Azad ${ }^{2,4}$, Triana Amen ${ }^{1}$, Eran Meshorer $^{2,3}$, and Daniel Kaganovich ${ }^{1}$

1. Department of Experimental Neurodegeneration, University Medical Center Göttingen, Waldweg 33, 37073 Göttingen, Germany

2. Department of Genetics, The Institute of Life Sciences, The Hebrew University of Jerusalem, Edmond J. Safra Campus, Jerusalem 91904, Israel

3. The Edmond and Lily Safra Center for Brain Research (ELSC), The Hebrew University of Jerusalem, Edmond J. Safra Campus, Jerusalem 91904, Israel

4. Current address: Department of Biochemistry, Yong Loo Lin School of Medicine, NUS, Singapore

Running title: Vimentin promotes differentiating cell survival under stress

\section{Keywords}

Vimentin, Intermediate Filaments, Aggregation, Stress Granules, RNP granules, Asymmetric inheritance, Aging, Differentiation, Embryonic stem cells

Correspondence: eran.meshorer@mail.huji.ac.il and daniel.kaganovich@med.unigoettingen.de 


\section{Summary}

Vimentin is the first cytoplasmic intermediate filament to be expressed in mammalian cells during early differentiation, but its role in cellular fitness has long been a mystery. Vimentin is acknowledged to play a role in cell stiffness, cell motility, and cytoplasmic organization, yet it is thought to be dispensable for cellular function and organismal development. Here, we show that Vimentin plays a role in cellular stress response in differentiating cells, by directly binding aggregates and RNA-binding proteins, directing their elimination and asymmetric partitioning. In the absence of Vimentin, pluripotent embryonic stem cells fail to differentiate properly, with a pronounced deficiency in neuronal differentiation. Our results uncover a novel function for Vimentin, with important implications for development, tissue homeostasis, and in particular, stress response.

\section{Introduction}

Vimentin is a type III intermediate filament (IF), and is the first cytoplasmic filament to be expressed upon differentiation (Franke et al., 1982). Embryonic Stem Cells (ESCs) have low levels of vimentin, which is turned on early in differentiation, and is later replaced by tissue specific intermediate filaments in most cell types (Castro-Munozledo et al., 2017). It is composed of flexible head and tail regions, which vary between different type III IFs such as GFAP, Neurofilaments, Desmin, and Peripherin; and two coiled-coil rod domains which are conserved between type III Ifs (Danielsson et al., 2018; Qin and Buehler, 2011; Strelkov et al., 2003). Vimentin associates with the actin and tubulin cytoskeleton, with organelles, including mitochondria and Lipid Droplets, and with chaperones like $\alpha \beta$-crystallin (Nicholl and Quinlan., 1994; Matveeva et al., 2015; Katsumoto et al., 1990., Guojuan Liao et al., 1998). The cellular function of vimentin is not completely established, although it was shown to contribute to cell stiffness, cell motility, actin positioning, and organelle trafficking (Eckes et al., 1998; Guo et al., 2013; Matveeva et al., 2015).

Despite the early and ubiquitous expression of Vimentin, its physiological role has been unclear. The Vimentin-/- knockout mouse displays few reported abnormalities, aside from poor wound healing, a smaller carotid artery, and intestinal defects (Eckes et al., 2000; Moisan et al., 2007; Terzi et al., 1997). One study recently showed that murine embryonic stem cells (mESCs) from Vimentin-/- mice have slower Embryoid Body (EB) growth relative to wild-type(Boraas and Ahsan, 2016). It has also been observed that Mouse Embryonic Fibroblasts (MEFs) lacking vimentin are difficult to immortalize and delay entry into senescence (Tolstonog et al., 2001). Indeed, vimentin is implicated in tumorigenesis, since it is highly upregulated during the epithelial-mesenchymal transition, and there are studies showing that Vimentin is needed for metastasis (Jiu et al., 2017; Kokkinos et al., 2007; Mendez et al., 2010). Recent work has also shown that Vimentin modulates inflammation in macrophages during atherogenesis and regulates notch signaling during angiogenesis (Antfolk et 
al., 2017; Haversen et al., 2018). This suggests that vimentin confers a protective or pro-survival function on cells (Hol and Capetanaki, 2017; Toivola et al., 2010).

In recent work, we showed that vimentin is partitioned asymmetrically in dividing immortal cell lines (Ogrodnik et al., 2014). A subsequent study reported the asymmetric partitioning of Vimentin together with ubiquitinated proteins in developing NPCs away from the differentiating neuron (Moore et al., 2015). Together these and other observations led us to propose a role for vimentin in replicative rejuvenation the process of asymmetrically partitioning aggregated proteins and other damaged components during mitosis, so as to produce a pristine lineage (Amen and Kaganovich, 2015; Erjavec et al., 2008; Moore et al., 2015; Pattabiraman and Kaganovich, 2014; Shcheprova et al., 2008; Spokoini et al., 2012). However, a physiological requirement for vimentin in stress response or rejuvenation is yet to be demonstrated.

We set out to systematically examine the requirement of Vimentin for mouse ESC neuronal differentiation and stress tolerance. Using CRISPR knock-out mESC lines, we show that vimentin is critical for stress tolerance in differentiating, but not pluripotent stem cells. Examining the Vimentin interactome during differentiation and stress, revealed that vimentin protects cells by binding aggregates and Ribonucleoprotein (RNP) granule proteins, and directing their asymmetric partitioning during mitosis. Vimentin knock-out cells had dramatically altered gene expression and differentiation profiles. Cells deleted for vimentin fail to differentiate into neuronal progenitors, and the defect is severely exacerbated during stress. Our data suggest that vimentin may be dispensable during normal conditions, but is critically important when cells are exposed to protein folding stress. 


\section{RESULTS}

\section{Validation of mouse embryonic stem cell line with vimentin knockout}

The mouse embryonic stem cells were taken and GRNA was introduced and the resulting cell line was knocked out of vimentin. In order to examine the role of vimentin in ESC differentiation, and stress response, we generated a mouse ESC-R1 line with a homozygous deletion for vimentin introduced via CRISPR/Cas9 gene editing. The knockout was validated by three methods - (1) Genomic DNA sequencing (2) Immuno-fluorescence and (3) RT-PCR. For validation, three clones were chosen and from the genomic DNA sequencing, we could see that the region of the start codon was deleted. For the validation by immunofluorescence, the cells were differentiated for 4 days with retinoic acid $(1 \mathrm{ug} / \mathrm{ml})$ and no signal was detected (Fig 1B-D).

\section{Expression of vimentin increases through differentiation and vimentin knockout cells grow significantly during the process of differentiation}

Vimentin is expressed at low levels in mESCs, but its expression level rises significantly following two days of retinoic acid (RA) differentiation and peaks after four days (Fig 2A). We first wanted to show that, vimentin intermediate filaments are upregulated during differentiation (Fig $1 \mathrm{~A})$. To see if there is any change in the growth of the cells when vimentin was knocked out, two conditions were chosen - (1) cells maintained and grown in pluripotent media and (2) cells differentiated with retinoic acid $(1 \mu \mathrm{g} / \mathrm{ml})$ for 5 days until they stop growing and dividing. The growth of the cells were not affected when the cells were grown in pluripotent cell media, since only less vimentin are expressed in pluripotent cells. However, when the cells were differentiated, significant decrease in the growth rate was observed after 2 days of differentiation (Fig $2 \mathrm{C}$ ). Not only differentiation with retinoic acid, when the cells were differentiated to an intermediate state consisting of cells from all the three germ layers (embryoid bodies) - the vimentin knockout cells were forming significantly smaller sized embryoid bodies when compared to the wildtype cells (Fig 2D) 


\section{Vimentin interactome shows binding to misfolded proteins, stress regulating proteins, stress granule proteins and other RNA binding proteins.}

The formation of juxtanuclear quality compartment by the misfolded protein aggregates and vimentin forming a cage around them prompted us to do an interactome study on vimentin. For this we utilized the BiolD approach (Roux et al., 2012), consisting of fusing a promiscuous biotin Ligase, BirA* to vimentin. This allowed us to acquire the comparative interactome of vimentin in RA differentiated cells and mESCs in distinct conditions by adding biotin following heat stress, arsenite treatment, treatment with nocodazole, as well as in control conditions.

Comparative interactome analysis showed enrichment in a few discrete protein networks during heat $\left(44^{\circ} \mathrm{C}\right.$ for 2 hours) and arsenite stress ( $150 \mu \mathrm{M}$ for $\left.2 \mathrm{hours}\right)$. During stress vimentin preferentially associated with model misfolded proteins, including synphilin and VHL, that were ectopically expressed confirming the cell biological evidence of interaction from. Of the endogenous proteins that were enriched in the vimentin interactome during stress, the two dominant networks consisted of low structural complexity RNA-binding proteins, many of which were Stress Granule (SG) components, and stress response proteins including chaperones and proteasome subunits (Figure 3A). Interestingly, looking closely at the fold enrichment enabled a stress specific resolution of protein network enrichment. Hence, stress response proteins including chaperones and proteasome subunits were equally enriched in heat stress and during arsenite treatment (Figure 3B), whereas SG components interacted with vimentin a bit more during arsenite stress than with heat stress, corresponding to conditions favorable to SG formation (Figure $3 \mathrm{C}$ ). When western blot analysis was performed on wildtype and vimentin knockout cells with and without stress for Heat shock factor protein (HSF-1). I was observed that HSF 4 upregulated during stress as expected. However, in the vimentin Knockout cells, without any stress the HSF 1 protein was enriched indicating that the vimentin knockout cells are constantly vulnerable to stress (Fig 3D).

Since the most prominent networks of proteins enriched in the vimentin interactome during stress were either aggregate of granule forming proteins, or protein folding quality control proteins that associate with aggregates, we wanted to verify whether the interactome of a model misfolded protein overlaps with that of vimentin during heat shock of arsenite treatment. Indeed, examining the BiolD interactome of synphilin during stress, we observed that it includes endogenous vimentin, and overlaps strongly with the vimentin interactome (Figure 3E). Together, our data argue for a stress response role for vimentin in differentiating $\mathrm{mESC}$ cells. 


\section{Validation of interactome of vimentin results.}

We confirmed the interactomics with live cell imaging. Since tagged Ubiquitin (Ub) can be used as a proxy for following endogenous aggregate localization during heat stress, we investigated the co-localization of endogenous vimentin (visualized with GFPtagged chromobodies) with mCherry-tagged Ub-positive aggregates. Confocal imaging (Figure 4A upper panels) and Structured Illumination Microscopy (SIM) (Figure 4A, lower panels) showed direct contacts between vimentin fibrils and Ubpositive aggregates, which persisted over time, despite substantial movement of vimentin fibrils. We also sought to confirm the interaction of granule-forming RNAbinding proteins with vimentin during arsenite stress. To do this, we chose a P-body component (Dcp1) and an SG component (VCP). SIM imaging once again showed direct association between vimentin filaments and P-bodies, with nearly all P-bodies associating with a filament (Figure 4B, upper panel). Moreover, the retraction of vimentin filaments to the juxtanuclear space over time recruited $\mathrm{P}$-bodies there as well (Figure 4B, lower panels time-lapse; zoomed out start and finish shown in panels on the right). SGs behaved identically (data not shown). What's more, SGs associated with vimentin-ULFs similarly to synphilin aggregates (Figure 4C), and the complementation of a vimentin -/- line with ULFs was sufficient to recruit SGs to the juxtanuclear region (Figure 4D).

\section{Vimentin binds with stress granule protein during stress and is required for their formation}

Next, we wanted to confirm the interaction of vimentin with the stress granules. We took the stress granule protein - G3BP and performed the proximity ligation assay (PLA). We used the interaction of vimentin with tubulin subunit as control. As expected, vimentin and tubulin interacted with and without stress. G3BP on the other hand did not interact without stress and during stress, the interaction was abundant and significantly higher (Fig 5A). The no interaction without stress, might be due to the fact that, stress granules are diffused all over the cell and during stress they form aggregates. Confocal imaging and immunoprecipitation also indicated direct interaction of vimentin with stress granule components (Fig 5B, C). When we checked if there is any difference in the formation of stress granules between the wildtype and the vimentin knockout cells, indeed there was a difference - the knockout cells had a delayed formation of stress granule aggregates upon stress and after the withdrawal of stress, they had a delayed disruption of the aggregates. These results confirm that vimentin is required for the formation of stress granules (Fig 5D, E and F). 


\section{Vimentin forms a cage as a response to stress and aids the misfolded protein aggregates to accumulate near the Juxta nuclear position of the cell}

We wanted to check when the vimentin retraction occurs in the cell. We took three commonly used cellular stress agents - (1) heat at 44 degrees/2 hours (2) puromycin and (3) arsenite, $150 \mu \mathrm{M} / 2$ hours. Analyzing the results, not many cells had retracted vimentin without stress and during stress around 80 percent of the cells formed vimentin cages (Fig 6A), statistics in (Fig 6B). Our observation was that, vimentin collapses and forms a cage when the cell is subjected to some stress. The formation of the vimentin cage was reversible, and it regained its non-retracted or filamentous form once the stress was washed out. However, we also observed vimentin to form a cage, even without any external stress explaining a physiological role of vimentin. Our next aim was to look for a common pathway by which mammalian cell accumulates misfolded proteins into an inclusion body (IB) which will then facilitate degradation and asymmetric inheritance. These IBs have been described before in a study, which describes them to be encapsulated in the vimentin cage. They have been earlier observed using MTOC, peri-nuclear markers. Misfolded proteins of different properties require different signals for the triage between aggregation, degradation and autophagy.

We have in particular expressed a misfolded protein aggregate, synphilin which accumulates in the JUNQ over time to form an aggresome or an inclusion body. The synphillin misfolded protein first forms stress focis (SFs), each of this SFs then travel towards the JUNQ to form a big aggresome (Fig 6D), where they get degraded. juxtanuclear IBs have been proposed before by showing the co-localization of misfolded proteins with quality control proteins. We next visualized wildtype GFPtagged vimentin interacting with RFP-tagged synphilin aggregates prior to mitosis. Tracking a single aggregate clearly showed that synphilin aggregates are retained by Vimentin filaments and are dragged into the vimentin cage as vimentin retracts to the juxtanuclear region (Fig $6 \mathrm{C}$ ). The statistics are in (Fig $6 \mathrm{E}$ ), the error bars indicate standard deviation. 


\section{Vimentin cage is a cytoprotective response and rescues the cell from aggregate toxicity during differentiation}

We wanted to then check how this cage formation along with the misfolded proteins benefits the differentiating stem cells. When we differentiated the stem cells to embryoid bodies, the knockout cells formed smaller embryoid bodies compared to the wildtypes and during the misfolded protein stress and misfolded protein stress coupled with heat stress, the vimentin knockout cells started to die (Fig 7A). We wanted to see if this formation of cage had any cytoprotective role and the answer was yes, when LDH assay was performed on the sample the vimentin knockout cells were more cytotoxic than the wildtype cells during stress (Fig 7C). In order to examine the relationship between vimentin asymmetry and the accumulation of synphilin aggregates in differentiating mESC, we imaged live cells with RFP-tagged vimentin and GFP tagged synphilin. Remarkably, synphilin aggregates can be seen to interact directly with Vimentin filaments (Fig. 6). Aggregates of other proteins, including mutants of SOD1, VHL, AggDD, Ubiquitin-positive aggregates showed identical interaction properties with vimentin, in other cell lines (not shown here). In order to rule out co-localization that was independent of direct interaction, we attempted to visualize interaction between synphilin and non-assembled Vimentin Unit Length Filaments, and to track synphilin aggregates on assembled Vimentin filaments over time. We employed a mutant form of Vimentin (Y117L) which is unable to assemble into filaments of cables, and instead forms Unit Length Filaments (ULFs) of 8 tetramers assembled in a barrel shape. Normally ULFs assemble end to end into a mature filament, but the mutant is expressed in cells as a ULF. We expressed synphilin in vimentin -/- cells, and co-expressed Vimentin Y117L ULFs tagged with GFP. ULFs, visualized as green puncta, bound to the surface of synphilin aggregates, proportionally to the surface area of the aggregate (Fig. 7D, top panel for large synphilin aggregate, lower for small synphilin aggregate). 


\section{Vimentin Knockout cells ends up with more aggregates after differentiation due to symmetric partitioning of aggregates during mitosis}

Next, we sought to investigate the mechanism of the protective effect that we observed for vimentin. Although we have previously observed asymmetric partitioning of vimentin in cultured cell lines this has not been demonstrated in dividing mESC cells. Moreover, in previous studies, we only observed an asymmetric partitioning of vimentin that was retracted into a juxtanuclear "Vimentin cage". Although Vimentin that is cytoplasmically distributed still partitions in an asymmetric fashion, in most dividing cells a significant sub-cellular pool of vimentin retracts to the juxtanuclear region prior to metaphase. Following cells through metaphase demonstrated asymmetric partitioning of the Vimentin-aggregate complex. vimentin -/- cells, in contrast, showed perfectly symmetrical partitioning of synphilin aggregates (Fig 8A). Over time, cells lacking vimentin accumulated significantly more synphilin aggregates that were much larger in size (Fig $8 \mathrm{C}$ ). What these data cumulatively argue, is that vimentin interacts directly with misfolded protein aggregates, directs their accumulation in juxtanuclear "Vimentin cages" and promotes their asymmetric partitioning during mitosis.

\section{Over expressed Vimentin intermediate filament is segregated asymmetrically during mitosis in cancer lines}

We looked at division of vimentin since, it collapses during stress, and also brings the misfolded protein aggregates to the JUNQ. Whereas F-actin, mitochondria, and $\alpha$ tubulin all partitioned symmetrically, vimentin demonstrated a nearly uniform polarity during mitosis with one of the daughter cells receiving a substantially smaller fraction of cellular vimentin (Fig 9A and B). Although the vimentin JUNQ formed before mitosis and often dissociated after, and despite global cytoskeletal reorganization, the JUNQ vimentin structure remained intact throughout mitosis. PhoC experiments showed that vimentin is a long-lived protein; therefore, the inherited vimentin is "old" and might therefore be a more general vehicle for asymmetric partitioning by defining polarity, and perhaps by physically retaining old or damaged cellular material. In support of this model, our time-lapse studies showed that roughly $50 \%$ of HEK cells (not expressing a misfolded substrate or treated with proteasome inhibitors) had a JUNQ at any given time (when we started imaging) whereas the other 50\% formed a JUNQ just before mitosis (Fig 9E). Using extremely long 3D time-lapse studies, over the course of 3-4 $\mathrm{d}$, we were able to observe multiple generations of HEK cell divisions. We first wanted to determine whether the asymmetric partitioning of vimentin JUNQs correlated with asymmetric inheritance of old versus new mitochondria (similarly to what has been shown in yeast). We therefore undertook four-color live-cell imaging of cells expressing far-blue vimentin and far-red nucleus, together with mito-Dendra2. We 
photoconverted whole-cell mitochondria and followed divisions. Following successive mitoses demonstrated no asymmetry between cells inheriting the JUNQ and JUNQfree daughter cells, with respect to inheritance of new (blue) versus old (red) mitochondria. We then asked whether inheriting or failing to inherit a JUNQ nevertheless confers any advantage on the daughter cells. In every second-generation division that we were able to track, the cell that failed to inherit a JUNQ divided several hours sooner than its sister cell that inherited the JUNQ. This observation may suggest that withholding of JUNQ substrates through the replicative rejuvenation process eases the proteostasis burden on the noninheriting cells, thus giving certain cells a fitness advantage (Fig 9F).

\section{Vimentin is critical for mESC neuronal differentiation}

Given that vimentin has a clear role in cellular fitness, which emerges upon differentiation, we investigated the effect of vimentin knockout on the ability of mESC to differentiate into specific lineages. Indeed, vimentin -/- ESCs showed a slight delay in losing the OCT4 pluripotency marker, while other pluripotency genes were lost similarly to WT (Fig 10A). RNAseq profiling of 4-day RA-differentiated cells showed that several gene networks were up-regulated and others down-regulated in vimentin -/- as compared to WT. These included regulators of cell death, differentiation, metabolism, lipid synthesis, and development. However, similarly to the growth effect observed in, the dysregulation was only evident in RA differentiated mESC, and not in pluripotent cells (Fig 10B).

The RNAseq profiling of RA-differentiated cells revealed that of the three germ layers, ectodermal markers were significantly lower in vimentin knockout cells (Fig 10B). Since aggregates and misfolded proteins are thought to pose a particular danger to neurons, which arise from the ectodermal germ layer, we directly examined the ability of Vimentin -/- mESC to differentiate into Neuronal Precursor Cells (NPCs). When mESCs were differentiated along a neuronal program, neuronal differentiation markers showed a significant difference between vimentin KO and WT. In particular, axon extension and migration markers as well as other neuronal differentiation genes had significantly lower levels of expression in Vimentin -/- cells as compared to control. Whereas WT cells immunostained for the Tuj1 (Tubb3 $\beta$ ) neuronal lineage marker at the end of the differentiation program showed abundant expression, vimentin -/- cells showed almost no Tuj1 expression and significantly less outgrowth of neurons from the EBs (Fig 10E).

Next, we investigated whether vimentin retracts into a cage before division in NPCs. Indeed, it was the case, though there was a population of cells in which vimentin divided asymmetrically in its non-retracted form (Fig 10C). One explanation for the neuronal differentiation defects observed in vimentin -/- cells could be that diminished stress response impairs proper development. As cells differentiate into NPCs and 
neurons, they express less Vimentin, which is retained in non-differentiating cells. This was also observed in our experimental model: NPCs expressed less vimentin. We suggest that this phenomenon produces damage-free neurons and promotes survival. Indeed, vimentin -/- NPCs accumulated more synphilin aggregates and partitioned them symmetrically during divisions during differentiation, similarly to EBs and RAdifferentiated cells. As expected, the retracted vimentin cage promotes the asymmetric partitioning of synphilin aggregates leading to a lower aggregation load in the cell after differentiation (Fig 10D). Alternatively, however, given its ubiquitous role in asymmetric partitioning of many factors, including RNA-binding proteins, an intriguing hypothesis could be that vimentin also plays a role in differentiation signaling, by regulating the inheritance of specific signals to one daughter cell in mitosis. Together these data clearly argue that vimentin is important for neuronal differentiation in mESCs. 


\section{Discussion}

Cells possess the capacity to reverse the aging process that they inevitably undergo (Coelho et al. 2014). Cellular rejuvenation enables multi-cellular organisms to produce a pristine germline and is also required to produce and maintain immortalized tumorigenic cell populations. Embryonic Stem Cells (ESCs) similarly have the capacity to self-renew indefinitely, and to give rise to youthful differentiated cells (Clevers et al. 2005; Yamashita et al, 2005). Induced pluripotency technology (iPSC) has opened a new window into cellular rejuvenation, by showing that any somatic cell can be reprogrammed into an immortal pluripotent cell. Remarkably, even old cells, with aging-induced pathology, can be reprogrammed not only to become pluripotent, but to become youthful as well (Takahashi et al, 2007; Rowe et al, 2019). This study was designed to study the mechanism of replicative rejuvenation by investigating the role of inclusion bodies (IBs) and the asymmetric inheritance of damaged proteins. There have been previous studies explaining in detail the role of IBs in aggregating/misfolded protein degradation, since they associate extensively with ubiquitin, lysosomes and proteasomes. However, there have been very less number of evidences showing degradation happening inside the IBs, as opposed to the degradation happening elsewhere due to the diffusion from the IBs. The protein turnover in the JUNQ is demonstrated by the 3D longitudinal experiments. The various subpopulations of the cell were monitored by $4 \mathrm{D}$ imaging and the transient structures where tracked over generations of divisions. By our experiments, we are demonstrating that, JUNQ is asymmetrically partitioned giving a basis of how cellular aging happens and also provides direct observations of the turnover of misfolded proteins in the IBs.

To develop efficient tissue engineering therapies based on stem cells, we need to understand the stem cell biology and also the efficient ways of directed differentiation. Determining the regulators of early differentiation, events that occur when pluripotency is lost is important to fully understand the personalized medicine based on the induced pluripotent stem cells. Directing the differentiation to one of the three germ layers (ectoderm, endoderm and mesoderm) is the first significant step towards functional downstream phenotypes. Therefore, factors that regulate the early specification is very important in the promotion of differentiation downstream to relevant therapeutic phenotypes.

Although the main function is noted to be "mechanical strength" and "anchoring organelles", vimentin intermediate filaments are highly dynamic components of the cytoskeleton. The functions include migration of cells, cell adhesion, interaction with mitochondria and ER and apoptosis. To perform all the above-mentioned functions, the defined vimentin network should directly or indirectly interact with its targets. The post-translational modification play an important role in deciding the organizing factors in the filament like assembly regulation, acetylation, organization and phosphorylation. The plakin, kinesin and dynein family known as the intermediate filament associated proteins are influencers of the vimentin filament to interact and connect with the 
microtubules and actin (BT Helfand et al, 2002). Furthermore, they also pave way to the interaction of vimentin or connect them to cell matrix hemi-desmosome adhesion to the other cytoskeleton proteins like actin and tubulin family, nucleus and also between the intermediate filaments. Some intermediate filaments can also orient themselves along the actin or microtubule cytoskeleton. Actin and microtubules thereby form the guiding structures where filaments are transported along, either by kinesin and dynein (microtubules) or myosin (actin), resulting in a mutually dependent organization of intermediate filaments and actin and/or microtubules. The interaction of vimentin with cytoskeletal components is evident from the fact that, the transport of vimentin along the microtubules can be inhibited by the meshwork of actin (Erickson JE et al, 2009).

Two mechanisms can reverse damage accumulated during aging in order to allow rejuvenation. Cells can either degrade damaged components with high efficiency via the Ubiquitin-Proteasome System (UPS) and autophagy. Alternatively, dividing cells can partition damaged components into one of the daughter cells during mitosis, thus generating one lineage that is pristine and one that will accumulate damage (Bufalino et al, 2014). Both rejuvenation systems have been observed in developing organisms. ESCs have an elevated level of UPS function, which declines upon loss of pluripotency. Differentiating stem cells partition misfolded and aggregated proteins away from specific lineages and into others. Neuronal precursor cells (NPCs), which divide asymmetrically into a self-renewing NPC and a differentiated neuron, partition ubiquitinated misfolded proteins away from the neurons and into the self-renewing NPC (Saez et al, 2018; Vilchez et al, 2012).

We examined the role of vimentin and its ability to asymmetrically partition aggregates in the process of early differentiation of mESCs. We sought to use a system that is physiologically relevant to organismal development, because previous studies have mostly not found a role of vimentin in the organismal context, even though at the cellular level vimentin has been implicated in many cell biological processes. The JUNQ's selective association with one of the daughter cells during mitosis needs to be determined. Mammalian cell divisions are polar in nature, (i.e) when a cell divides into two cells, one daughter contains the specific old material and one the new materials. Some studies have detailed the asymmetric inheritance of old centrosomes and other cellular components and that, the intermediate filaments are the driving factors for the polarity in mammalian cells (Vilchez et al, 2012). In this study we have evidences suggesting that, the cells not inheriting the JUNQ has a slight fitness advantage, leading the cell devoid of the JUNQ to divide faster. From these evidences, vimentin may be considered as a regulator of aging by regulating the polar divisions of the cell. The asymmetric segregation by vimentin happens by its interaction with tubulin, actin and membranes, mediating the asymmetric inheritance during division. In compliance with other studies, the cellular levels of vimentin increase when the cells exposed to heat stress, proteasome inhibitors. This maybe for the effective partitioning of the damaged materials. Therefore, the daughter inheriting the JUNQ also inherit 
other old cellular material. However, when viewed from a different angle, the inheritance of the JUNQ by one cell also means that, chaperones, proteasomes are enriched in that cell after division leading to also inheriting other quality control factors. Our observation shows that the ability to control JUNQ inheritance may be the key for various multicellular systems given our data on JUNQ maturation ranging quality control IB to the source of aggregation and toxicity. For example, it has been reported in T-lymphocytes that asymmetric inheritance of proteasomes results in an asymmetric degradation of the transcription factor T-bet.

Spatial quality control and replicative rejuvenation remain as the essential components of homeostasis, in both single cell and multicellular organisms. The level of misfolded and damaged proteins in the cell are determined by the chronological lifespan of the cell and its ability of replicative rejuvenation. Hence the effect or the susceptibility of various tissues to aggregate toxicity can be understood and are regulated by the mechanisms governing replicative rejuvenation (Styers et al, 2004). Stem cells and cancer cells undergo polar divisions. The cells survival mechanism is replicative rejuvenation and this study provides a focal point to explore the molecular mechanisms governing the cell survival mechanism during stress. This is done by observing the asymmetry happening in the living cells and the markers for that. The asymmetric segregation of damaged / non damaged cargoes is governed by the proteasome of the cell also. There is less consistent observation between studies showing functional outcome of the asymmetric inheritance of damaged proteins. Most of the groups agree upon the fact that, inheritance of the damaged proteins leads to reduction in the proliferation of stem cells and increase in cell death.

Our data show that vimentin is indeed required for viability in differentiated cells (but not in stem cells); however, the requirement of vimentin is only uncovered during stress. We further demonstrated that vimentin protects differentiated cells from protein misfolding stress by binding aggregates and granules formed by RNA-binding, intrinsically disordered proteins, and directing their asymmetric partitioning. These results are consistent with previous findings showing that pluripotent cells have a higher level of UPS function, hence it is likely that they are able to degrade misfolded proteins more effectively without the need for asymmetric partitioning. It is not entirely clear how vimentin interacts with aggregates and granules, but the data point to a direct interaction, as has been observed previously between vimentin and FUS granules (Lin et al, 2016). Since vimentin has several disordered regions, it is possible that these directly adsorb disordered aggregates. It is also possible that the extensive interactions between vimentin and protein folding quality control machinery, including chaperones, functions to recruit aggregated proteins to vimentin (England et al 2011). What is clear from our data, is that vimentin interacts with aggregates everywhere in the cytoplasm, even as an ULF, and therefore aggregates need not accumulate in the juxta-nuclear region in order to be retained within the vimentin network. In fact, our data suggest that aggregates are recruited to the juxta-nuclear regions as a result of their interaction with vimentin, and not vice versa (Kaganovich et al, 2017). 
It is not clear whether the depletion of synphilin aggregates in differentiating cells expressing vimentin was solely due to asymmetric partitioning (perhaps followed by attrition of inheriting cell populations), or whether vimentin also enhanced the degradation of aggregates. There is evidence that the accumulation of aggregates in vimentin-associated juxta-nuclear inclusions and JUNQ compartments promotes degradation, however this is a topic for follow up study (Weisberg SJ. et al, 2012).

In previous work we found that, vimentin directs the asymmetric partitioning of aggregated and ubiquitinated proteins in dividing immortal cell lines, and that this partitioning affects cell fitness (Ogradonik et al, 2014). It was also subsequently shown that vimentin co-segregates with ubiquitinated protein aggregates in differentiating NPCs. Our findings also indicate that vimentin mediated transport of damaged material persist during differentiation. Though vimentin is not present in neuronal cells, they are observed to contribute to the regenerative capacity and plasticity of the olfactory receptor neurons where they persist throughout the life. Recent reports expanded the potential role of vimentin as a dynamic and mobile scaffold for localization and longdistance transport of soluble molecules. Vimentin can move bi-directionally on microtubules, towards plus ends in association with kinesin, and towards minus ends in association with dynein. After injury vimentin as observed to regulate axonal transport of phosphorylated MAP kinesis in neurons (Triolo D et al, 2012). In vitro findings not only confirmed that loss of vimentin in neurons results in increased myelin thickness, but also showed an increase in the number of myelin internodes (Battaglia et al, 2018). These data may suggest that ablation of neuronal vimentin is sufficient to initiate myelination also in vivo. It is possible that in vivo vimentin is mainly implicated in controlling myelin thickness and is not sufficient to dictate initiation of myelination, which could be controlled by other mechanisms. Another lab showed that neuronal differentiation being altered due to the phosphorylation of vimentin during mitosis (Meng Chen et al, 2018). These findings suggest that vimentin has an important role in cell fitness and organismal development, but mechanistic evidence for this idea has been sparse. One report showed that the expression of vimentin in neuroblastoma cells increased the number of axonal neurites. During development, the corticospinal tract elongates in proximity to vimentin-positive areas. Additionally, Hsu et al. showed that vimentin-positive astrocytes induced axonal regrowth after spinal cord hemisection and Schwann cell implantation in adult rats. Another group also suggested that increased vimentin expression is involved in spontaneous recovery after contusive SCl. Many studies have shown a relationship between vimentin and neurons, but most studies have focused on the role of vimentin in-vivo and not the cell biological role of vimentin. Together with these reports and our findings, vimentin cant be deemed as a dispensable protein during development and during stress.

Our extensive comparative interactome analysis of vimentin revealed a strikingly large number of RNA-binding proteins and SG components, as well quality control factors, interacting with vimentin during stress. This suggests that vimentin is an important regulator of stress response. In support of this, we showed that cells lacking vimentin 
show a base-line upregulation of the HSF1 stress-response. In addition to compromising quality control, deletion of vimentin significantly altered the differentiation program of $\mathrm{mESCs}$, and severely decreased neuronal differentiation. Future experiments will reveal whether, in addition to quality control and stress response, the asymmetric partitioning of vimentin also regulates differentiation signaling in dividing populations of stem cells.

\section{Future Direction}

The tissue susceptibility to aggregate toxicity needs to be understood, and the mechanisms governing the replicative rejuvenation might hold the answer for that. Vimentin and other intermediate filament protein levels increase (5-fold), although they are abundant to start with in response to stress like the HSPs. However, the reason for this increase in levels should be studied if it is response to the stress, or as a process to start regeneration in the cell. We have some preliminary studies and also studies from other labs have explained that overexpression of intermediate filaments have either led to mice living without any apparent change or being disease models (GFAP overexpression) (Liem RK et al, 2009) and from our study we showed that, vimentin overexpression in cells leads to slower division rate after mitosis when one daughter receives more vimentin. These tell that in-vivo or in-vitro overexpression of intermediate filament proteins is dependent, on the cell state and the consequences of forced or physiologic causes for vimentin upregulation which needs to be explained, for the understanding the protective role of vimentin and other filaments.

We have in this study explained that, vimentin knockout cells don't lose the expression of OCT4, a transcription factor responsible for maintaining pluripotency after complete differentiation. This raises the question, of what the link between vimentin expression and the OCT4 expression which needs to be studied. This will lead to studying the self-renewal mechanism of stem cells, during both pluripotent state and during differentiation. One way of defining the self-renewal mechanism is showing which cells receives the old centrosome, and the one receiving the new centrosome after division. Other differentiation signal proteins like NUMB, NUMA are binding with vimentin during mitosis according to the proteomic analysis, which leads to ask the question of its reason since NUMB is asymmetrically inheriting during division and promotes neuronal differentiation.

The next question to be analyzed, is whether interaction of vimentin with other intermediate filaments. There have been previous studies telling that vimentin null cells doesn't form GFAP filaments. The preliminary results of our lab suggest that, there is some interplay between lamin intermediate filament and vimentin. Lamin, a nuclear envelop protein involved in stress granule formation, and the transport of proteins to the cytosol from the nucleus and vice versa. We are seeing that, in Lamin null cells 
vimentin is symmetrically inheriting. Going further in this line, will tell whether this is just a response from the cells or lamin governs the asymmetry, which in turn governs the mechanism of replicative rejuvenation. This will also strengthen our claim that vimentin protects the cells from aggregate toxicity by asymmetric inheritance.

The interesting question to be addressed, is the mechanism by which vimentin interacts with misfolded proteins, and other proteins such as chaperones and stress granule. Vimentin doesn't have any motor system. But there have been studies telling that vimentin binds with other proteins by the help of microtubules. Other studies suggest that, intermediate filament associating protein (IFAP) serves as linkers to vimentin to bind with HSPs. This need to be further studied to fully understand the protective role of vimentin and other intermediate filaments. 
A Confirmation by genomic DNA sequencing

\section{WT}

:AGTCCTCTGCCACTCTTGCTCCGGGACCCCAGAGACCCCAGCGCTCCTACGATTCACAGCCACCGCGCCCTCATTCCCTTGTTGCAGTTTTTCCA GCCGCAGCAAGCCAGCCCACCTTCGAAGCCATGTCTACCAGGTCTGTGTCCTCGTCCTCCTACCGCAGGATGTTCGGTGGCTCCGGCACATCGA GCCGGCCCAGCTCCAACCGGAGCTATGTGACCACGTCCACACGCACCTACAGTCTGGGCAGCGCACTGCGCCCCAGCACTAGCCGCAGCCTCT ATTCCTCATCCCCCGGTGGCGCCTATGTGACCCGGTCCTCGGCAGTGCGCCTGCGGAGCAGCGTGCCGGGCGTGCGGCTGCTTCAAGACTCGG TGGACTTCTCGCTGGCCGACGCC

KO5

:AGTCCTCTGCCACTCTTGCTCCGGGACCCCAGAGACCCCAGCGCTCCTACGATTCACAGCCACCGCGCCCTCATTCCCTTGTTGCAGTTTTTCCA GCCGCAGCAAGCCAGCCCACCTTC$264 \mathrm{nt}$ deleted-

-TCGCTGGCCGACGCC

K013:AGTCCTCTGCCTC

GCGGAGCAGCGTGCCGGGCGTGCGGCTGCTTCAAGACTCGGTGGACTTCTCGCTGGCCGACGCC

B Confirmation by immunofluorescence

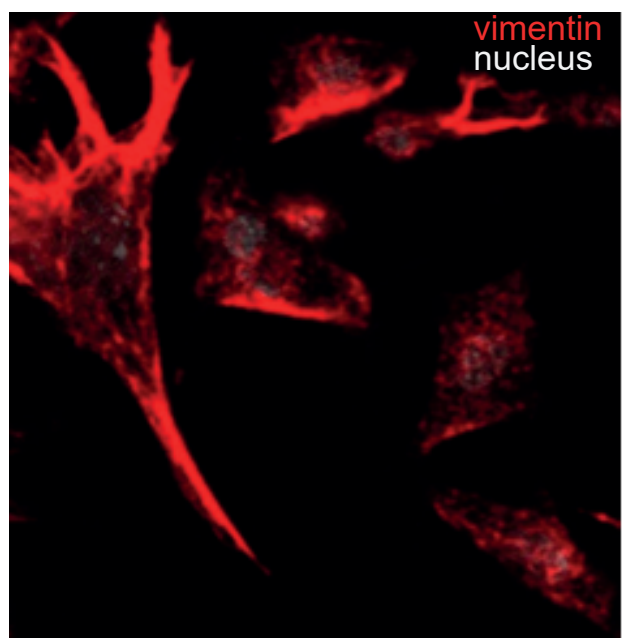

Wildtype

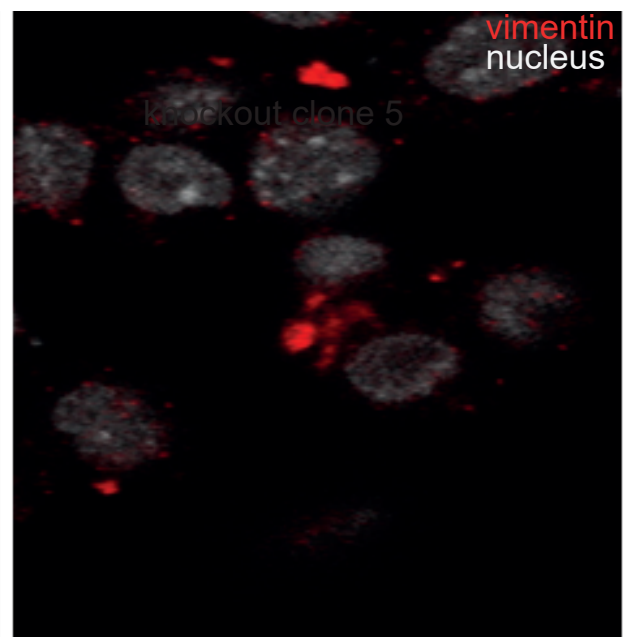

vimentin knockout Clone 9

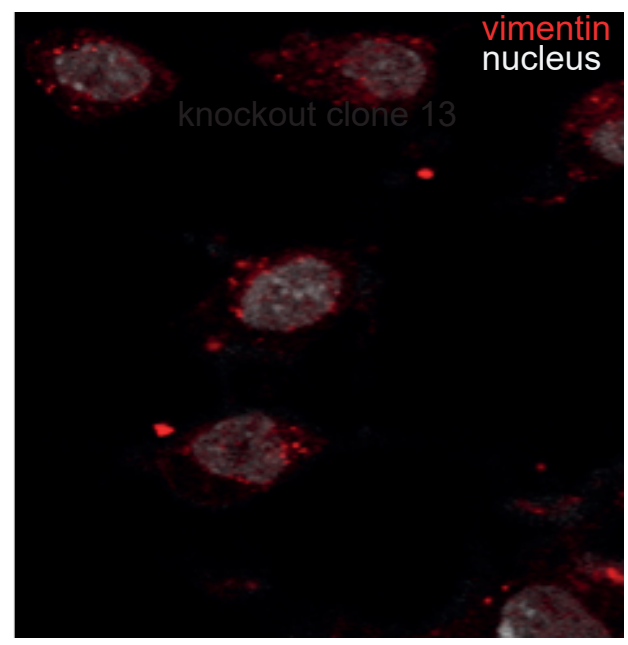

vimentin knockout Clone 13

C Confirmation by RT-PCR

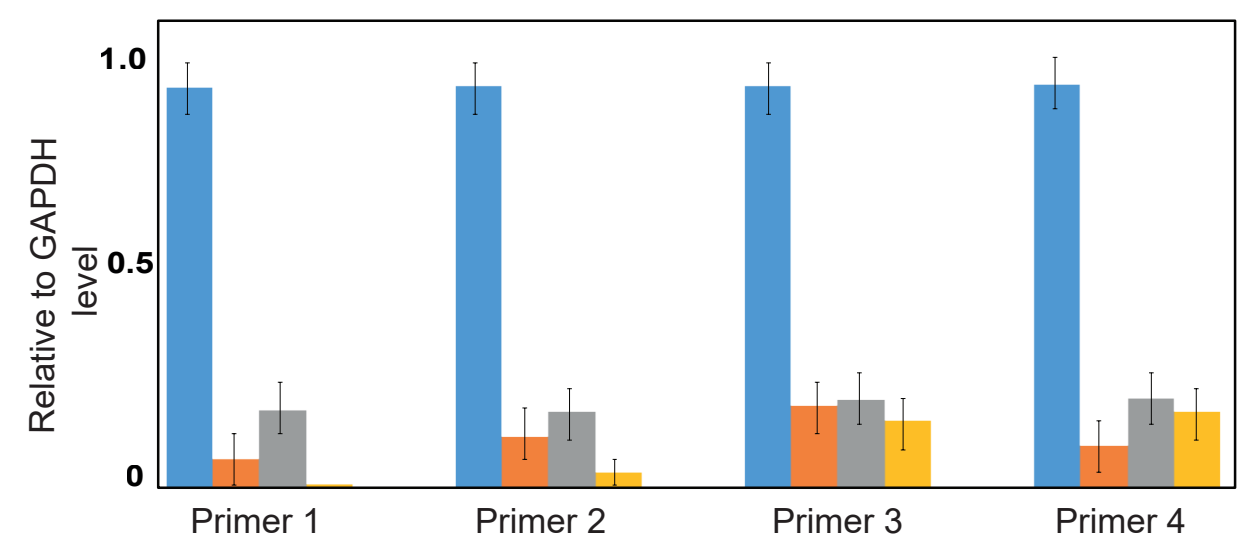




\section{Result 2}

A Expression of vimentin increases over days of differentiation with retinoic acid (RA)
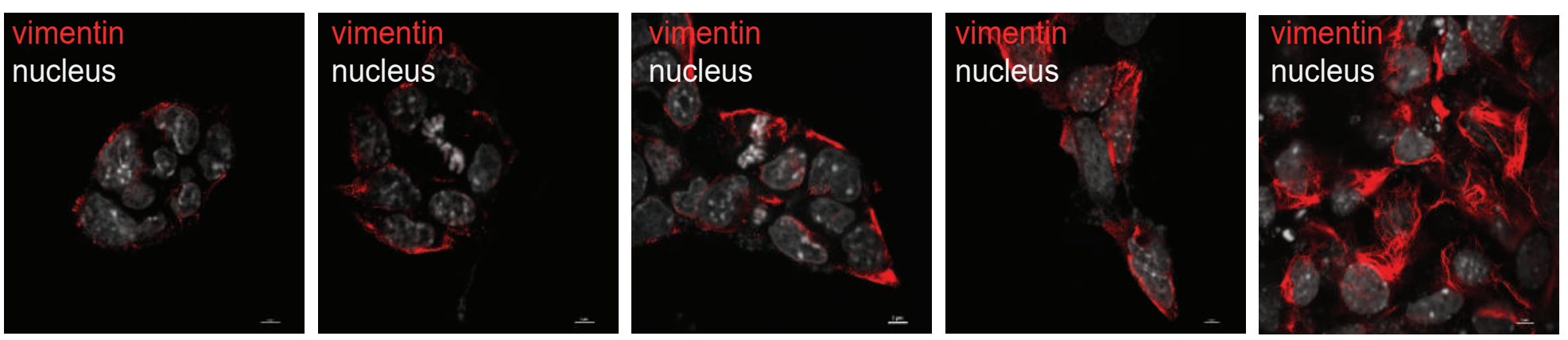

B

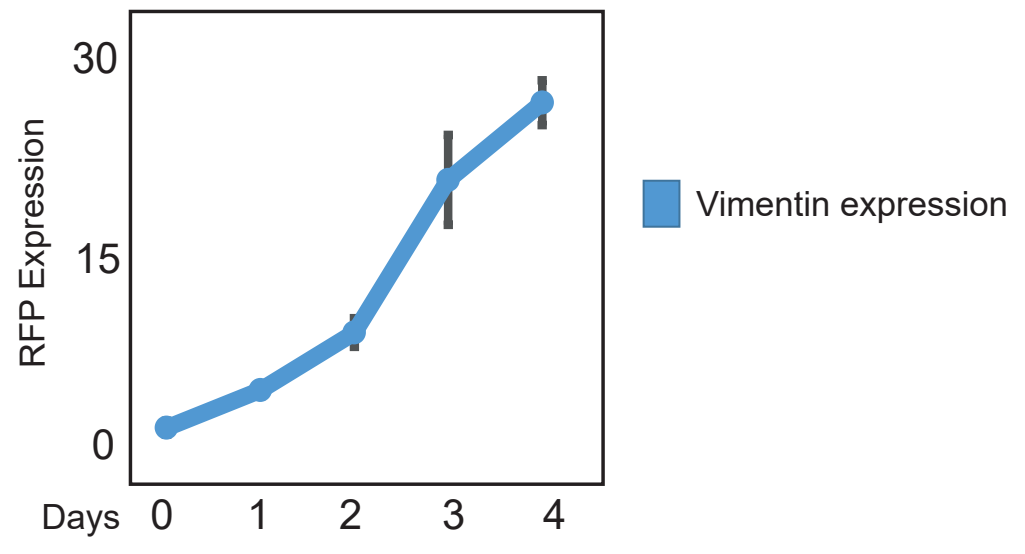

C Vimentin Knockout cells grows slowly while differentiating them with retinoic acid

Undifferentiated mESCs $\quad \mathrm{N}=3$

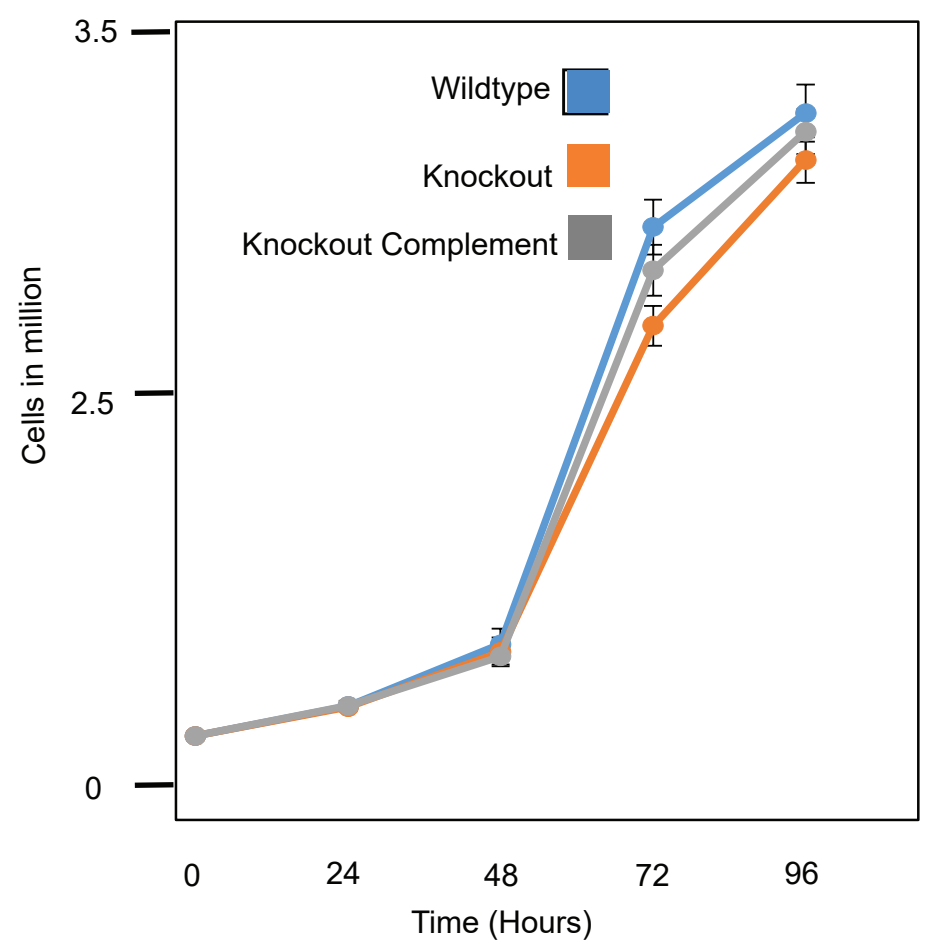

Differentiated with Retinoic acid

$N=3$

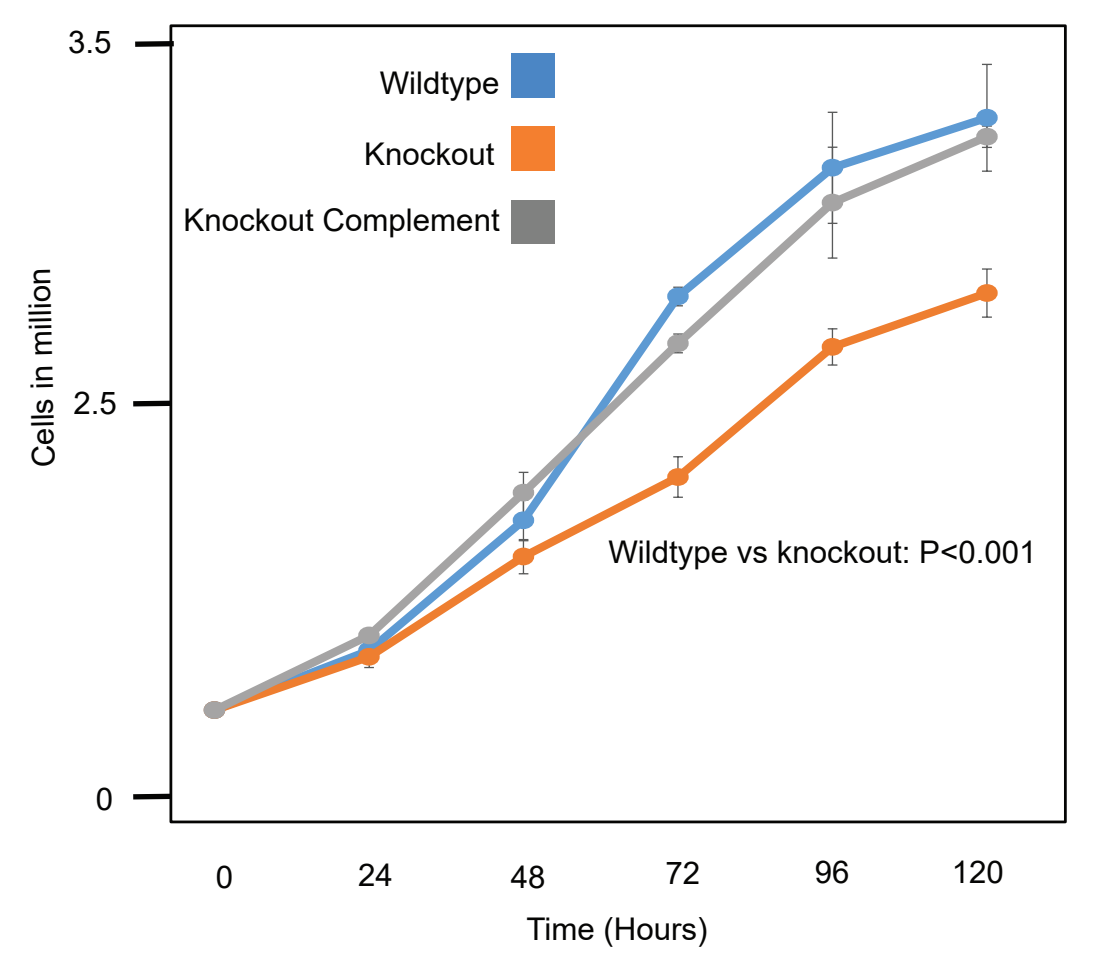


D Vimentin Knockout cells forms significantly smaller Embryoid bodies upon differentiation

Embryoid body (EBs) differentiation

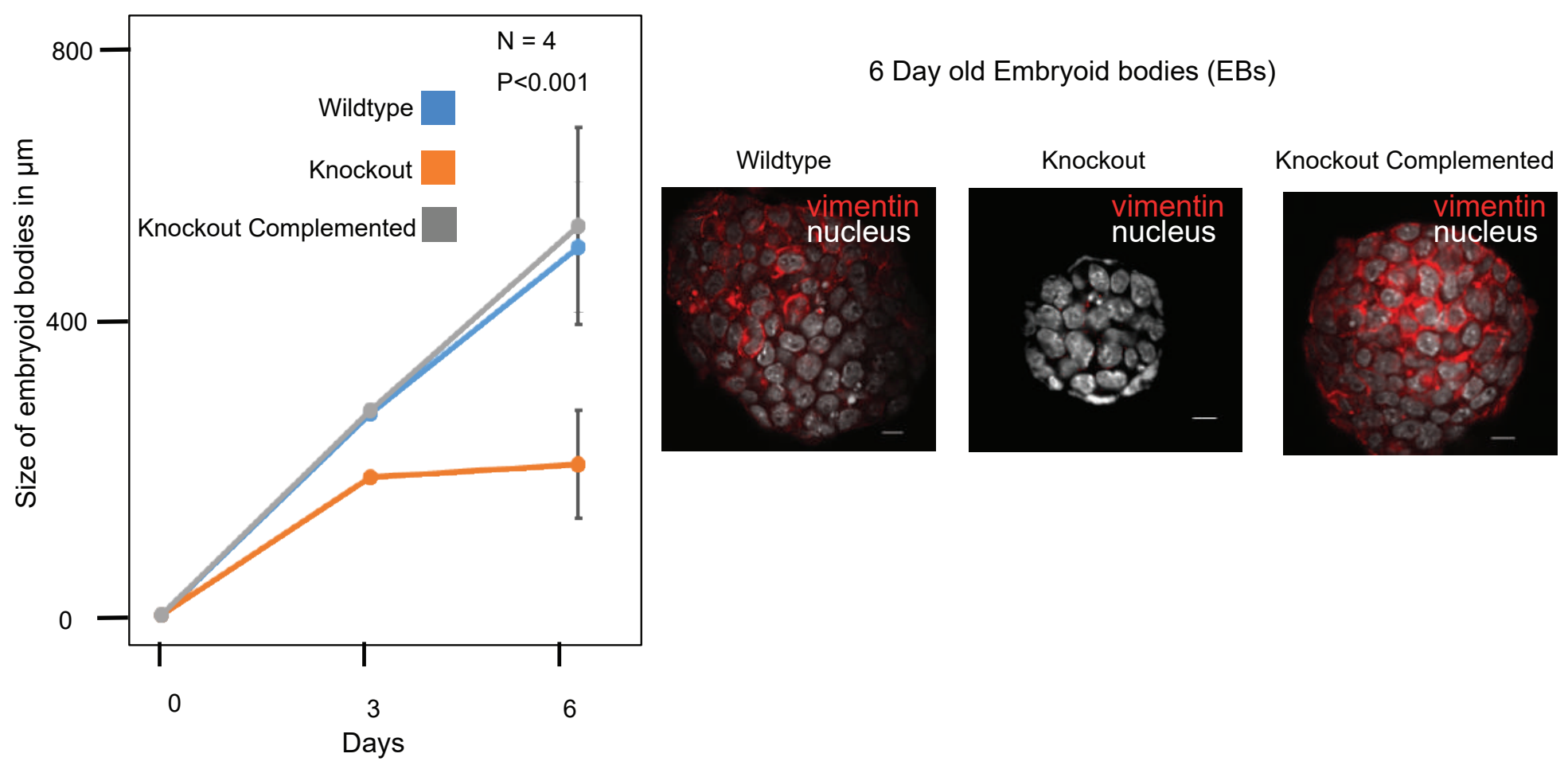

\section{Result 1: Validation of Vimentin knockout clones}

(A) Genomic DNA was isolated from wildtype and the vimentin knockout clones. The isolated genomic DNA was sequenced and was found that the exon 1 was deleted from the clones. One of the clone from this was selected for the future experiments.

(B) Immunofluorescence was done to check for the expression of the vimentin in the knockout clones obtained. No expression was observed in the clones.

(C) Confirmation by RT PCR. Four different primers were designed and checked on the clones of knockouts.

\section{Result 2: Vimentin expression increases through differentiation and is required for the growth during differentiation}

(A) mESCs induced to differentiate by the addition of retinoic acid and fixed every 24 hours. IF of Vimentin (red) and nucleus (white) is shown at each time point. Scale bar is $5 \mu \mathrm{M}$. Expression of vimentin increases during differentiation - immunofluorescence and quantification of vimentin immunofluorescence. Error bars represent standard deviation.

(C) Growth curve comparison between (1) wildtype, (2) knockout and (3) knockout complemented with full length vimentin when maintained in stem cell (2i) media and retinoic acid media. The cells were counted every 24 hours. The wildtype and knockout complement cells have higher proliferating potential than the knockout cells during differentiation. In stem cell media, all the three cell lines had no significant change in the rate of proliferation. Error bars represent standard deviation. (D) Embryoid body size growth comparison between the (1) wildtype (2) knockout and (3) knockout complement. The knockout cells were able to grow significantly smaller EBs after 6 days of differentiation and growth. Error bars represent standard deviation. Scale bar is $40 \mu \mathrm{M}$. 
A

No stress

Cell growth and differentiation

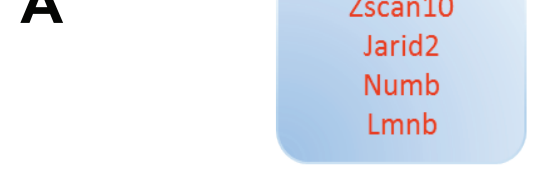

RNA Transport

Hnrnpa

Npm1

G3BP2

Nob1

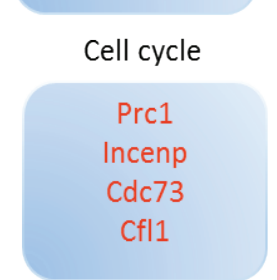

Cytoskeletal

Proteins

Actn1

Myo5a

Kif2c

Dync2h1

B

Vimentin binding to stress proteins $P<0.001$

\begin{tabular}{rl|} 
Hspb8 & \\
Hsp70 \\
Hspb1 \\
Hsp90b \\
Hsp7c \\
Wdr5 \\
Eif2b1 \\
Eif2b2 \\
Eif2bd \\
Hsp90a \\
Vcp \\
Vim \\
Psmd4 \\
Hspa8 \\
Wdr43 \\
Wdr74 \\
Tubb5 \\
Tuba1b \\
Psmc4 \\
Eif2b2 \\
Usp7 \\
\hline
\end{tabular}

E

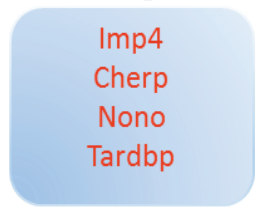

Nucleosome and Chromatin assembly

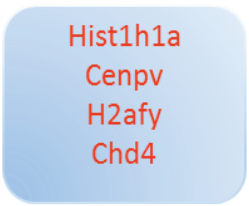

Response to

DNA damage

Ruvbl2

Ruvbl1

Hspa5

Xrcc1

Embryoid body

differentiation

Dnmt3b

Myole

Rpa1

Epb4115
RNA biogenesis

Stress granule

Proteins

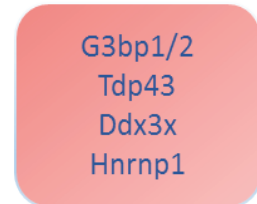

Proteasomal

Subunits

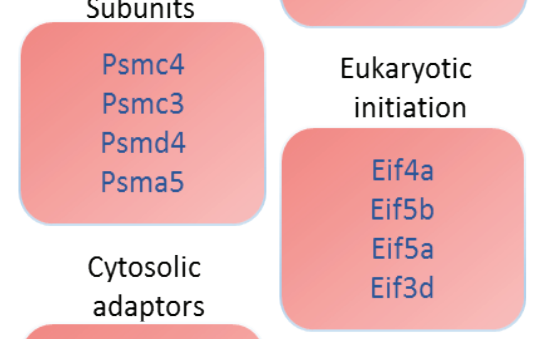

Heat/Arsenite

Stress

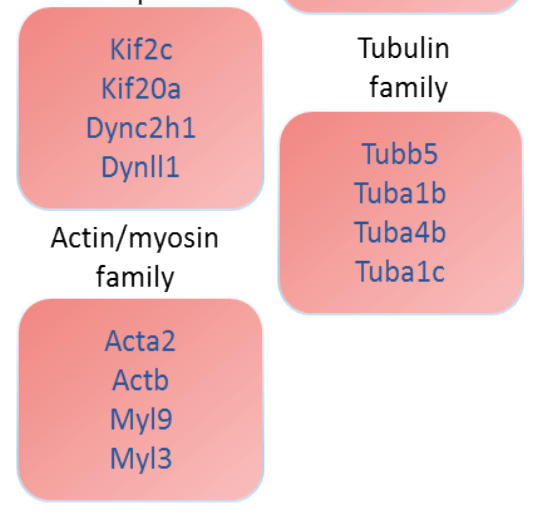

C Vimentin binding to RNA binding proteins

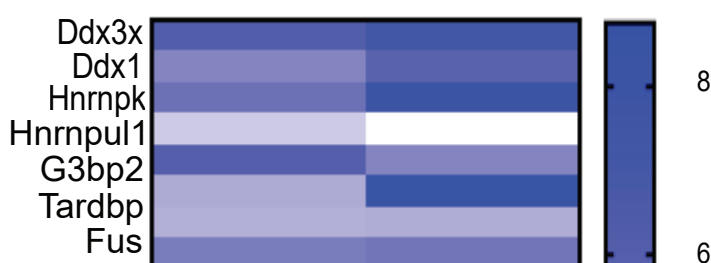

Rbm25

Rbm22

Hnrnpl

Hnrnph2

Hnrnpab

Znf706

Hnrnpd

Rbm5

lgf2bp2

Hnrnpa0

Rnps1

Hnrnpd

Hnrnp2b1

Rpl14

\section{Vimentin}

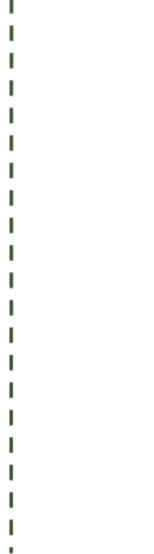

D

D

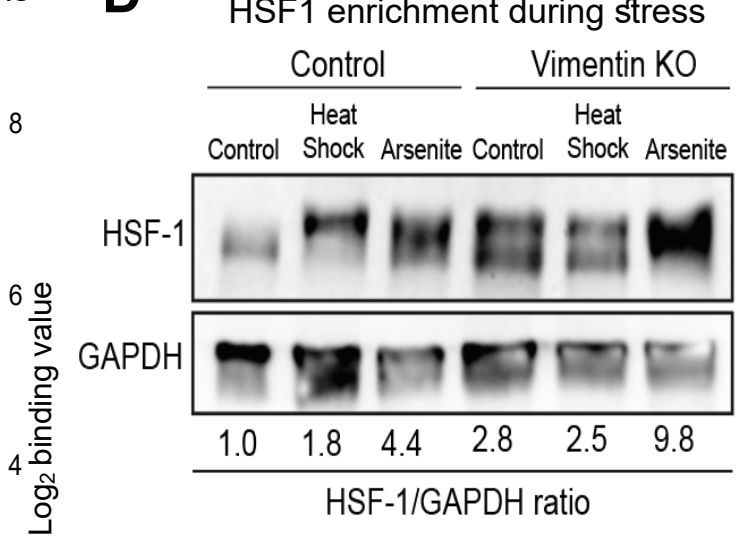

Heat shock

chaperones

Hspb1

Hsp90aa1

Hsp90ab1

Hspa8

initiation

Eif5a

Tubulin

Tubb5

Tuba1b

Tuba4b

Tuba1c
Untreated

Vimentin and synphilin interact with same stress proteins

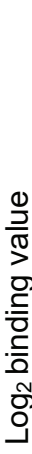

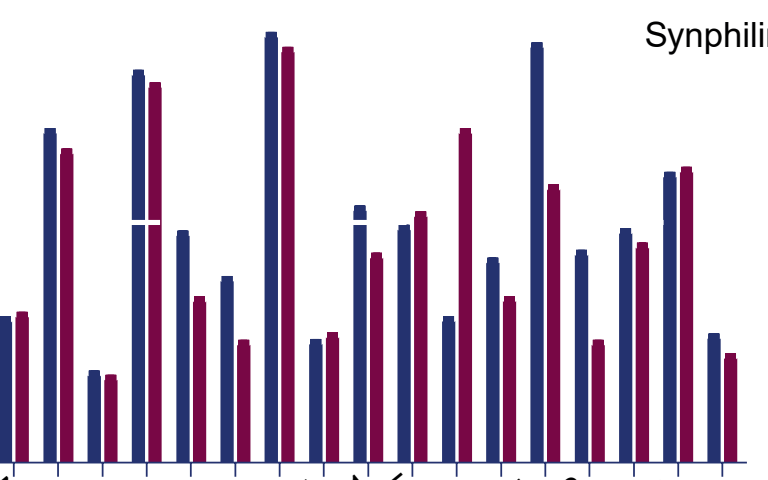

$1+1010101010$

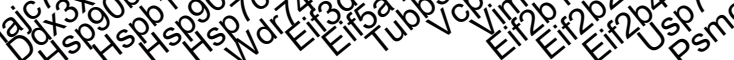

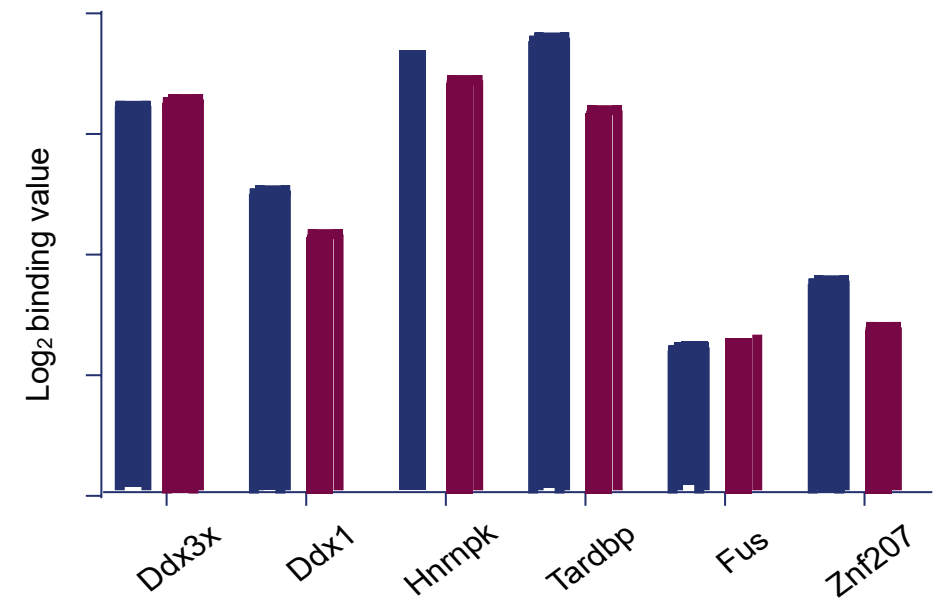

Vimentin and synphilin interact with same RNA binding proteins

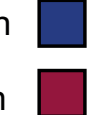


Result 3: BiolD of vimentin interactome identifies protein folding quality control components, RNA-binding proteins, and stress granule proteins.

(A) Vimentin proteomics overview showing the interacting partners during control, heat ( $44^{\circ} \mathrm{C}$ for 2 hours), and arsenite $(150 \mu \mathrm{M}$ for 2 hours) stress conditions.

(B) Vimentin interacts with stress response proteins during heat $\left(44^{\circ} \mathrm{C}\right.$ for 2 hours) and

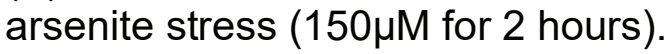

(C) Plots showing the interaction of vimentin with RNA-binding proteins.

(D) Western blot for HSF-1 protein after 4 days of differentiation with retinoic acid $(1 \mu \mathrm{g} / \mathrm{ml})$ in wildtype and vimentin knockout cells.

(E) Vimentin and synphillin binding to the same set of stress and RNA binding proteins during stress 


\section{Result 4}

A Vimentin interacts with Ub positive aggregates
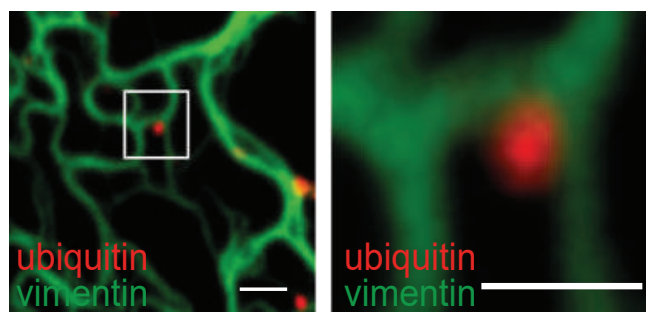

Vimentin - aggregate interaction persists over time
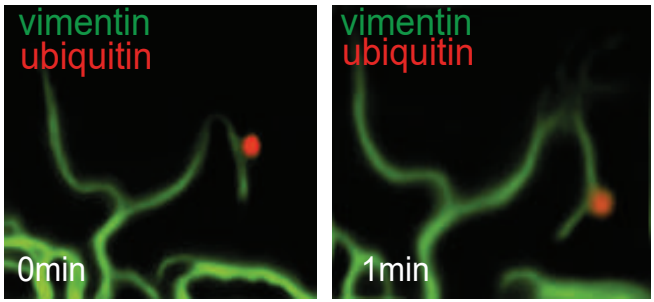

B Vimentin interaction with RNA binding proteins
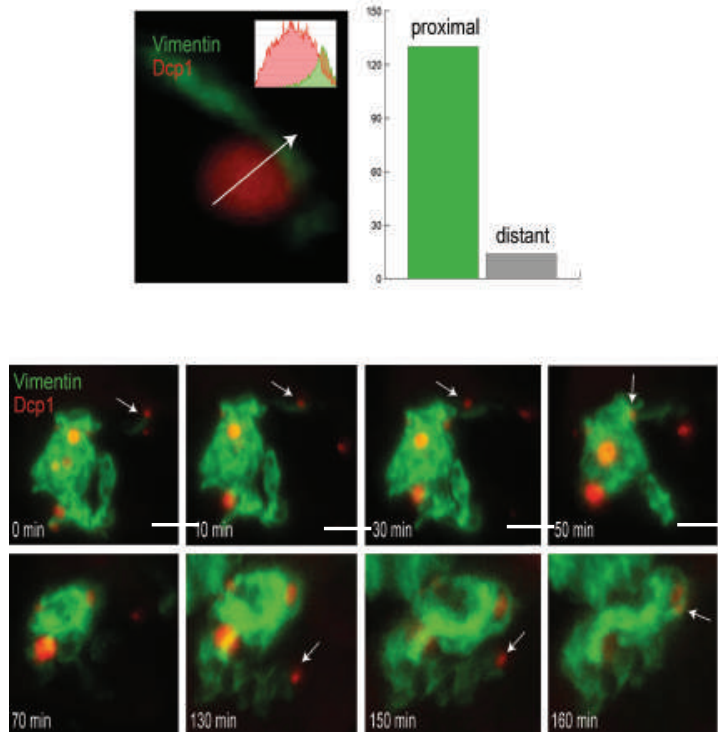
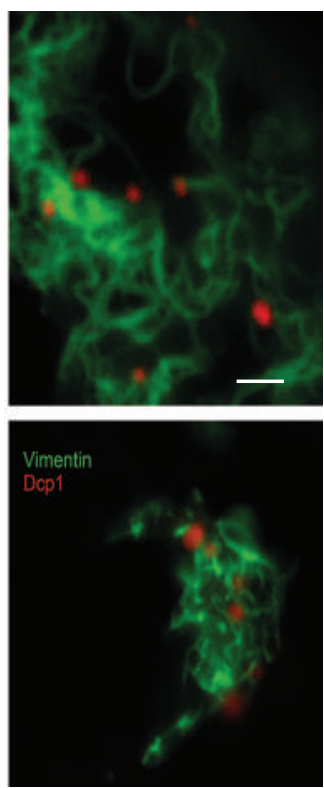

Vimentin-ULF also interacts with chaperones during stress and brings them to the JUNQ

C Arsenite stress, 10 mins
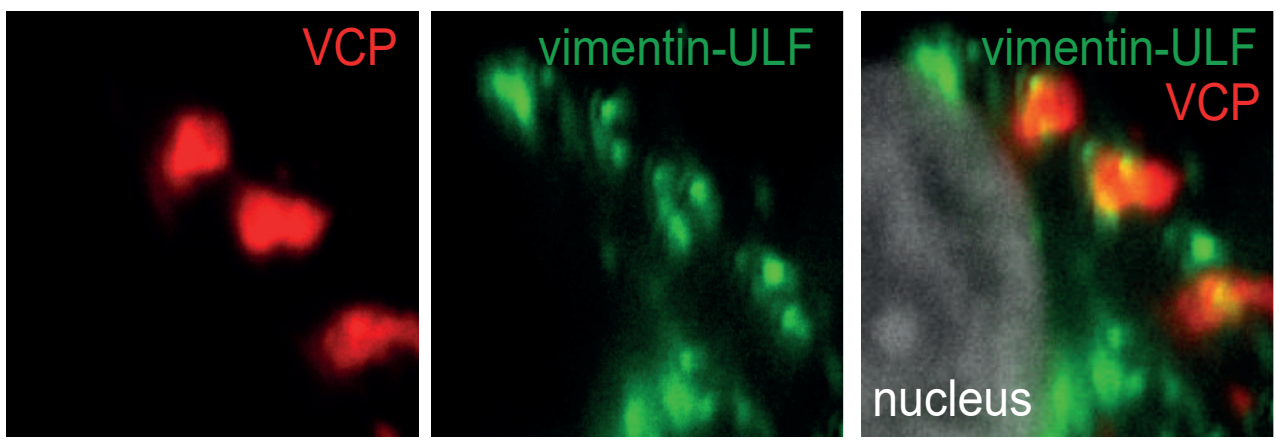

D Arsenite stress, 30 mins
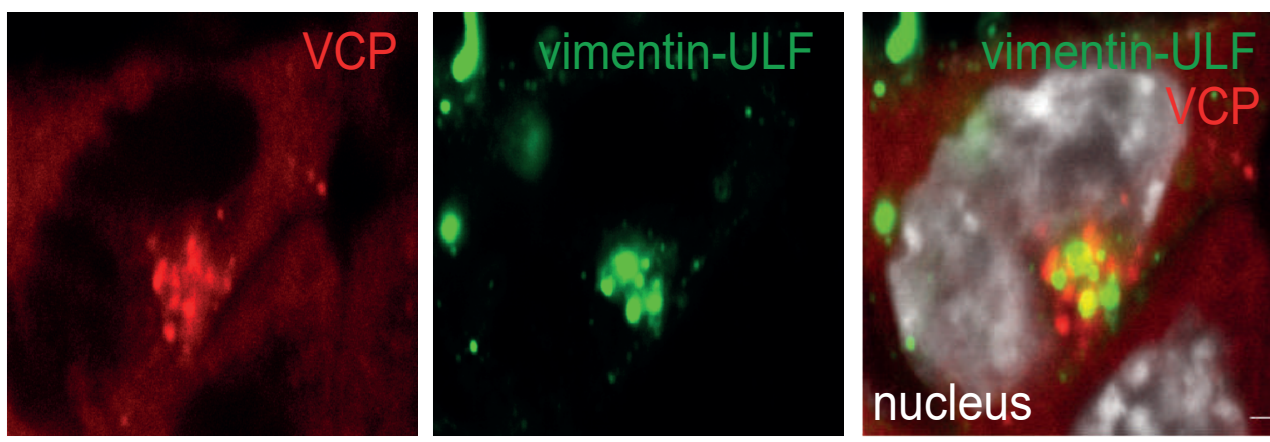
Result 4: BiolD of vimentin interactome identifies protein folding quality control components, RNA-binding proteins, and stress granule proteins.

(A) Structured illumination microscopy images of vimentin -GFP (green) binding to RFP-ubiquitin-positive foci (red) in live cells. The interaction of vimentin and ubiquitin persists over time shown by the time-lapse. Scale bar is $2 \mu \mathrm{m}$

(B) vimentin -GFP (green) interacting with DCP1-RFP (a P-body component and RNAbinding protein) over time and the graph showing the interaction between the two. Scale bar is $5 \mu \mathrm{m}$.

(C) Confocal images of vimentin-ULF-GFP (green) interacting with VCP-RFP (endogenously tagged, red) during arsenite stress $(100 \mu \mathrm{m}, 10$ minutes).

(D) Images of VCP (red) colocalizing with vimentin -ULF (green) in the juxtanuclear region. 


\section{Result 5}

Vimentin interacts with stress granule proteins during stress

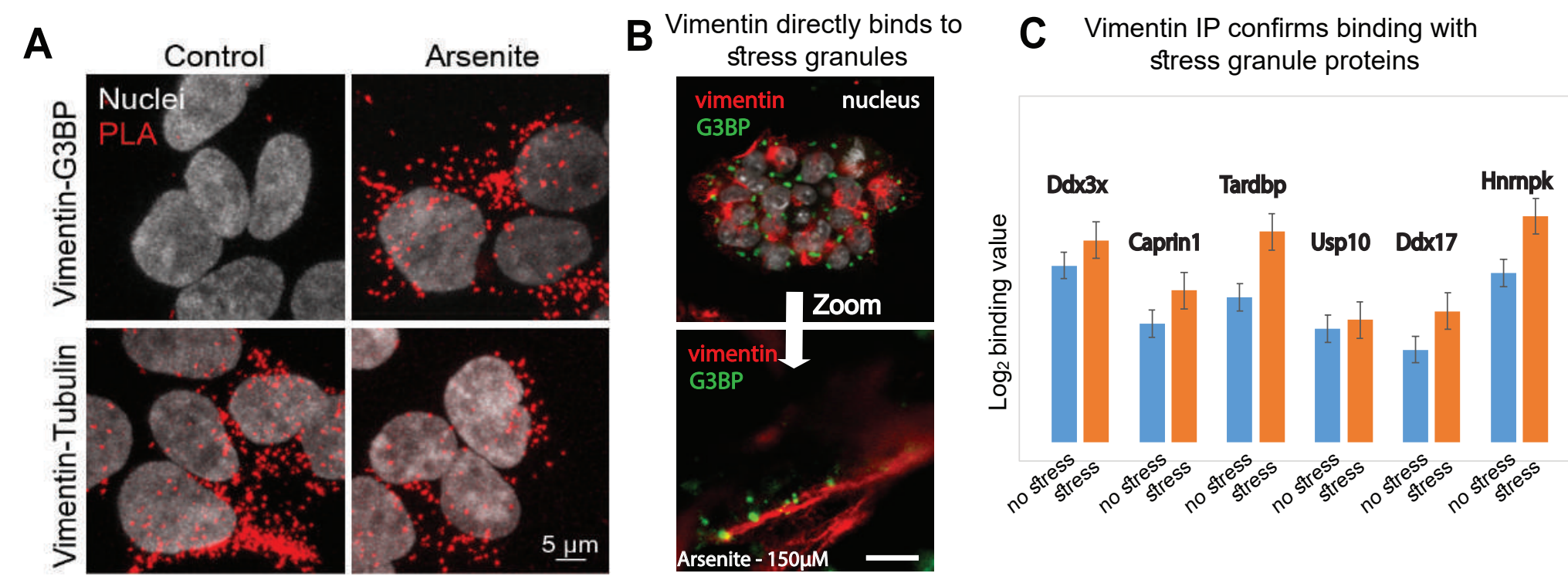

Vimentin knockout leads to delay in the formation of stress granules

D Arsenite 10 minutes

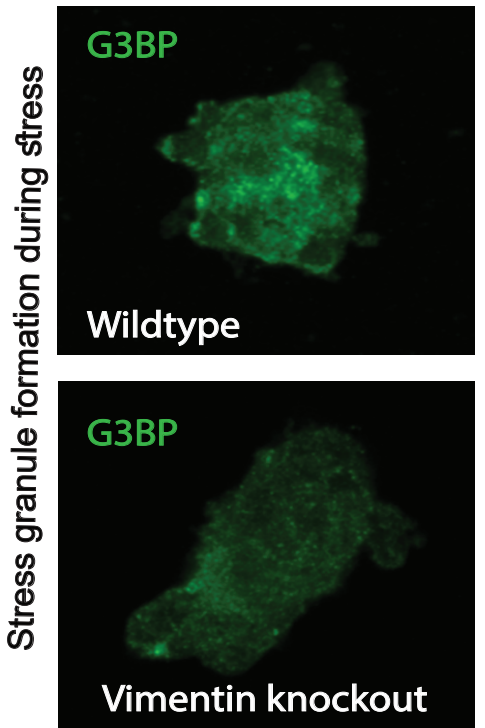

F Washout 10 minutes

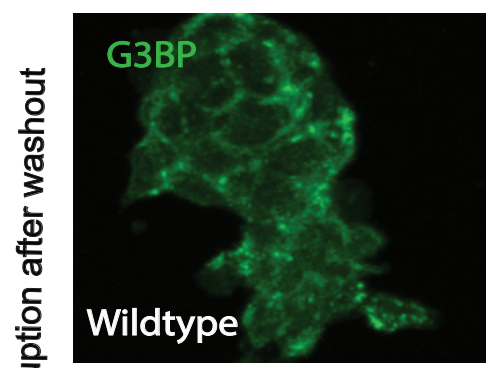

음
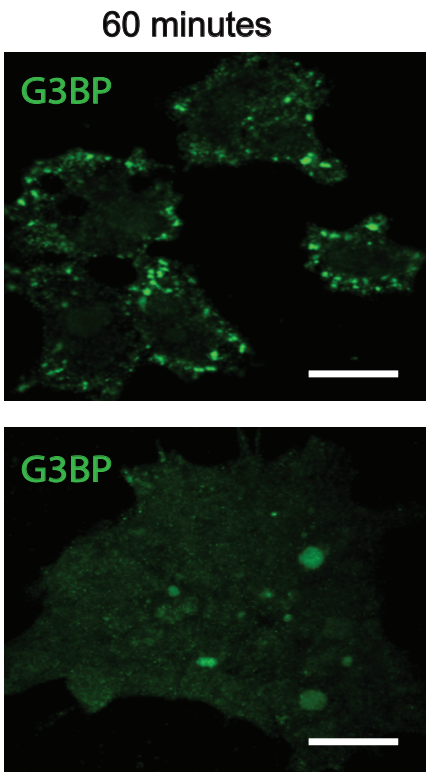

60 minutes

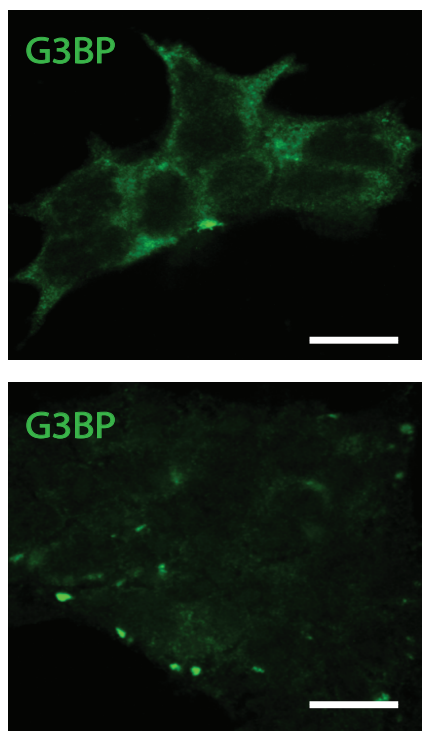

Percentage of cells with

E aggregates after stress

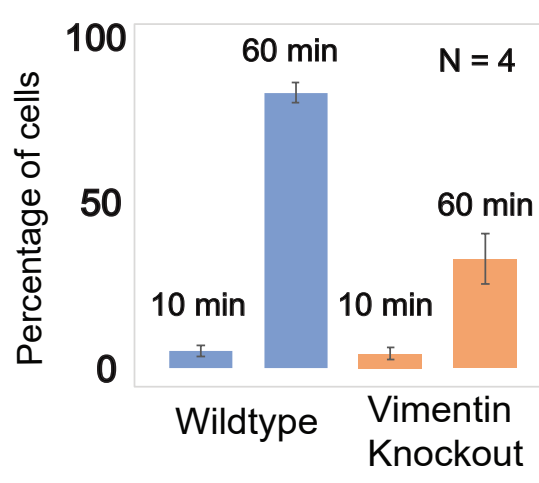

Percentage of cells with aggregates after washout of stress

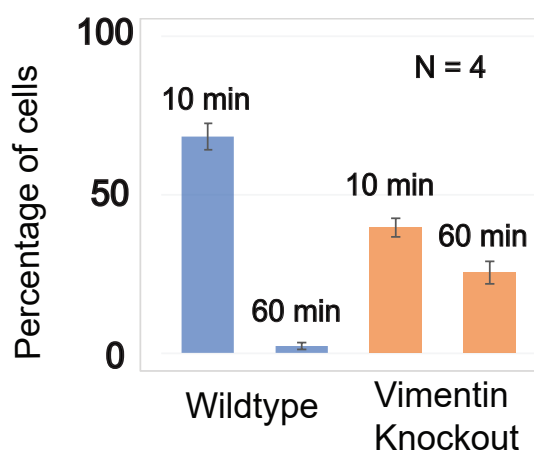


Result 5: Vimentin interacts with SG components and is required for their formation during stress

(A) Proximity ligation assay (PLA) was performed on the cells to confirm the interaction of vimentin with stress granule (SG) protein G3BP. Vimentin and tubulin interaction was taken as control. This assay shows that vimentin interacts with the stress granule protein G3BP during stress and not without stress.

(B) The confocal image shows the direct binding of vimentin with G3BP during arsenite stress Scale bar is $5 \mu \mathrm{m}$

(C) Along with BioID and PLA, immunoprecipitation was also performed to check the interaction of vimentin with RNA binding proteins and we can see from the graph that vimentin binds with various SGs and RBPs during arsenite stress.

$(D, E$ and $F$ ) When the stress granule formation was checked in the vimentin knockout cells, it was observed that the vimentin knockout cells had a delayed formation of stress granule aggregation $(F)$ and when the stress was taken out from the media, they had a delayed disruption of the aggregates with aggregates ending up in the cells even without stress. The statistics of the study have been shown in (E). The error bars indicate standard deviation. Scale bar is $20 \mu \mathrm{m}$ 


\section{Results 6}

A Vimentin forms a cage as a response to stress
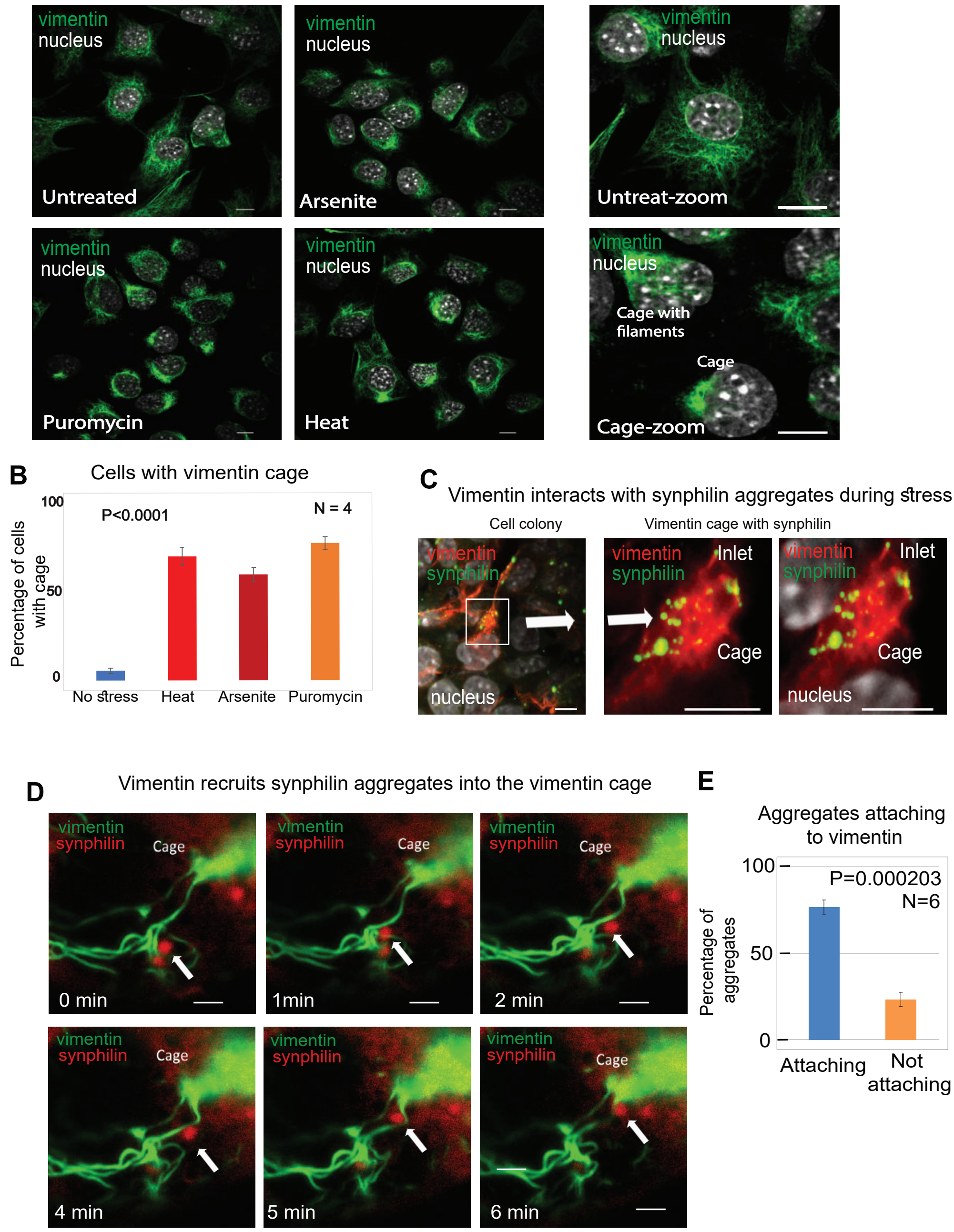
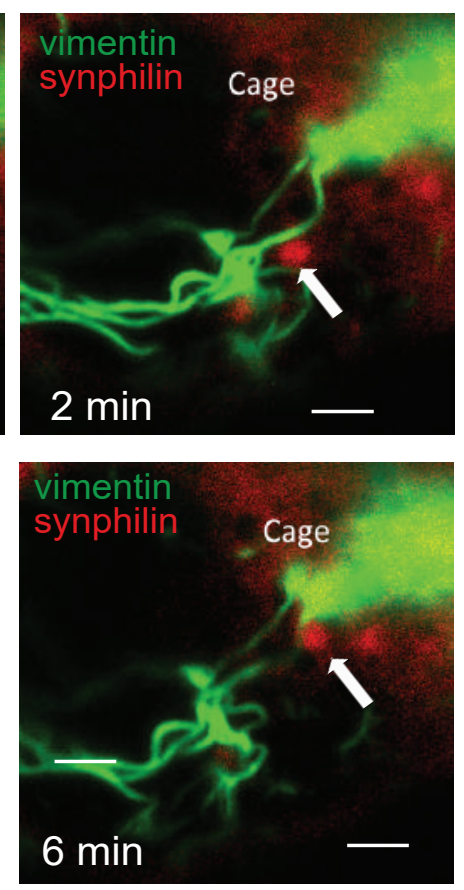

E

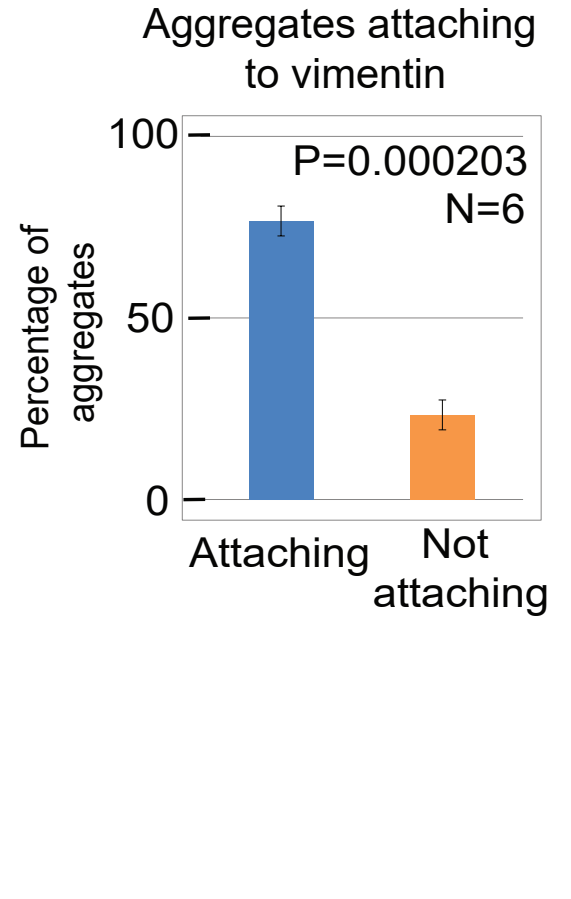


Result 6: Vimentin forms a cage during stress and brings the misfolded proteins along with it to the cage

(A) Cells were immunostained for vimentin during different stresses- (1) untreated (2) heat -44 degrees $/ 2$ hours (3) puromycin $-10 \mu \mathrm{g} / \mathrm{ml}(4)$ arsenite $-150 \mu \mathrm{M} / 2$ hours. The images show that cells form a vimentin cage in the juxtanuclear position of the cell as a response to the stress. The statistics for the percentage of cells forming a cage for different stresses are shown in the right panel. (C) Confocal Images of vimentin-RFP (red) interacting with synphilin-GFP (green) and forming a cage along with the misfolded protein aggregates (scale bar is $5 \mu \mathrm{m}$ ) (D) synphillin -RFP travelling on the vimentin filament (GFP) to reach the vimentin cage. (scale bar is $5 \mu \mathrm{m}$ ). (E) Statistics for the percentage of aggregates interacting with the vimentin filament. 


\section{Results 7}

Vimentin is required in the growth of embryoid body (EB) during stress

A EBs expressing synphillin at $37^{\circ} \mathrm{C}$

EBs expressing synphillin at $42^{\circ} \mathrm{C}$
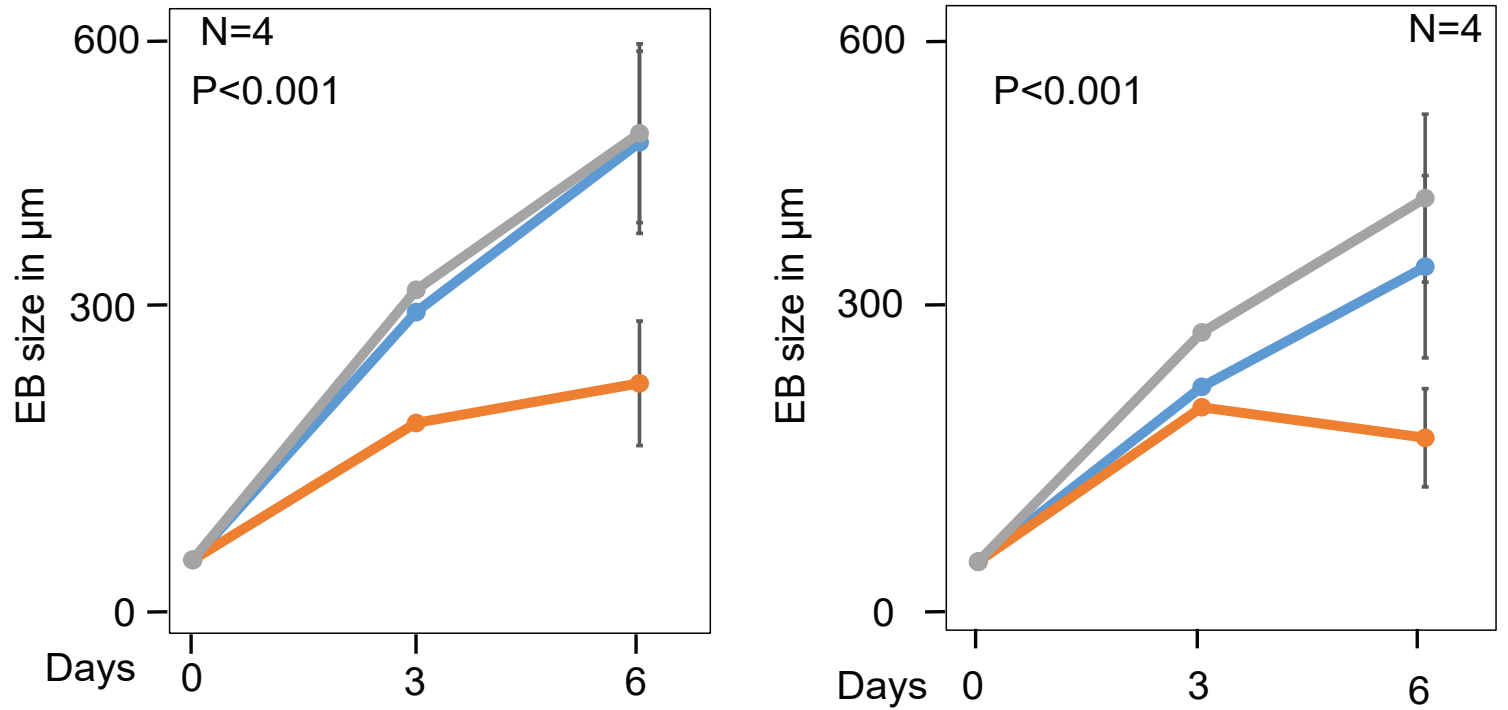

Wildtype $\square$ Vimentin knockout $\square \quad$ Knockout complemented $\square$

B EBs expressing synphillin at $37^{\circ} \mathrm{C}$

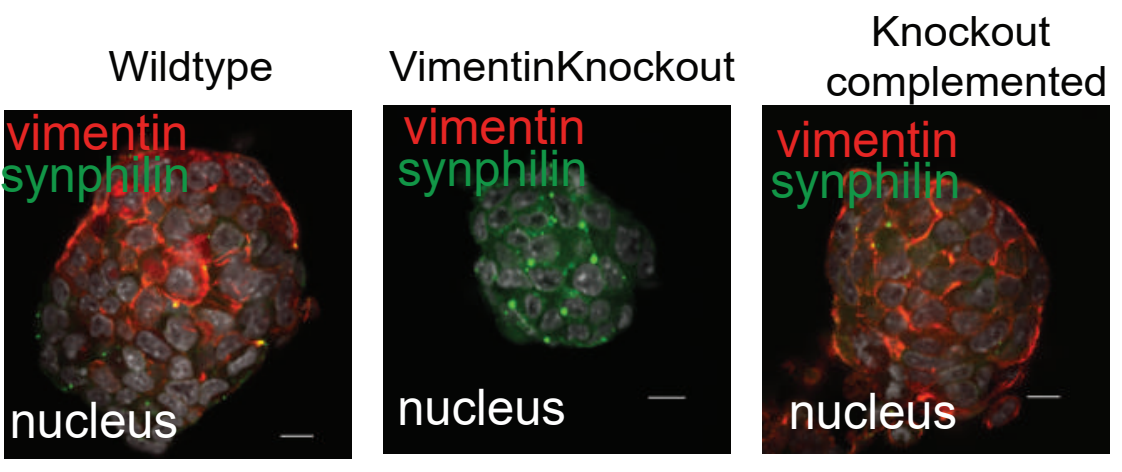

EBs expressing synphillin at $42^{\circ} \mathrm{C}$

Wildtype

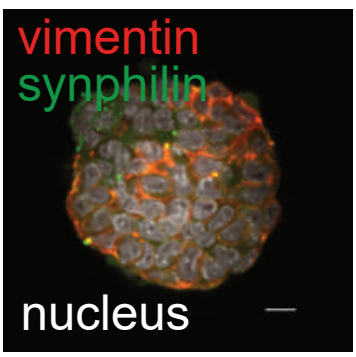

Knockout

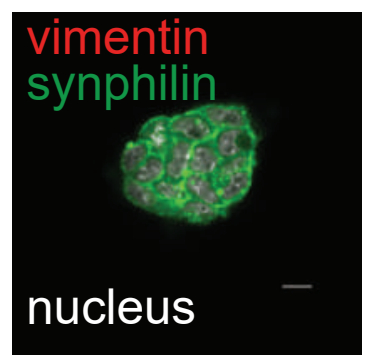

Knockout complemented

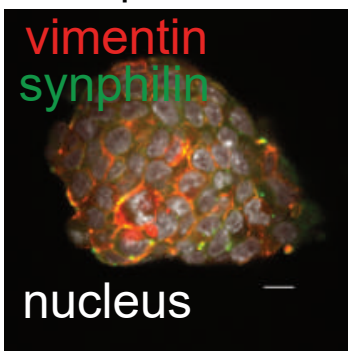

C

Vimentin knockout cells are more cytotoxic

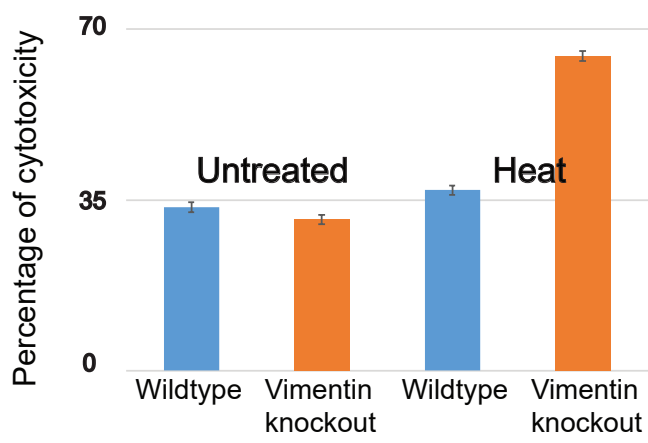

D Vimentin-ULF interacts with synphilin aggregates

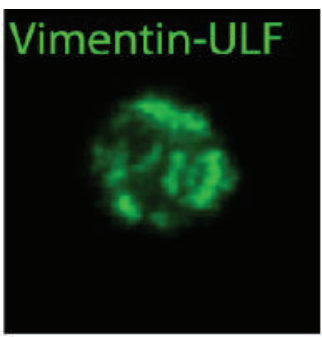

Vimentin-ULF
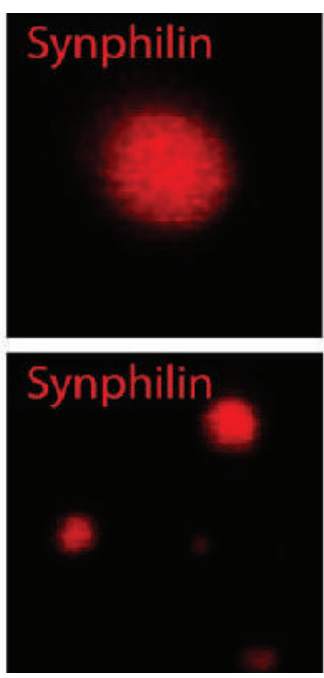
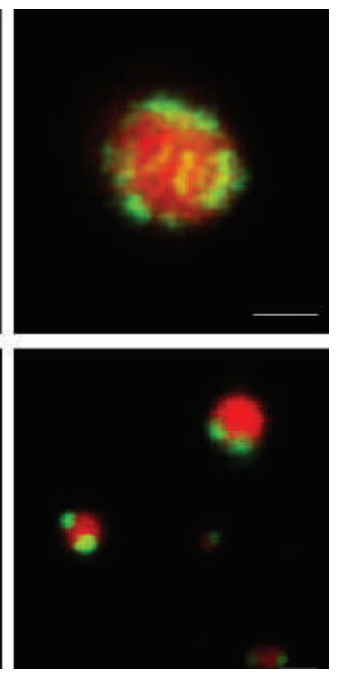
Result 7: Vimentin cage formation is a cytoprotective response and rescues the differentiating stem cells from aggregate toxicity

(A) Comparison of sizes of embryoid bodies (EBs) in (1) wildtype, (2) knockout and (3) knockout complement cells ectopically over-expressing synphilin. The growth of the EBs were observed at normal and during heat shock. Error bars represent standard deviation.

(B) Immunofluorescence images of 6-day old embryoid bodies expressing synphilin at $37^{\circ} \mathrm{C}$ and during heat shock $\left(42^{\circ} \mathrm{C}\right)$. Scale bar is $30 \mu \mathrm{m}$. (C) Cytotoxicity assay showing that vimentin knockout cells are more cytotoxic during stress indicating they are not able to cope up with stress. The error bars indicate standard deviation (D) VimentinULF-GFP (green) interacting with synphilin-RFP foci (red). Top panel -Scale bar is $5 \mu \mathrm{m}$, Bottom Panel - Scale bar is $10 \mu \mathrm{m}$. 


\section{Results 8}

B Asymmetric inheritance of different substrates by vimentin $\quad \mathrm{N}=4$

Vimentin mediates asymmetric inheritance of misfolded proteins

\section{A Knockout complemented cells}
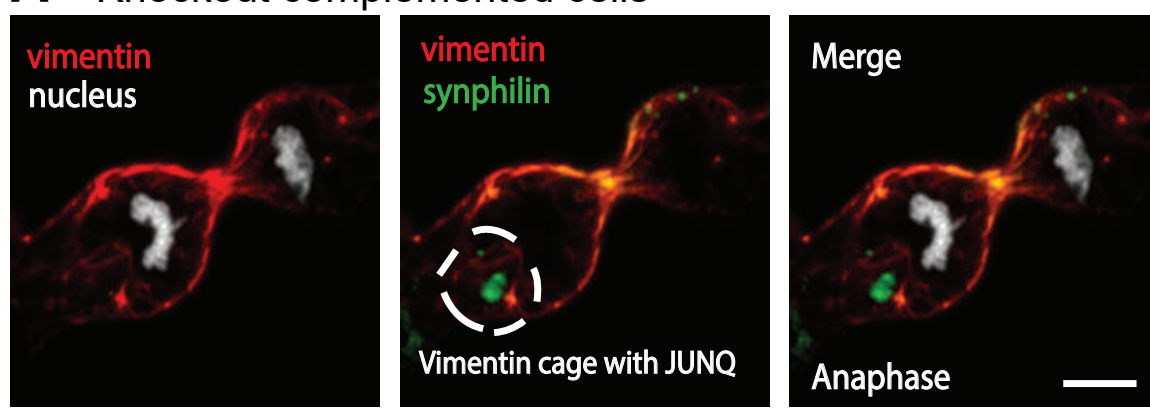

Symmetric partitioning of synphilin in vimentin knockout cells
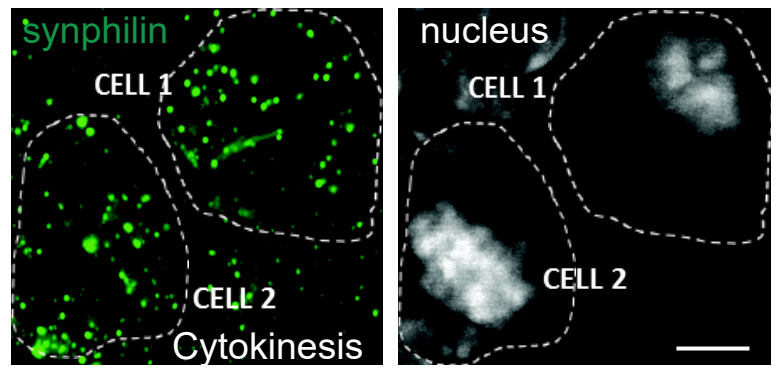

CELL 1
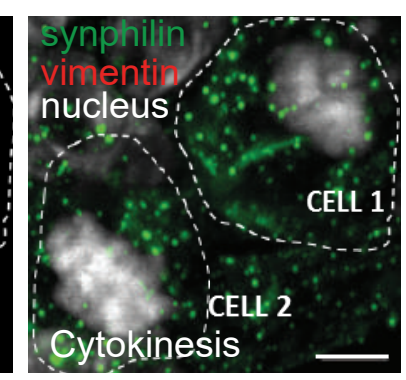
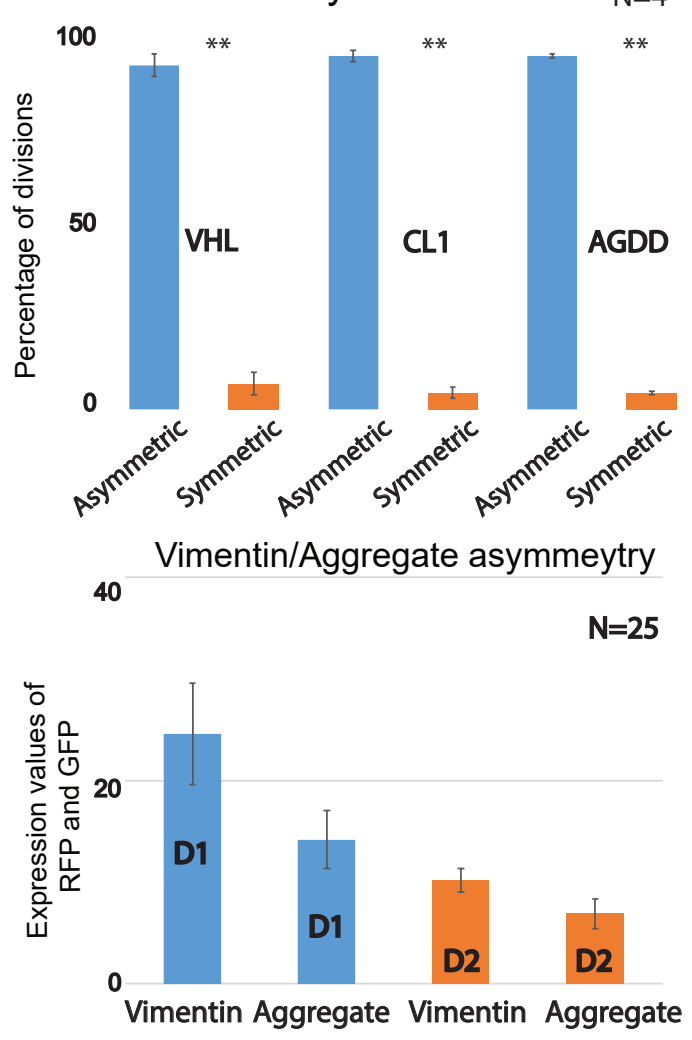

$N=25$

Vimentin knockout cells accumulates more aggregates after differentiation

C

Vimentin knockouts
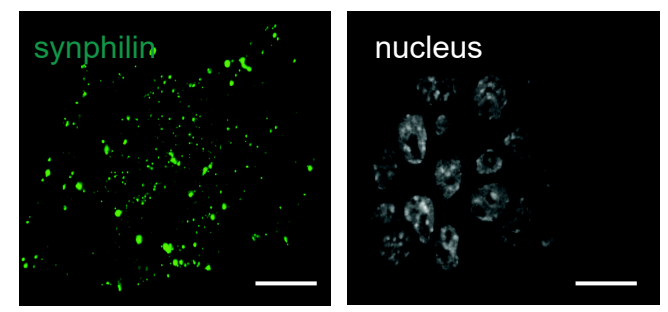

Knockout complements
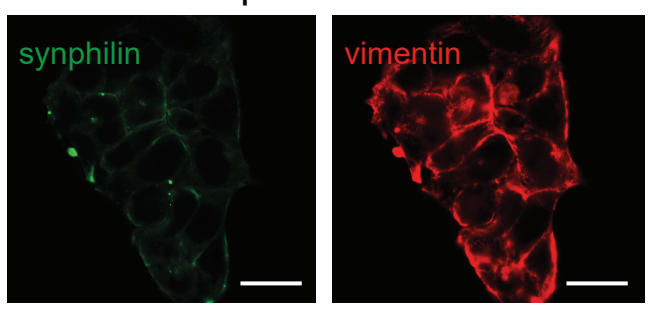

D
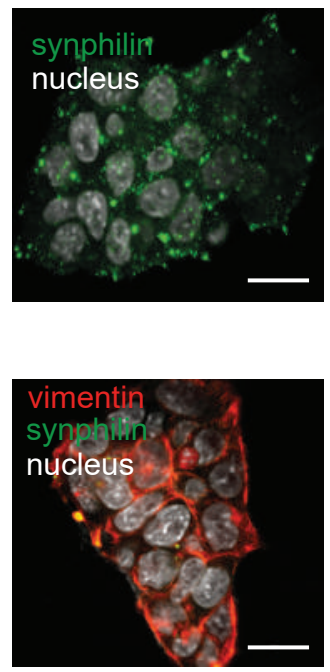

Result 8: Vimentin Knockout cells ends up with more aggregates after
differentiation due to symmetric inheritance during mitosis

(A) Images showing the asymmetric partitioning of the synphilin aggregates (green) that are bound to vimentin (red) in differentiating mESCs complemented with vimentin (top) versus symmetric partitioning of synphillin (green) aggregates in the vimentin knockout cells (bottom). Scale bar is $5 \mu \mathrm{m}$. (B) The right panels are the statistics for the asymmetric inheritance by vimentin when the cells are expressed with different misfolded proteins. The bottom graph is for the amount of asymmetry calculated by measuring the expression values. (C) Colonies of vimentin knockout complemented cells, vimentin (red), synphilin (green) and nucleus (white) (top) and knockout cells, synphilin (green) and nucleus (white) (bottom). knockout cells have a higher number of larger synphilin aggregates (green) after 3 days of differentiation compared to wildtype or the vimentin complements. Scale bar represents $20 \mu \mathrm{m}$.

(D) Quantification showing (1) symmetric partitioning of synphilin (2) percentage of cells with synphilin aggregate after differentiation and (3) size of synphilin aggregates. Error bars represent standard deviation. 
Result 9: The vimentin intermediate cytoskeletal network is partitioned asymmetrically during mitosis and confers slight fitness advantage on cells failing to inherit a JUNQ.

(A) Vimentin forms a JUNQ before mitosis, is partitioned asymmetrically, and then returns back to fibrilar vimentin. $(B)$ Vimentin is partitioned asymmetrically whereas tubulin and actin are not. (C) Quantification of actin, tubulin, mitochondria, and vimentin partitioning during mitosis $(n=36)$. (D) JUNQ remains intact during mitosis. (E) JUNQ formation dynamics were quantified in $82 \mathrm{HEK}$ cells. $(F)$ Cells were followed through two mitoses. Cells that failed to inherit a JUNQ in the first mitosis (D1) divided sooner than their sister cells that did inherit a JUNQ (eight out of eight two-generation cell divisions). Mitochondria marked with Mito-Dendra2 were inherited symmetrically. Experiments were performed on HEK cells without MG132 treatment. 


\section{Results 10 - Page 1}

\section{Vimentin wildtype}

\section{A}
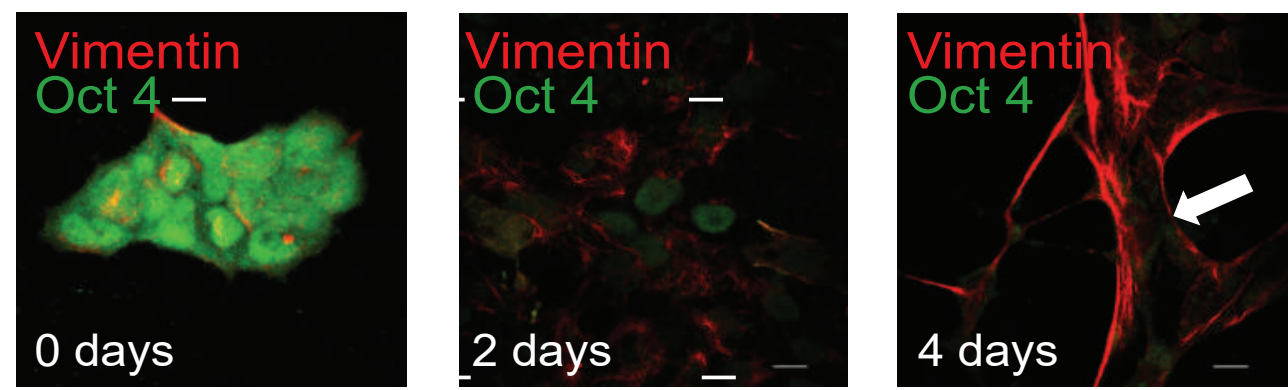

\section{Vimentin knockout}
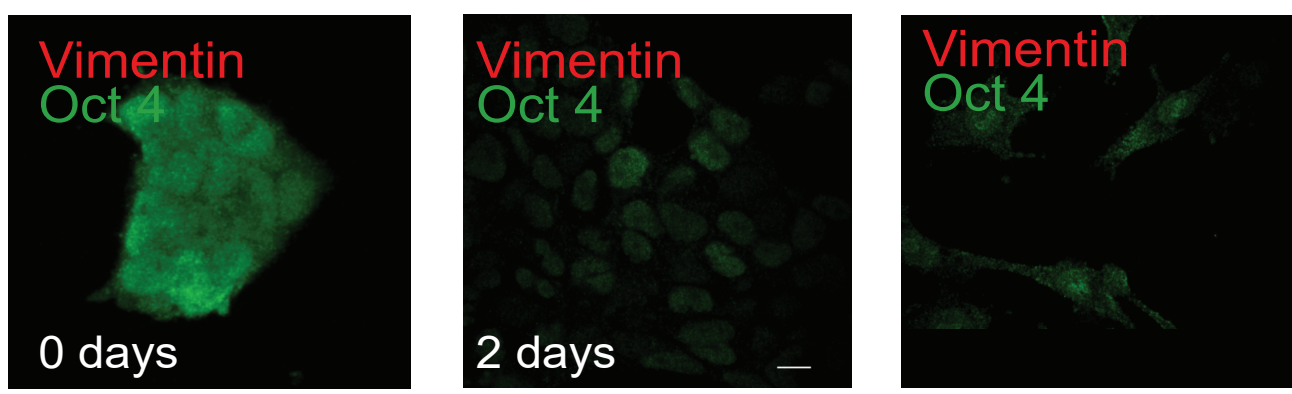

Percentage of OCT4 positive cells

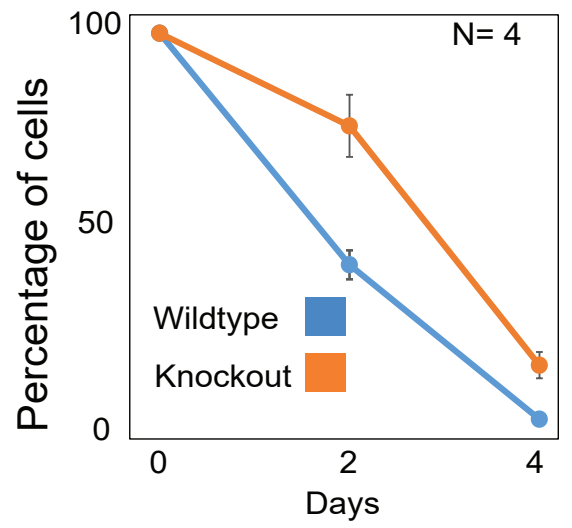

B Comparitive RNA seq of embryonic development and neronal differentiation genes between wildtype and knockout cells

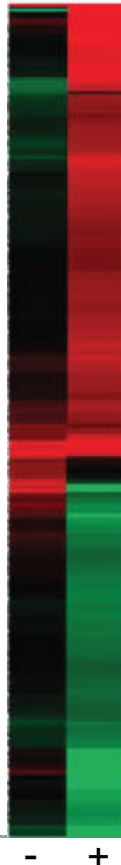

$-2 \quad 0 \quad 2 \quad P<0.000$
Log 2 (FC) KO compar
to WT
GO Categories
Up
Cell death
Intracellular
signalling pathways
Metabolism
Down
Differentiation
Skeletal davelopment
Lipid Biosyrthesis
Tissue development
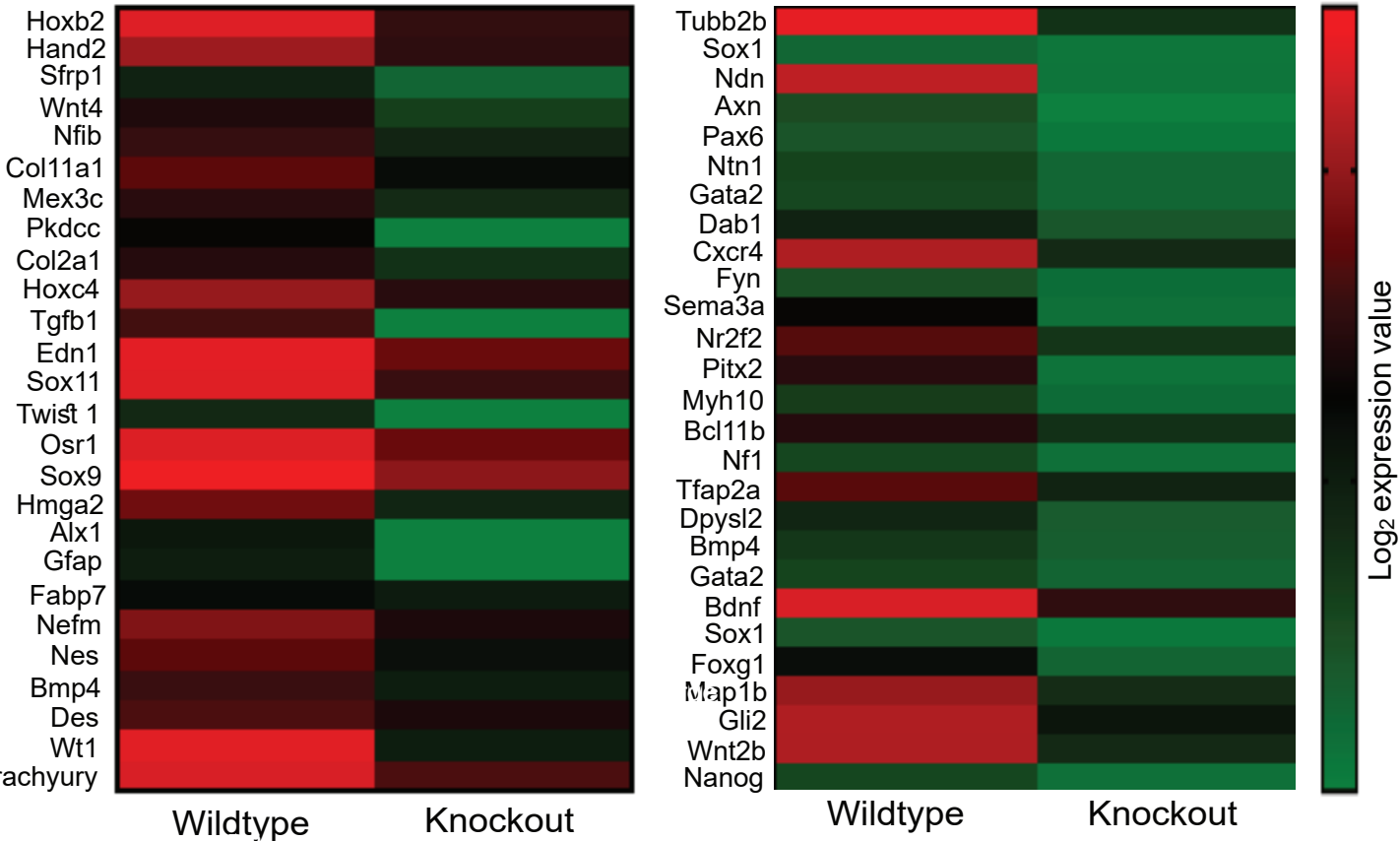
C Vimentin cage is inherited asymmetrically in NPCs
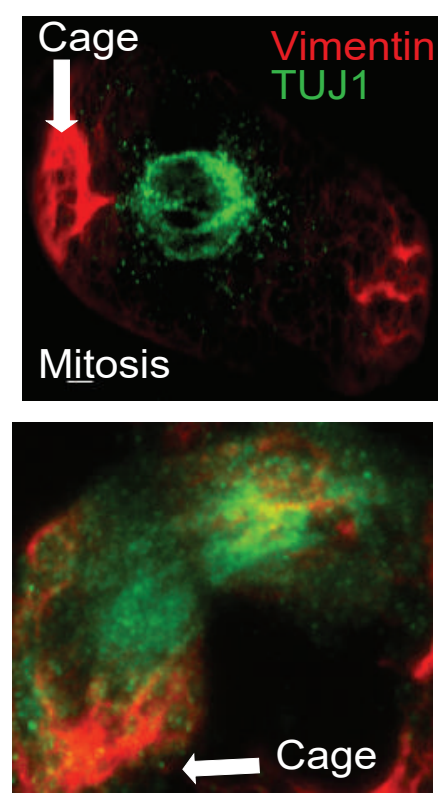

Mitosis

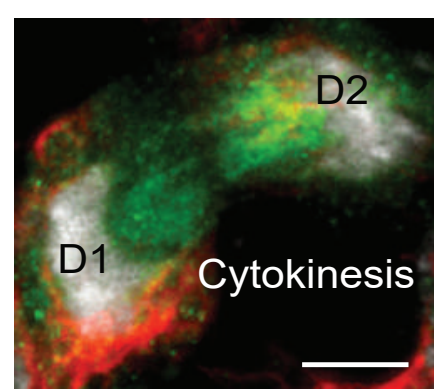

D Vimentin cage mediates asymmetric partitioning of misfolded proteins in NPCs

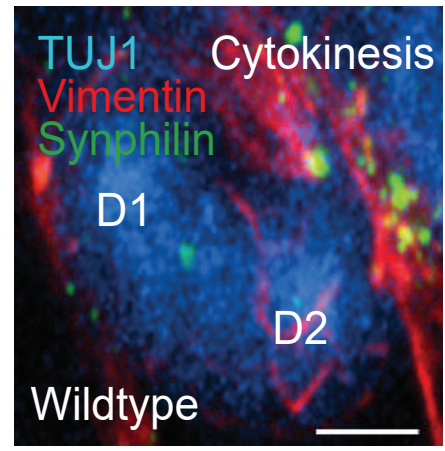

TUJy + Cytokinesis

Vimelntin

Synp'hilin

D1

D2

Vimentin $\mathrm{KO}$
Cells forming a cage before division

Results 10 - Page 2

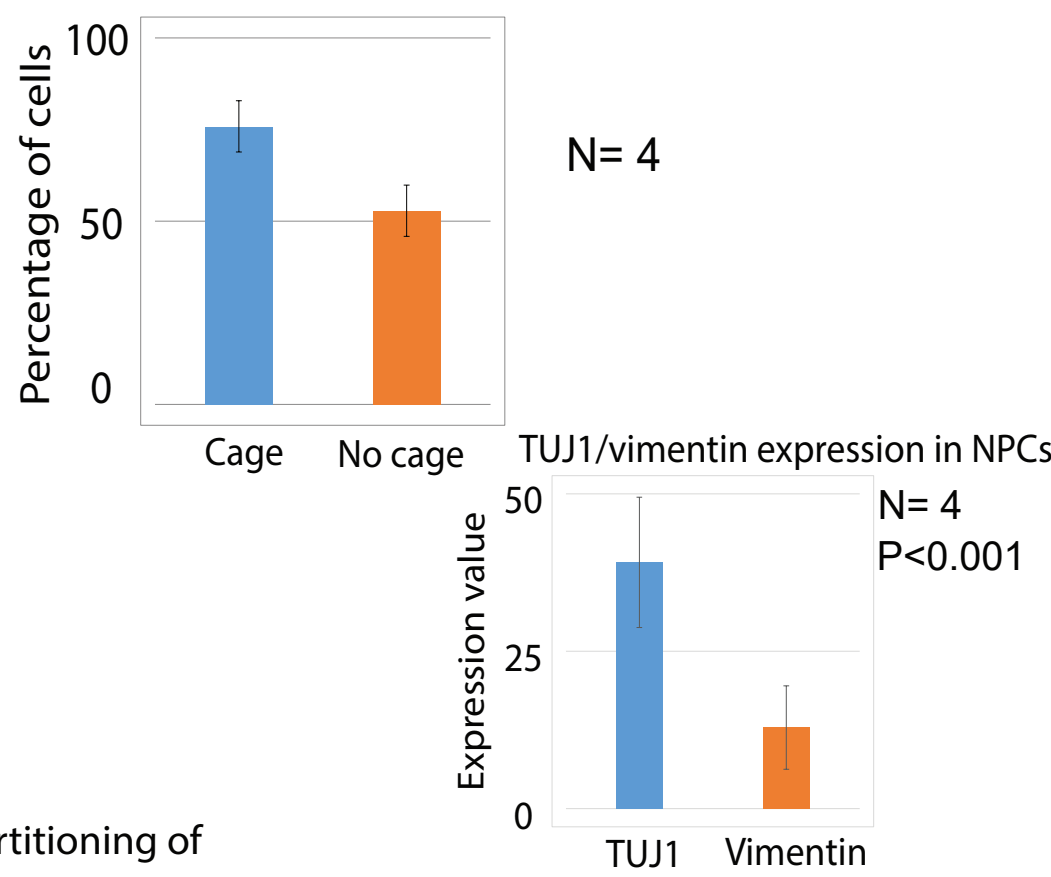

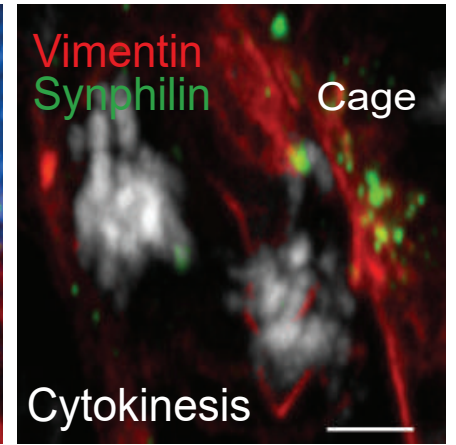
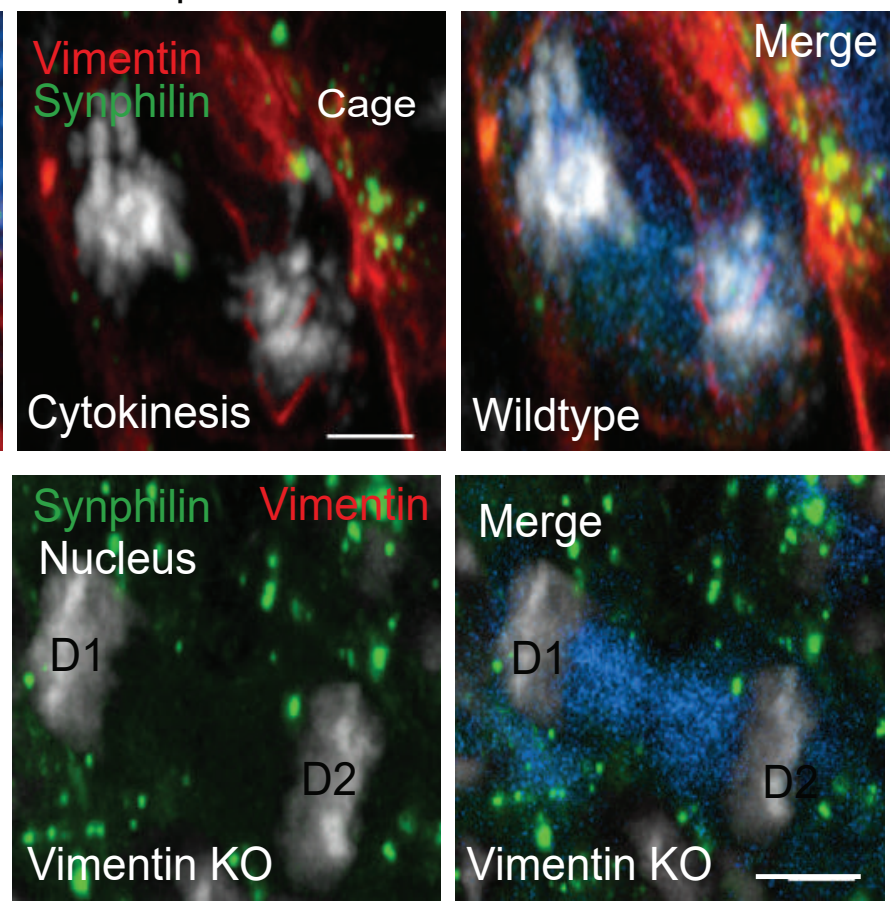

Cells with synphilin aggregates

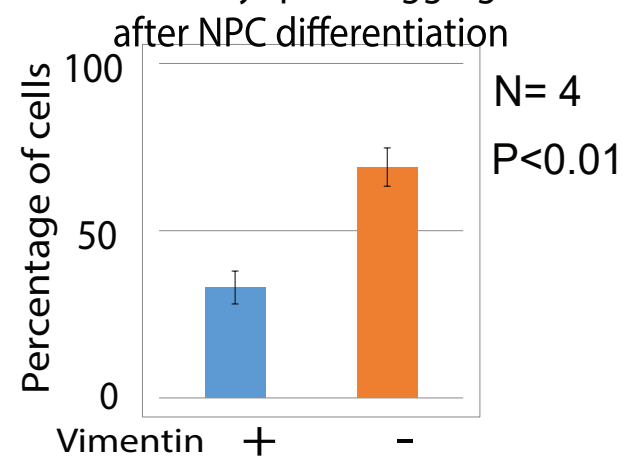

E Vimentin knockout leads to defective NPC differentiation
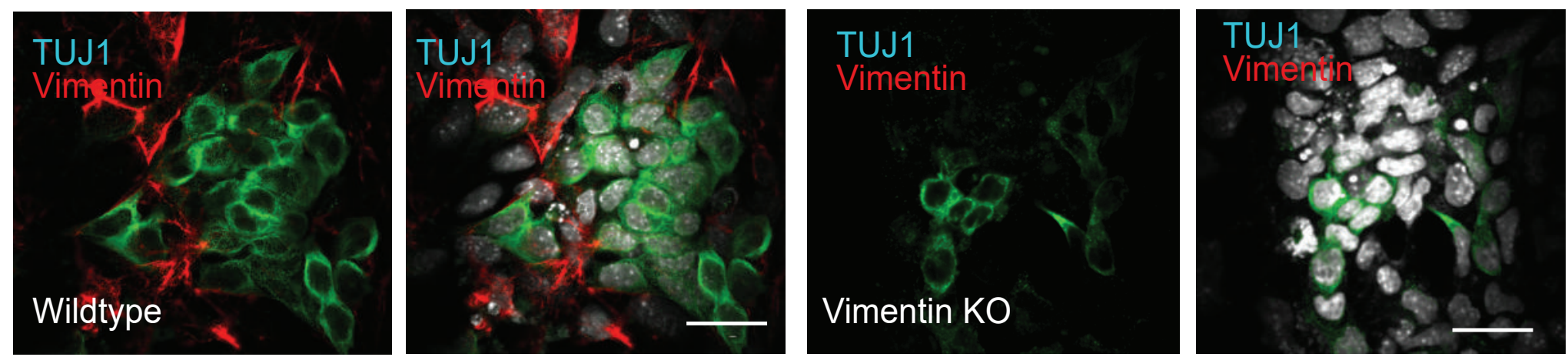

Cells expressing the NPC marker

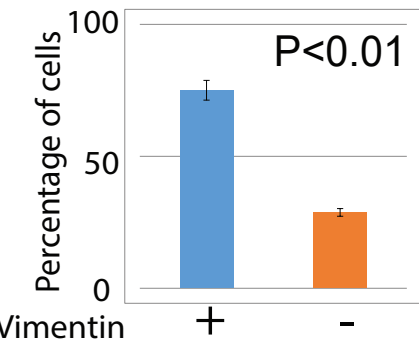




\section{Result 10: Vimentin is critical for mESC neuronal differentiation}

(A) Comparison of OCT4 (green) expression during 4 days of differentiation in wildtype and vimentin knockout cells. Cells were fixed and immunostained for oct4 (green) and vimentin (red). The graph was plotted counting the number of cells positive for oct4. Scale bar is $20 \mu \mathrm{m}$. Error bars represent standard deviation. (B) Whole genome RNA seq data comparison between wildtype and vimentin knockout using Matlab software. Heat map illustrates that vimentin knockout does not affect pluoripotent cells (first column on the left) while differentiated cells are affected in their gene expression patterns (right column). Embryonic development genes were shown separately (heatmap on the right). (C) Confocal images of the NPCs stained with TUJ1 (green), vimentin (red) and nucleus (white) in vimentin wildtype cells to show the asymmetric inheritance of vimentin cage. Scale bar represents $5 \mu \mathrm{m}$. (D) Images of the misfolded protein synphilin-GFP (green) getting asymmetrically partitioned along with vimentin-RFP (red) in the knockout complemented (top panel) and symmetrically partitioned (bottom panel) in the neuronal precursor cells. Scale bar is

$5 \mu \mathrm{m}$.

(E) Confocal images of NPCs stained with neural marker TUJ1 (green), vimentin (red) and nucleus (white) in vimentin wildtype and vimentin knockout cells. Scale bar represents

$20 \mu \mathrm{m}$.

Quantification are shown beside each result (1) Cells with vimentin cage before division in NPCs (2) Percentage of cells with synphilin aggregates after differentiation in wildtype and knockout cells (3) Comparison of TUJ1 expression with vimentin expression in NPCs (4) Percentage of cells having TUJ1 expression in wildtypes and knockouts. Error bars represent standard deviation.

(F) RT PCR of genes of all the three germ layers. (G) GO analysis for the RNA seq data showing the gene groups upregulated and downregulated in vimentin knockout cells compared to the wildtype cells. $(\mathrm{H})$ Brightfield images of defective NPC outgrowth in vimentin knockout cells compared to wildtype and knockout complemented cells after 3 days of NPC differentiation. (I) Quantification showing (1) number of EBs getting attached after culturing in NPC media (2) the size of the NPC projection coming out of the EBs after getting attached to the plate. Error bars represent standard deviation. (J) Model showing that vimentin interacts and collapses along with the misfolded protein aggregates and RNP granules, asymmetrically inheriting them to one daughter cell after division. 


\section{MATERIALS AND METHODS}

\section{Cell culture}

MEFs were maintained in Dulbecco's modified Eagle's medium (DMEM, Sigma), $10 \%$ fetal bovine serum (FBS), $2 \mathrm{mM}$ L-glutamine, $50 \mu \mathrm{g} / \mathrm{ml}$ Penicillin and $50 \mu \mathrm{g} / \mathrm{ml}$ Streptomycin. R1ESCs were cultured on a feeder layer of mitomycin-C treated MEFs, and maintained in ESC culture medium (DMEM, 10\% ESC-grade FBS, $2 \mathrm{mM} \mathrm{L-}$ glutamine, $1 \mathrm{mM}$ sodium pyruvate, $0.1 \mathrm{mM}$ nonessential amino acids, $50 \mu \mathrm{g} / \mathrm{ml}$ Penicillin, $50 \mu \mathrm{g} / \mathrm{ml}$ Streptomycin, $0.1 \mathrm{mM} \beta$-mercaptoethanol and $1000 \mathrm{U} / \mathrm{ml}$ (LIF). For retinoic acid (RA) induced differentiation, ESCs were grown on gelatin-coated dishes for 96 hours and then plated in ESC medium without LIF supplemented with $1 \mu \mathrm{M}$ RA. For Embryoid body differentiation (EBs) the ESCs were cultured in bacterial culture dishes in ESC media without LIF for 6 days, following the protocol previously described in (Alajem et al., 2015). For neuronal precursor cells differentiation, the ESCs were plated on bacterial culture dishes without LIF for 4 days to allow for EB formation. EBs were replated on poly-L-ornithine/fibronectin (R\&D Systems and Sigma respectively)coated plates in DMEM/F12 medium (Sigma) supplemented with ITS $(5 \mathrm{mg} / \mathrm{ml}$ insulin, $50 \mathrm{mg} / \mathrm{ml}$ transferrin, $30 \mathrm{nM}$ selenium chloride) and fibronectin $(5 \mathrm{mg} / \mathrm{ml})$. In all differentiation protocols MEF removal was achieved by passaging the ESCs 3 times (20 minutes each).

\section{Generation of knock-out cells in mouse ES cells}

Guides targeted to Vimentin gene were designed using CRISPR design tool from Zhang lab (http://crispr.mit.edu/) (Randall et al., 2014). Appropriate target guide was selected for Vimentin gene. The sequences of guides are as follows Vimentin KO Guide FP: CACCGCCTGGTAGACATGGCTTCGA, Vimentin KO Guide RP: AAACTCGAAGCCATGTCTACCAGGC. This guide was cloned into mammalian expression vector PX458 (addgene \#48138). Mouse R1ESCs were transfected with Vimentin expressing guide and GFP positive cells were sorted after $48 \mathrm{~h}$ posttransfection. The sorted cells were clonally expanded and knocking out of Vimentin gene were verified by DNA sequencing, Immuno-fluorescence and real-time PCR, the protocol is described in (Azad et al., 2018).

\section{Plasmids}

For transient transfection of mammalian cells, we used the plasmids DCP1-RFP (Red fluorescence protein) and UB-Cherry (ubiquitin - cherry) which drives the expression of full length CDNA of DCP1 and ubiquitin respectively. For producing the lentiviral plasmids, Vimentin-GFP (green fluorescence protein), Vimentin - RFP (red fluorescence protein), chromobodies - RFP (red fluorescence protein) (Julia et al., 2015)and Synphilin-GFP were subcloned into psin-ef2-nanog-pur (addgene \#16578). 
Vimentin-BirA*-GFP and Synphilin-BirA-GFP were subcloned into plnducer 20 plasmid.

\section{RNA isolation, reverse transcription and quantitative real-time PCR.}

Total RNA from ESCs, EBs, Cardiomyocytes and RA differentiated cells was prepared as described in the RNeasy Mini Kit (Qiagen: 74106 supplemented with RNase-free DNase set) following their instruction. Approximately 1000ng total RNA was used for reverse transcription, the High Capacity cDNA RT kit (Applied Biosystems, 4368814) to make cDNA following manufacturer's instructions with a mix of random hexamers and poly $(\mathrm{dT})$ primers. Quantitative real-time PCR was performed in a BioRad sequence detection system with diluted cDNA as template. Power SYBR Green PCR Master Mix (Applied Biosystems) was used for real-time PCR.

\section{Genomic DNA isolation}

Total genomic DNA was isolated using Sigma genomic DNA isolation kit following manufacturer's instructions. Approximately 200ng DNA was used for PCR to screen knock-out clones.

\section{Immunofluorescence (IF)}

For IF experiments the cells were grown on glass coverslips in 24 well plate and fixed in $4 \%$ PFA ( $15 \mathrm{~min}$, room temp). The fixed cells were permeabilized $(0.5 \%$ Triton, 5 min, R.T.) and incubated with the primary antibodies at $4^{\circ} \mathrm{C}$ over-night. Cells were then washed (X3) in PBS (5 min, R.T.), incubated with secondary antibodies (45 minutes at room temperature, washed again and stained with DAPI (5 min, R.T.). The coverslip was mounted in a drop of mounting solution and left for drying at room temperature and slides were stored in dark at $4^{\circ} \mathrm{C}$ till imaging. The following antibodies were used (1) anti - Vimentin antibody (Santa cruz sc-6260), (2) anti TUJ1 antibody (Santa cruz sc-51670), (3) anti OCT4 antibody (Abcam ab-27985).

\section{RNA sequencing analysis}

The library was made using manufacturer's instructions. The integrity of library was confirmed by running tape station. The analysis of RNA sequencing data begins with raw RNA -seq reads for each condition are mapped to the reference mouse genome using TopHat programme. After running TopHat, the resulting alignment files are used to run another program called Cufflinks that generates a transcriptome assembly file for each input condition. Further, these assembled files are combined together using the Cuffmerge program. This merged assembly is the final file that is used to calculate 
gene and transcript expression in each sample. The reads and the merged assembly are provided to Cuffdiff that calculates differential expression levels as well as tests the statistical significance.

\section{Affinity capture of biotinylated proteins}

Cells were incubated for $24 \mathrm{~h}$ in complete media supplemented with $1 \mu \mathrm{g} / \mathrm{ml}$ doxycycline and $50 \mu \mathrm{M}$ biotin. The cells were visualized under the microscope for Vimentin and Synphilin expression and localization. Lysis and affinity capture were performed according to Roux et al., (2012). After three PBS washes, cells (for smallscale analysis, $<107$; for large scale analysis, $4 \times 107$ ) were lysed at $25^{\circ} \mathrm{C}$ in $1 \mathrm{ml}$ lysis buffer (50 mM Tris, pH 7.4, $500 \mathrm{mM} \mathrm{NaCl}, 0.4 \%$ SDS, $5 \mathrm{mM}$ EDTA, $1 \mathrm{mM}$ DTT, and 1x Complete protease inhibitor (Roche)) and sonicated. Triton X-100 was added to $2 \%$ final concentration. After further sonication, an equal volume of $4^{\circ} \mathrm{C} 50 \mathrm{mM}$ Tris $\left(\mathrm{pH}\right.$ 7.4) was added before additional sonication (subsequent steps at $4^{\circ} \mathrm{C}$ ) and centrifugation at 16,000 relative centrifugal force. $10 \%$ of the sample were saved for western blot analysis. Supernatants were incubated with $300 \mu \mathrm{l}$ of streptavidin-coated magnetic beads (NEB). Beads were collected (subsequent steps at room temperature) and washed according to Roux et al.

\section{Preparing samples for the Mass spectroscopy}

The beads were washed free of detergents by two washes with $25 \mathrm{mM}$ Tris- $\mathrm{HCl} \mathrm{pH}$ 8.0. Then the packed beads were resuspended in $100 \mathrm{ul}$ of $8 \mathrm{M}$ urea, $10 \mathrm{mM}$ DTT, 25 $\mathrm{mM}$ Tris- $\mathrm{HCl} \mathrm{pH} 8.0$ and incubated for $20 \mathrm{~min}$, followed by addition of iodoacetamide to a concentration of $55 \mathrm{mM}$ and incubation for $20 \mathrm{~min}$ in the dark. The urea was diluted

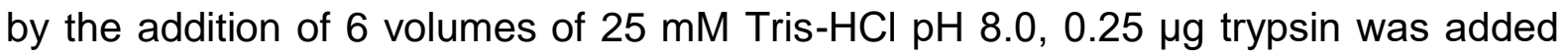
(Promega Corp., Madison, WI, USA) and the beads were incubated overnight at $370 \mathrm{C}$ with gentle agitation. The released peptides were desalted by loading the whole bead supernatant on C18 Stage tips. Two thirds of the eluted peptide material were used for MS analysis.

\section{MS data analysis}

Mass spectra data were processed using the MaxQuant computational platform, version 1.5.3.12. Peak lists were searched against the Mus musculus Uniprot FASTA sequence database containing a total of 9,591 reviewed entries. Peptides with minimum of seven amino-acid length were considered and the required FDR was set to $1 \%$ at the peptide and protein level. Protein identification required at least 3 unique or razor peptides per protein group. Relative protein quantification in MaxQuant was performed using the label free quantification (LFQ) algorithm. LFQ in MaxQuant uses 
only common peptides for pair-wise ratio determination for each protein and calculates a median ratio to protect against outliers. It then determines all pair-wise protein ratios and requires a minimal number of two peptide ratios for a given protein ratio to be considered valid.

\section{Growth Curve}

Cells were grown on a $10 \mathrm{~cm}$ tissue culture plate and then seeded ( 100000 cells/well) to $5 \mathrm{~cm}$ tissue culture plate coated with gelatin. The cells were grown for 5 days. The number of cells were measured every 24 hours. Cells were measured by the automatic cell counter. Graphs were plotted by using standard tools.

For embryoid body growth curve, the cells (1 million) were seeded on a $10 \mathrm{~cm}$ plate and grown for 6 days. Images were taken on the 3rd and the 6th day. Some cells were also taken and fixed on a coverslip by adding $4 \%$ para formaldehyde (20 minutes at $37^{\circ} \mathrm{C}$ ) and centrifuging them at $3000 \mathrm{rpm}$ for 5 mins at RT.

\section{Analysis of genome-wide data and proteomics data}

GO-annotation was done for categorizing the proteins into their respective processes they are involved in. For the analysis of the proteomics data, first the values obtained for the control samples were subtracted from the other samples and Log (base 2) were calculated for the values of proteins of interest. The values were then plotted as a graph using graph pad prism software.

\section{Lentiviral Infection}

The lentiviral transfer vector DNA, together with psPAX2 packaging and pMD2. G envelope plasmid DNA were combined at a ratio of $4: 3: 1$, respectively. Production of 3 rd generation lentivirus was performed using the combined ratio of transfer plasmid, packaging plasmid, Env plasmid and pRSV-Rev plasmid at 4:2:1:1, respectively. The precipitate was formed by adding $6 \mu \mathrm{g}$ of DNA to a final volume of $500 \mathrm{ul}$ of non-serum media along with $20 \mathrm{ul}$ of $\mathrm{PEI}$. The solution was briefly vortexed and incubated at room temperature for $30 \mathrm{~min}$. Following this, the solution was mixed again by gentle vortexing, and then added dropwise to the cells. Flasks were rocked gently in a circular motion to distribute the precipitates, and then returned to the incubator at $5 \% \mathrm{CO} 2$ unless otherwise stated. 10 to 12 hrs later, cells were gently washed once with PBS and fresh growth medium with $15 \%$ FBS were added. $24 \mathrm{hrs}$ post-addition of the new media, the initial collection of viral supernatant was done. A second collection was made after a further $24 \mathrm{hrs}$. The conditioned medium from the two harvests was combined and cleared by centrifugation at $1500 \mathrm{rpm}$ for $5 \mathrm{~min}$ at $4^{\circ} \mathrm{C}$ then passed through a $0.45 \mu \mathrm{m}$ pore PVDF Millex-HV filter. This viral supernatant media was then 
added to the cells needed to be infected. After infection, the cells were maintained in the viral supernatant media for 48 Hours and then passaged to a new plate.

\section{FACS cell sorting}

The cells were trypsinized and new media was added. The cell suspension was centrifuged at 1800rpm for 3 minutes. This is the first wash to take out the trypsin from the media. After centrifuging the media was aspirated and PBS with 1\% FBS was added to the pellet and mixed. This solution was again centrifuged again at $1800 \mathrm{rpm}$ for 3 minutes. This is the second wash to take out the remaining media from the cell suspension. The supernatant was again aspirated and PBS with 1\% FBS was added. This tube of cell suspension was kept in ice till FACS sorting. The cell suspension was made to pass through a fluorescent activated cell sorter (FACS Aria, Becton Dickinson) to separate tagged and negative fractions, which were collected. The sorting was performed at room temperature with the laser (Coherent Innova 70) set at appropriate wavelength and $200 \mathrm{~mW}$ power.

\section{Statistical analysis}

Three or more independent experiments were performed to obtain the data. $P$ values were calculated by two-tailed Student t-test, or one-way ANOVA. The sample sizes were not predetermined.

\section{Live Cell Imaging}

Cells (20000 cells) were seeded on a glass bottom 4 well plate (De Groot - 76-D35C420). Imaging was started 24 hours after the seeding of cells. Images were acquired depending upon the experiment. Cells were cultured and transfected according to standard protocols. For time-lapse imaging, we used a dual point-scanning Nikon A1R-si microscope equipped with a Piezo stage, using a 60× PlanApo IR oil objective NA 1.4, $0.3 \mu \mathrm{m}$ slices, and $0.2-2 \%$ laser power (from $65-\mathrm{mW} 488-\mathrm{nm}$ laser and 50 $\mathrm{mW} 561$-nm laser) to acquire 3D movies. Images were acquired in resonant-scanning or Galvano-scanning mode. Each Z series was acquired with 0.5- to 1- $\mu \mathrm{m}$ step size and 10-35 steps. For super resolution Structured Illumination Microscopy (SIM) Cells were prepared as described above. Images were acquired using a Nikon nSIM microscope in 2D mode with a $488 \mathrm{~nm}$ and $561 \mathrm{~nm}$ lasers. A $100 x$ oil TIRF objective (NA 1.49) was used for the imaging. Prior to imaging the point-spread function was visualized with $100 \mathrm{~nm}$ fluorescence beads in order to adjust the correction ring of the objective to the coverslip thickness. The final image was reconstructed using NISElements software 


\section{References - Chapter 3}

Alajem, A., Biran, A., Harikumar, A., Sailaja, B.S., Aaronson, Y., Livyatan, I., NissimRafinia, M., Sommer, A.G., Mostoslavsky, G., Gerbasi, V.R., et al. (2015). Differential association of chromatin proteins identifies BAF60a/SMARCD1 as a regulator of embryonic stem cell differentiation. Cell Rep 10, 2019-2031.

Amen, T., and Kaganovich, D. (2015). Dynamic droplets: the role of cytoplasmic inclusions in stress, function, and disease. Cell Mol Life Sci 72, 401-415.

Antfolk, D., Sjoqvist, M., Cheng, F., Isoniemi, K., Duran, C.L., Rivero-Muller, A., Antila, C., Niemi, R., Landor, S., Bouten, C.V.C., et al. (2017). Selective regulation of Notch ligands during angiogenesis is mediated by Vimentin. Proc Natl Acad Sci U S A 114, E4574-E4581.

Azad, G.K., Ito, K., Sailaja, B.S., Biran, A., Nissim-Rafinia, M., Yamada, Y., Brown, D.T., Takizawa, T., and Meshorer, E. (2018). PARP1-dependent eviction of the linker histone $\mathrm{H} 1$ mediates immediate early gene expression during neuronal activation. JCB 217, 473-481.

Boraas, L.C., and Ahsan, T. (2016). Lack of Vimentin impairs endothelial differentiation of embryonic stem cells. Sci Rep 6, 30814.

Bufalino, M.R., and van der Kooy, D. (2014). The aggregation and inheritance of damaged proteins determines cell fate during mitosis. Cell Cycle 13, 1201-1207.

Castro-Munozledo, F., Meza-Aguilar, D.G., Dominguez-Castillo, R., HernandezZequinely, V., and Sanchez-Guzman, E. (2017). Vimentin as a Marker of Early Differentiating, Highly Motile Corneal Epithelial Cells. J Cell Physiol 232, 818-830. Chen, M., Puschmann, T.B., Marasek, P., Inagaki, M., Pekna, M., Wilhelmsson, U., and Pekny, M. (2018). Increased Neuronal Differentiation of Neural Progenitor Cells Derived from Phosphovimentin-Deficient Mice. Mol Neurobiol 55, 5478-5489.

Clevers, H. (2005). Stem cells, asymmetric division and cancer. Nat Genet 37, 10271028.

Coelho, M., Lade, S.J., Alberti, S., Gross, T., and Tolic, I.M. (2014). Fusion of protein aggregates facilitates asymmetric damage segregation. PLoS Biol 12, e1001886.

Danielsson, F., Peterson, M.K., Caldeira Araujo, H., Lautenschlager, F., and Gad, A.K.B. (2018). Vimentin Diversity in Health and Disease. Cells 7.

Eckes, B., Colucci-Guyon, E., Smola, H., Nodder, S., Babinet, C., Krieg, T., and Martin, P. (2000). Impaired wound healing in embryonic and adult mice lacking Vimentin. J Cell Sci 113 ( Pt 13), 2455-2462.

Eckes, B., Dogic, D., Colucci-Guyon, E., Wang, N., Maniotis, A., Ingber, D., Merckling, A., Langa, F., Aumailley, M., Delouvee, A., et al. (1998). Impaired mechanical stability, migration and contractile capacity in Vimentin-deficient fibroblasts. J Cell Sci 111 ( Pt 13), 1897-1907.

England, J.L., and Kaganovich, D. (2011). Polyglutamine shows a urea-like affinity for unfolded cytosolic protein. FEBS Lett 585, 381-384. 
Erjavec, N., Cvijovic, M., Klipp, E., and Nystrom, T. (2008). Selective benefits of damage partitioning in unicellular systems and its effects on aging. Proc Natl Acad Sci U S A 105, 18764-18769.

Erjavec, N., and Nystrom, T. (2007). Sir2p-dependent protein segregation gives rise to a superior reactive oxygen species management in the progeny of Saccharomyces cerevisiae. Proc Natl Acad Sci U S A 104, 10877-10881.

Franke WW, Grund C, Kuhn C, Jackson BW, Illmensee K. (1982). Formation of cytoskeletal elements during mouse embryogenesis. III. Primary mesenchymal cells and the first appearance of vimentin filaments. Differentiation; research in biological diversity 23, 43-59.

Guo, M., Ehrlicher, A.J., Mahammad, S., Fabich, H., Jensen, M.H., Moore, J.R., Fredberg, J.J., Goldman, R.D., and Weitz, D.A. (2013). The role of Vimentin intermediate filaments in cortical and cytoplasmic mechanics. Biophys J 105, 15621568.

Guojuan Liao and Gregg G. Gundersen. (1998). Kinesin Is a Candidate for Crossbridging Microtubules and Intermediate Filaments. The Journal of Biological Chemistry 273, 9797-9803.

Haversen, L., Sundelin, J.P., Mardinoglu, A., Rutberg, M., Stahlman, M., Wilhelmsson, U., Hulten, L.M., Pekny, M., Fogelstrand, P., Bentzon, J.F., et al. (2018). Vimentin deficiency in macrophages induces increased oxidative stress and vascular inflammation but attenuates atherosclerosis in mice. Sci Rep 8, 16973.

Hol, E.M., and Capetanaki, Y. (2017). Type III Intermediate Filaments Desmin, Glial Fibrillary Acidic Protein (GFAP), Vimentin, and Peripherin. Cold Spring Harb Perspect Biol 9.

Jiu, Y., Peranen, J., Schaible, N., Cheng, F., Eriksson, J.E., Krishnan, R., and Lappalainen, P. (2017). Vimentin intermediate filaments control actin stress fiber assembly through GEF-H1 and RhoA. J Cell Sci 130, 892-902.

Julia Maier., Bjoern Traenkle and Ulrich Rothbauer. (2015). Real-time analysis of epithelial-mesenchymal transition using fluorescent single-domain antibodies. Scientific Reports 5, 13402.

Kaganovich, D. (2017). There Is an Inclusion for That: Material Properties of Protein Granules Provide a Platform for Building Diverse Cellular Functions. Trends Biochem Sci 42, 765-776.

Katsumoto T.; Mitsushima A.; Kurimura T. (1990). "The role of the vimentin intermediate filaments in rat $3 Y 1$ cells elucidated by immunoelectron microscopy and computer-graphic reconstruction". Biol Cell. 68, 139-46.

Kokkinos, M.I., Wafai, R., Wong, M.K., Newgreen, D.F., Thompson, E.W., and Waltham, M. (2007). Vimentin and epithelial-mesenchymal transition in human breast cancer--observations in vitro and in vivo. Cells Tissues Organs 185, 191-203.

Leor, J., Gerecht, S., Cohen, S., Miller, L., Holbova, R., Ziskind, A., Shachar, M., Feinberg, M.S., Guetta, E., and Itskovitz-Eldor, J. (2007). Human embryonic stem cell transplantation to repair the infarcted myocardium. Heart 93, 1278-1284. 
Li, H.S., Wang, D., Shen, Q., Schonemann, M.D., Gorski, J.A., Jones, K.R., Temple, S., Jan, L.Y., and Jan, Y.N. (2003). Inactivation of Numb and Numblike in embryonic dorsal forebrain impairs neurogenesis and disrupts cortical morphogenesis. Neuron 40, 1105-1118.

Lin, Y., Mori, E., Kato, M., Xiang, S., Wu, L., Kwon, I., and McKnight, S.L. (2016). Toxic PR Poly-Dipeptides Encoded by the C9orf72 Repeat Expansion Target LC Domain Polymers. Cell 167, 789-802 e712.

Matveeva, E.A., Venkova, L.S., Chernoivanenko, I.S., and Minin, A.A. (2015). Vimentin is involved in regulation of mitochondrial motility and membrane potential by Rac1. Biol Open 4, 1290-1297.

Mendez, M.G., Kojima, S., and Goldman, R.D. (2010). Vimentin induces changes in cell shape, motility, and adhesion during the epithelial to mesenchymal transition. FASEB J 24, 1838-1851.

Moisan, E., Chiasson, S., and Girard, D. (2007). The intriguing normal acute inflammatory response in mice lacking Vimentin. Clin Exp Immunol 150, 158-168.

Moore DL., Jessberger S. (2017). Creating Age Asymmetry: Consequences of Inheriting Damaged Goods in Mammalian Cells. Trends Cell Biol 27, 82-92

Moore, D.L., Pilz, G.A., Arauzo-Bravo, M.J., Barral, Y., and Jessberger, S. (2015). A mechanism for the segregation of age in mammalian neural stem cells. Science 349, 1334-1338.

Nava Zaarur., Anatoli B. Meriin., Vladimir L. Gabai., and Michael Y. Sherman. (2008). Triggering Aggresome Formation. The Journal of Biological Chemistry 283, 2757527584.

DISSECTING AGGRESOME-TARGETING AND AGGREGATION SIGNALS IN SYNPHILIN 1

Nicholl, I.D., and Quinlan, R.A. (1994). Chaperone activity of alpha-crystallins modulates intermediate filament assembly. EMBO J 13, 945-953.

Ogrodnik, M., Salmonowicz, H., Brown, R., Turkowska, J., Sredniawa, W., Pattabiraman, S., Amen, T., Abraham, A.C., Eichler, N., Lyakhovetsky, R., et al. (2014). Dynamic JUNQ inclusion bodies are asymmetrically inherited in mammalian cell lines through the asymmetric partitioning of Vimentin. Proc Natl Acad Sci U S A 111, 8049-8054.

Pattabiraman, S., and Kaganovich, D. (2014). Imperfect asymmetry: The mechanism governing asymmetric partitioning of damaged cellular components during mitosis. Bioarchitecture 4, 203-209.

Qin, Z., and Buehler, M.J. (2011). Structure and dynamics of human Vimentin intermediate filament dimer and tetramer in explicit and implicit solvent models. J Mol Model 17, 37-48.

Randall J. Platt., Sidi Chen., Yang Zhou., Michael J. Yim., Lukasz Swiech., Hannah R. Kempton., and Feng Zhang. (2014). CRISPR-Cas9 Knockin Mice for Genome Editing and Cancer Modeling. Cell 159, 440-455

Rowe, R.G., and Daley, G.Q. (2019). Induced pluripotent stem cells in disease modelling and drug discovery. Nat Rev Genet. 
Rujano, M.A., Bosveld, F., Salomons, F.A., Dijk, F., van Waarde, M.A., van der Want, J.J., de Vos, R.A., Brunt, E.R., Sibon, O.C., and Kampinga, H.H. (2006). Polarised asymmetric inheritance of accumulated protein damage in higher eukaryotes. PLoS Biol 4, e417.

Saez, I., Koyuncu, S., Gutierrez-Garcia, R., Dieterich, C., and Vilchez, D. (2018). Insights into the ubiquitin-proteasome system of human embryonic stem cells. Sci Rep 8, 4092.

Selenina, A.V., Tsimokha, A.S., and Tomilin, A.N. (2017). Proteasomes in Protein Homeostasis of Pluripotent Stem Cells. Acta Naturae 9, 39-47.

Shcheprova, Z., Baldi, S., Frei, S.B., Gonnet, G., and Barral, Y. (2008). A mechanism for asymmetric segregation of age during yeast budding. Nature 454, 728-734.

Spokoini, R., Moldavski, O., Nahmias, Y., England, J.L., Schuldiner, M., and Kaganovich, D. (2012). Confinement to organelle-associated inclusion structures mediates asymmetric inheritance of aggregated protein in budding yeast. Cell Rep 2, 738-747.

Strelkov, S.V., Herrmann, H., and Aebi, U. (2003). Molecular architecture of intermediate filaments. Bioessays 25, 243-251.

Takahashi, K., Tanabe, K., Ohnuki, M., Narita, M., Ichisaka, T., Tomoda, K., and Yamanaka, S. (2007). Induction of pluripotent stem cells from adult human fibroblasts by defined factors. Cell 131, 861-872.

Terzi, F., Henrion, D., Colucci-Guyon, E., Federici, P., Babinet, C., Levy, B.I., Briand, P., and Friedlander, G. (1997). Reduction of renal mass is lethal in mice lacking Vimentin. Role of endothelin-nitric oxide imbalance. J Clin Invest 100, 1520-1528.

Toivola, D.M., Strnad, P., Habtezion, A., and Omary, M.B. (2010). Intermediate filaments take the heat as stress proteins. Trends Cell Biol 20, 79-91.

Tolstonog, G.V., Shoeman, R.L., Traub, U., and Traub, P. (2001). Role of the intermediate filament protein Vimentin in delaying senescence and in the spontaneous immortalization of mouse embryo fibroblasts. DNA Cell Biol 20, 509-529.

Vilchez, D., Boyer, L., Morantte, I., Lutz, M., Merkwirth, C., Joyce, D., Spencer, B., Page, L., Masliah, E., Berggren, W.T., et al. (2012). Increased proteasome activity in human embryonic stem cells is regulated by PSMD11. Nature 489, 304-308.

Weisberg, S.J., Lyakhovetsky, R., Werdiger, A.C., Gitler, A.D., Soen, Y., and Kaganovich, D. (2012). Compartmentalization of superoxide dismutase 1 (SOD1G93A) aggregates determines their toxicity. Proc Natl Acad Sci U S A 109, 15811-15816.

Yamashita, Y.M., Fuller, M.T., and Jones, D.L. (2005). Signaling in stem cell niches: lessons from the Drosophila germline. J Cell Sci 118, 665-672.

Yusuke Miyazaki., Kota Mizumoto., Gautam Dey., Takamasa Kudo., John Perrino., Ling-chun Chen., Tobias Meyer., and Thomas J. Wandless. (2016). A method to rapidly create protein aggregates in living cells. Nature Communications 7, 11689.

Daniela Triolo et al. (2012). Vimentin regulates peripheral nerve myelination. Development 2012 139: 1359-1367. 
Battaglia RA, Delic S, Herrmann H, Snider NT. Vimentin on the move: new developments in cell migration. F1000Res. 2018;7:F1000 Faculty Rev-1796. Published 2018 Nov 15. 